\title{
Earth and Mars - distinct inner solar system products
}

\author{
Takashi Yoshizaki*1 and William F. McDonough ${ }^{1,2,3}$ \\ ${ }^{1}$ Department of Earth Science, Graduate School of Science, Tohoku University, Sendai, \\ Miyagi 980-8578, Japan \\ ${ }^{2}$ Department of Geology, University of Maryland, College Park, MD 20742, USA \\ ${ }^{3}$ Research Center for Neutrino Science, Tohoku University, Sendai, Miyagi 980-8578, \\ Japan
}

February 3, 2021

\begin{abstract}
Composition of terrestrial planets records planetary accretion, core-mantle and crust-mantle differentiation, and surface processes. Here we compare the compositional models of Earth and Mars to reveal their characteristics and formation processes. Earth and Mars are equally enriched in refractory elements $(1.9 \times \mathrm{CI})$, although Earth is more volatile-depleted and less oxidized than Mars. Their chemical compositions were established by nebular fractionation, with negligible contributions from post-accretionary losses of moderately volatile elements. The degree of planetary volatile element depletion might correlate with the abundances of chondrules in the accreted materials, planetary size, and their accretion timescale, which provides insights into composition and origin of Mercury, Venus, the Moon-forming giant impactor, and the proto-Earth. During its formation before and after the nebular disk's lifetime, the Earth likely accreted more chondrules and less matrix-like materials than Mars and chondritic asteroids, establishing its marked volatile depletion. A giant impact of an oxidized, differentiated Mars-like (i.e., composition and mass) body into a volatile-depleted, reduced proto-Earth produced a Moon-forming debris ring with mostly a proto-Earth's mantle composition. Chalcophile and some siderophile elements in the silicate Earth added by the Mars-like impactor were extracted into the core by a sulfide melt ( $\sim 0.5 \%$ of the mass of the Earth's mantle). In contrast, the composition of Mars indicates its rapid accretion of lesser amounts of chondrules under nearly uniform oxidizing conditions. Mars' rapid cooling and early loss of its dynamo likely led to the absence of plate tectonics and surface water, and the presentday low surface heat flux. These similarities and differences between the Earth and Mars made the former habitable and the other inhospitable to uninhabitable.
\end{abstract}

\footnotetext{
*Corresponding author. E-mail: takashiy@ tohoku.ac.jp
} 


\section{Keywords}

Earth; Mars; chondrites; solar system; cosmochemistry

\section{Introduction}

Earth and Mars share many chemical and physical attributes, but are distinct in size and inventory of volatile elements. Chemical data from surface rocks and meteorites combined with seismological and geodetic observations (e.g., mass, density, moment of inertia (MOI)) provide a multiply constrained compositional model of the terrestrial planets (e.g., Ringwood, 1966; Morgan and Anders, 1980, Wänke, 1981; Longhi et al., 1992). The physicochemical similarities and differences between Earth and Mars provide useful insights on formation and evolution processes of these bodies, and potentially provide insights into the present-day properties and origin of other rocky bodies (Venus, Mercury, and exoplanets).

By definition, Earth and Mars are located within a habitable zone in which liquid water is available (Cockell et al., 2016, Ehlmann et al., 2016). However, currently life exists only on Earth, and it remains unclear if Mars were inhabited or uninhabited in its history. The occurrence of life only on Earth indicates that there are compositional limits for a habitable planet formation, which can be revealed by an Earth-Mars comparison. Previous comparative studies of chemical compositions of the interiors of Earth and Mars described their differences including abundances of volatile or siderophile elements and redox states (Anders and Owen, 1977, Dreibus and Wänke, 1987; Wänke and Dreibus, 1994), but the recent advances in compositional modeling of both Earth and Mars will provide further insights into their characters and origins.

Isotopic compositions of solar system materials provide strong constraints on the sources of the terrestrial planets. Mass-independent, nucleosynthetic isotope anomalies in meteorites reveal a heterogeneous distribution of distinct presolar materials and provide the basis for classifying the non-carbonaceous (NC) and carbonaceous meteorite (CC) groups (Trinquier et al., 2007, 2009, Warren, 2011; Kruijer et al. 2017a). The NC meteorites appear to be from the inner solar system, whereas the CC meteorites are considered to be samples from the outer solar system, including the Trojan asteroids and possibly beyond Jupiter's orbit (Walsh et al., 2011; Kruijer et al., 2017a). These isotopic observations demonstrate a link between Earth and enstatite chondrites, whereas Mars is thought to be most closely related to ordinary chondrites (e.g., Trinquier et al., 2007, 2009, Javoy et al. 2010; Warren, 2011; Dauphas, 2017).

Here we compare the compositional models of Earth (e.g., McDonough and Sun, 1995; Palme and O'Neill, 2014) and Mars (e.g., Wänke and Dreibus, 1994; Taylor, 2013; Yoshizaki and McDonough, 2020) to clarify their characteristics and formation processes. We explore the nature of the building blocks of the terrestrial planets, based on their compositional similarities and differ-

ences with chondritic meteorites. These comparisons provide a basis for insights into the conditions for habitable planet formation and evolution. 


\section{Comparisons}

\subsection{Bulk planet}

The geochemical classification of elements consists of four element groups: lithophile (rock-loving), siderophile (metal-loving), chalcophile (sulfide-loving), and atmophile elements. Lithophile elements (e.g., Si, Mg, Ca, Al, Ti, Na, K, rare earth elements) are preferentially incorporated into oxide phases, and thus concentrated in a silicate shell in a differentiated planetary body. Therefore, their abundances in the mantle can be converted to the bulk composition if we also know a mass fraction of a metallic core in a planet. In addition, elements are also classified based on their volatilities in a gas of solar composition at $10 \mathrm{~Pa}$ (Lodders, 2003).

Historically, there have been three families of compositional models for the bulk silicate Earth, in terms of the proportions of the refractory elements relative to $\mathrm{Mg}$ and $\mathrm{Si}$, which, together with Fe and O, make up $\sim 90 \%$ of rocky planets. These models have low (Javoy, 1995; Javoy et al. 2010, Warren, 2008, Caro and Bourdon, 2010), medium (Ringwood, 1975, Jagoutz et al., 1979. Wänke, 1981; Hart and Zindler, 1986;, Allègre et al., 1995; McDonough and Sun, 1995;, Palme and O'Neill, 2014), and high (Wasserburg et al., 1963; Turcotte et al., 2001;, Turcotte and Schubert, 2014) proportion of refractory elements (McDonough, 2016 and references therein). Here we estimate a primitive (i.e., the least melt-depleted) mantle composition based on compositional trends from basalts and mantle rocks and propose a model with medium refractory element abundance (e.g., McDonough and Sun, 1995, Palme and O'Neill, 2014, see also Section A.1). As summarized in Palme and O'Neill (2014), these geochemical models of Earth are basically similar to each other, and differences between the models do not affect comparison of Earth and Mars discussed in the current paper.

A similar geochemical approach has been applied in constraining compositional models of Mars (Wänke and Dreibus, 1994; Taylor, 2013, Yoshizaki and McDonough, 2020). Here we adopt the compositional model by Yoshizaki and McDonough (2020), which is compositionally and mineralogically similar to those of Wänke and Dreibus (1994) and Taylor (2013) (Fig. A.1; see also Bertka and Fei, 1997; Khan et al., 2018, Smrekar et al., 2019 for Martian mantle mineralogy models), but differ in model development. For example, Wänke and Dreibus (1994) assumed that Mn and more refractory elements (including $\mathrm{Fe}, \mathrm{Mg}$ and $\mathrm{Si}$ ) are in chondritic relative abundances in bulk Mars, which is denied by Yoshizaki and McDonough (2020). The details of previous Mars models are summarized by Taylor (2013) and Yoshizaki and McDonough (2020).

By establishing the planet's budget of the 36 refractory elements, recognizing that ratios of refractory elements (e.g., $\mathrm{Ca} / \mathrm{Al}, \mathrm{Th} / \mathrm{U})$ and $\mathrm{Fe} / \mathrm{Ni}$ are constant $( \pm 15 \%$ or better) in the chondritic building blocks (e.g., Wasson and Kallemeyn, 1988; Alexander, 2019a b), and either knowing the relative mass of the planet's core or the mantle's $\mathrm{Mg \#}$ (atomic ratio of $\mathrm{Mg} /(\mathrm{Mg}+\mathrm{Fe})$ ), limit the range of acceptable $\mathrm{Mg} / \mathrm{Si}$ (i.e., olivine/pyroxene) values for planetary compositional models (Figs. 1 and $2 \mathrm{~A}$ ). The $\mathrm{Fe} / \mathrm{Mg}$ vs $\mathrm{Fe} / \mathrm{Si}$ correlation seen in both the $\mathrm{NC}$ and $\mathrm{CC}$ chondrites is suggestive of 
metal-silicate gradients in the solar system (Figs. 1 and 2B); interestingly, Earth and Mars also follow this correlation.

The approach used here finds that the bulk Earth contains $1.85 \times \mathrm{CI}$ abundances for the refractory elements (e.g., McDonough and Sun, 1995; Palme and O'Neill, 2014), it has an olivine/pyroxene proportion equivalent to that of pyrolite (Ringwood, 1966), and is depleted in volatile elements (i.e., sub-CI Rb/Sr, K/U, and S; Fig. 3A;; Gast, 1960, Wasserburg et al., 1964). Mars also contains 1.9 $\times \mathrm{CI}$ abundances for the refractory elements and is depleted in volatile elements, but less so than Earth (Fig. 3B; Yoshizaki and McDonough, 2020). The net atomic oxygen/(metallic Fe) values of Earth and Mars (3.7 and 8.7, respectively; Table 1) provide a measure of its average oxidation state. These compositional models for Earth and Mars provide a time-integrated perspective for materials available for accretion at 1 and $1.5 \mathrm{AU}$, respectively. This spatial sampling contrasts with the tem-

poral comparison, as the mean timescales for Mars' formation ( $\tau_{\text {Mars }}^{\text {accretion }} \sim 2 \mathrm{Myr}$; Dauphas and Pourmand, 2011) differs from that for Earth ( $\tau_{\text {Earth }}^{\text {accretion }} \gtrsim 30$ Myr; Kleine et al., 2009).

\subsection{Bulk silicate planet}

\subsubsection{Geochemistry and mineralogy}

Chondritic ratios of refractory lithophile elements in the bulk silicate Earth and Mars (BSE and BSM, respectively) are further confirmed and constrained by Lu-Hf, Sm-Nd and La-Ce isotopic systematics of these planetary materials (e.g., Bouvier et al., 2008, Burkhardt et al., 2016, Willig et al. 2020). The moderately volatile, lithophile elements (lithophile MVE; e.g., alkali metals) are depleted in Earth and Mars when compared to chondritic meteorites, both planets showing comparable correlations with their condensation temperatures (Fig. 3). Earth, with K/U of 14000 and $\mathrm{Rb} / \mathrm{Sr}$ of 0.032 (i.e., MVE/refractory ratios; cf., 68000 and 0.30 in CI chondrites, respectively), shows such a strong depletion trend in these elements (Fig. 3A). Mars, with a K/U of 20000 and $\mathrm{Rb} / \mathrm{Sr}$ of 0.068 , also shows this trend (Fig. $3 \mathrm{~B}$ ), albeit less depleted than the Earth's.

Siderophile and chalcophile elements are depleted in the BSE and BSM compared to lithophile elements with similar condensation temperatures, due to their incorporation into the metallic cores (Fig. 4). The abundances of siderophile elements in the BSE and BSM do not show a sub-parallel trend with that defined by lithophiles (Fig. 4). The degree of siderophile and chalcophile element depletion reflects a combination of planetary building block compositions and element fractionation processes during planetary accretion and differentiation (McDonough, 2014).

The BSE and BSM both have high concentrations and chondritic relative proportions of highly siderophile elements (HSE: Re, Os, Ir, Pt, Ru, Rh, Pd and Au; Fig. 4), which is at odds with any combination of high-pressure and temperature conditions for the partitioning of these elements into a core forming melt (Brandon et al., 2012; Walker et al., 2015; Day et al., 2016; Tait and Day, 2018). For example, core-mantle equilibration model in Martian interior (Righter et al., 2015) 
predicts sub-CI Re/Os and super-CI Ir/Os and Ir/Ru values in silicates, which are inconsistent with the chondritic HSE pattern in the BSM (Brandon et al., 2012; Tait and Day, 2018). In addition, Righter et al. (2015) assumes a high S concentration $(>10 \mathrm{wt} \%)$ in the Martian core, which is much higher than a value predicted by the Martian volatility trend of lithophile elements $(\leq 7 \mathrm{wt} \%$; Yoshizaki and McDonough, 2020). These shared features of the HSE abundances in Earth and Mars are considered as evidence for late accretion of chondritic materials during the final stage (e.g., after $\geq 98 \%$ accretion) of planetary growth in the inner solar system (Kimura et al. 1974, Brandon et al. 2012, Day et al. 2016). Delivery of these HSE was also accompanied by an addition of volatile gases and fluids (H, C, N and O; Albarede, 2009; Alexander et al., 2012; Marty, 2012), although the late-accreted material to Mars might have been volatile-depleted (Wang and Becker, 2017, Righter et al. 2019).

On the other hand, the BSE is characterized superchondritic $\mathrm{Ru} / \mathrm{Ir}$ and possibly $\mathrm{Pd} / \mathrm{Ir}$, which cannot be easily accommodated by the late addition of volatile-rich materials (Becker et al. 2006). Experimental studies showed that these high ratios in the BSE might reflect $P, T$, and compositiondependent changes in partitioning behaviors of $\mathrm{Ru}$ and $\mathrm{Pd}$, and proposed no need for the late addition of these elements (Righter et al., 2008; Wheeler et al., 2011, Laurenz et al., 2016, Righter et al. 2018). Alternatively, these inconsistencies between the BSE and chondrites show an unrepresentative sampling of asteroidal materials in our meteorite collections (Walker et al. 2015).

The average, time-integrated, planet-scale redox condition (i.e., metal-silicate equilibrium) is recorded in the $\mathrm{Mg \#}$ of its mantle, with the BSE and BSM having an Mg\# of 0.89 and 0.75-0.8, respectively, and its core mass fraction (i.e., Mars $\sim 20 \%$ and Earth $\sim 32 \%$; Section 2.3 . These attributes document Mars being more oxidized than Earth. In addition, Mars lacks depletion in redox-sensitive, nominally lithophile elements (i.e., V, Cr, and $\mathrm{Mn}$ ), and its mantle has a lower Hf/W value ( 3.5; Dauphas and Pourmand, 2011; Yoshizaki and McDonough, 2020), which contrast with those for Earth (Fig. 4). The more oxidized conditions for the Martian mantle are also indicated by mineralogy, trace element compositions and valence states of Fe and $\mathrm{Eu}$ in Martian meteorites. The Martian mantle, however, as recorded in Martian meteorites, shows a heterogeneous redox state (e.g., Herd et al., 2001, 2002, Wadhwa, 2001, 2008; Goodrich et al., 2003; McCanta et al., 2009, Shearer et al. 2011, Righter et al., 2016; Herd, 2019). Oxygen might be one of the light elements in the Earth's core (Ohtani and Ringwood, 1984), but its limited solubility in iron liquids at high P-T conditions (O'Neill et al., 1998) indicates small effects of the core formation in the BSE's Mg\#, and supports the more reduced state of the BSE as compared to the BSM.

Earth and Mars have similar "upper mantle" mineralogies (Fig. 57). Both contain olivine, orthoand clino-pyroxenes, and garnet, with the Earth's mantle being richer in olivine than the Martian mantle ( $\sim 60 \%$ and $\sim 45 \%$ in modal proportion, respectively). Differences in composition (Table 1 ) and interior thermal gradient (Breuer and Spohn, 2003, Katsura et al., 2010) of Earth and Mars results in different depths of the olivine-wadsleyite and wadsleyite-ringwoodite phase transitions. For Earth, these transitions are at $410 \mathrm{~km}$ and $520 \mathrm{~km}$ depth, respectively, and in Mars, they occur at 
$1000 \mathrm{~km}$ and $1300 \mathrm{~km}$ depth, respectively. These phase transitions are sharper in the Earth's mantle than the Martian mantle, because of the former's higher $\mathrm{Mg \#}$, greater garnet abundance, and hotter temperature (Frost, 2003; Filiberto and Dasgupta, 2011, Putirka, 2016). The Martian mantle might not have a layer of bridgmanite, which is a dominant phase in the Earth's lower mantle (Fig. 6).

\subsubsection{Heat producing elements (HPE)}

The rocky planets are powered by both primordial accretion energy (and lesser amounts from core formation) and radiogenic heat by radioactive decays of heat producing elements (HPE: K, Th, U). All three of the HPE are incompatible, lithophile elements that have been excluded from their cores and concentrated into planetary crusts (e.g., Corgne et al., 2007; Blanchard et al., 2017, Wipperfurth et al. 2018), which is beneficial for carrying out remote gamma-ray surveys of planetary surfaces (e.g., Peplowski et al., 2011, Surkov et al., 1987, Prettyman et al., 2015). The Martian crust is thicker (estimated to be 30-60 km thick with an average value of $\sim 50 \mathrm{~km}$; Zuber et al. 2000; McGovern et al., 2002; Wieczorek and Zuber, 2004; Humayun et al., 2013), less enriched in incompatible elements, and contains $\sim 50 \%$ of the HPE budget of Mars, whereas Earth has a thinner, more chemically evolved crust, which contains only $\sim 35 \%$ of the planet's HPE budget (Table 1 and Section A.2, Rudnick and Gao, 2014). Mars' internal heating Rayleigh number of $>10^{5}$ (Section A.3) is consistent with a convecting Martian mantle and a dynamically stabilized Tharsis bulge (McKenzie et al., 2002, Kiefer, 2003).

With nearly a factor of 2 greater surface to volume ratio for Mars than Earth, the former cooled much faster (Filiberto and Dasgupta, 2011; Baratoux et al., 2011, 2013; Filiberto, 2017, Breuer and Moore 2015, Putirka 2016). Mars' surface heat flux is $19 \pm 1 \mathrm{~mW} / \mathrm{m}^{2}$ (Parro et al., 2017) (cf., Earth's average is $90 \mathrm{~mW} / \mathrm{m}^{2}$; Jaupart et al. 2015), equivalent to a global heat flux of $2.75 \pm 0.15$ TW, of which 2.5 TW comes from radioactive decay (Table 1 and Section A.2). Mars' planetary Urey ratio ( $U r$ : total radioactive heat production relative to total surface heat loss) is $0.92 \pm 0.05$, which is higher than that estimated for Earth (0.43) and its mantle $U r_{\text {Mars }}$ (planetary $U r_{\text {Mars }}$ minus the crustal fraction) is 0.8, more than double of that of the Earth's mantle (0.33). The high $U r_{\text {Mars }}$ demonstrates a minor contribution from secular cooling to the total Martian heat flux. Importantly, the modeled Martian surface heat flow varies between 14 and $25 \mathrm{~mW} / \mathrm{m}^{2}$ (Parro et al. 2017). A direct measurement the Martian surface heat flux by NASA's Interior Exploration using Seismic Investigations, Geodesy and Heat Transport (InSight) mission (Banerdt et al. 2020) will provide important constraints on its heat production and thermal history.

\subsection{Core}

The mantles of both Earth and Mars are depleted in siderophile and chalcophile elements due to core extraction (Fig. 4). Their core compositions are modeled using the following constraints: the planet's chondritic Fe/Ni value, temperature, mass, density, MOI, and for Earth, seismic profile (see 
McDonough, 2014, Yoshizaki and McDonough, 2020). Also, based on iron meteorite mineralogy (Scott and Krot, 2014) and cosmic abundance of elements (Lodders, 2020), planetary cores might contain sulfides, carbides and phosphides, and possibly other phases (e.g., silicides if formed under highly reduced conditions).

The Earth's core (32\% by mass) has an outer liquid layer and a solid inner core ( $\sim 5 \mathrm{wt} \%$ ) (Fig. 6). Estimates of the size of the Martian core ranges from 18-25 wt \% and 1500-1900 km, respectively (Section A.1.3. Data from multiply orbiting satellites provide a precise $( \pm 2 \%)$ measure of Mars' Love number solution $\left(k_{2}\right)$ and document a possible existence of a partially molten core (Yoder et al. 2003, Genova et al., 2016, Konopliv et al., 2016). This observation indicates significant amounts of light elements in the core that lowers its solidus temperature.

Sulfur is a prime candidate for light elements in a planetary core. The volatile element depletion trends for both Earth and Mars (Fig. 4) constrain the core's S content of $\sim 1.8 \%$ in Earth and $\sim 7 \%$ in Mars (Yoshizaki and McDonough. 2020; see also Sections A.1.2 and A.1.3). Since the estimated $\mathrm{S}$ contents of the Earth's and Mars' core are not high enough to explain their respected core density deficits, additional light elements in these cores are needed (e.g., Si, O, H and C). The additional light elements are likely to be different in these cores because metal-silicate partitioning behavior of elements depends on conditions of core formation (e.g., timing, $P, T, f_{\mathrm{O}_{2}}$ ) and compositions of coexisting silicate and metallic phases.

As described above, a planet's volatility trend sets expectations for the absolute amount of siderophile and chalcophile elements in the planet and defines the proportion of these elements that were partitioned into the core. The degree of depletion below the volatility trend defines an element's empirically established metal/silicate partition coefficient (McDonough, 2014; Yoshizaki and McDonough, 2020). The Martian core is enriched in siderophile and chalcophile MVE (e.g., P, $\mathrm{Ge}, \mathrm{S}$ ) as compared to the Earth's, and there appears to be little to no $\mathrm{Ga}$ in the cores of terrestrial planets, which contrasts with that seen in iron meteorite compositions (Figs. 7)and 8). Compared to the Earth's core, the Martian core is smaller, it might contain larger amounts of $\mathrm{H}$ and $\mathrm{O}$, and it has a lower Fe/Ni value, with its mantle being enriched in Fe (Table 1). Overall, these factors contribute to Mars' lower uncompressed density as compared to the Earth's (3750 vs $4060 \mathrm{~kg} / \mathrm{m}^{3}$; Table 1 ). There is no unique model for core compositions of Earth and Mars that satisfies the geodetic and geochemical constraints (McDonough, 2014, Yoshizaki and McDonough, 2020), and further experimental and theoretical efforts are needed to constrain the light element budget in the planetary cores. 


\section{Discussion}

\subsection{Origin of volatile depletion in terrestrial planets}

From Mercury to Mars and beyond to Vesta, the second biggest asteroid, their surface K/Th values are significantly lower relative to chondrites (Surkov et al., 1987; Taylor et al., 2006; Peplowski et al. 2011; Prettyman et al. 2015). The origins of this depletion and that of other MVE remain elusive, with possible explanations including post-nebular volatile loss due to internal or impact-induced heating (e.g., O'Neill and Palme, 2008, Norris and Wood, 2017) and incomplete condensation of nebular gas (e.g., Palme and O'Neill, 2014;:Siebert et al., 2018). Since planetary K/Th ratios and relative amounts of more refractory olivine $\left(\mathrm{Mg}_{2} \mathrm{SiO}_{4}\right)$ and less refractory pyroxene $\left(\mathrm{MgSiO}_{3}\right)$ do not correlate with their heliocentric distances in both the solar and extra-solar systems (e.g., Fig.2A; van Boekel et al. 2004, Kessler-Silacci et al., 2006; Bouwman et al., 2008, 2010; Sargent et al., 2008), these volatile depletions do not solely reflect an outward temperature decrease in the protoplanetary disk.

The absence of heavy isotope enrichment in rocks from Earth and Mars for multiple isotope systems (e.g., K, Zn, Rb, Fe, Cd; Humayun and Clayton, 1995; Nebel et al., 2011; Paniello et al., 2012a; Sossi et al. 2016, 2018; Pringle and Moynier, 2017, Wombacher et al., 2008) indicates negligible post-accretionary evaporative loss of the MVE. In contrast, isotopically heavier siderophile or chalcophile compositions (e.g., Fe, Ga, Sn) of terrestrial and lunar mantles might reflect (1) core-mantle differentiation, (2) evaporation of the giant impactor's core and addition of the metal/sulfur-loving elements to the terrestrial mantle during the giant impact (see Section 3.3), or (3) planetary surface processes (e.g., Poitrasson et al., 2004; Kato and Moynier, 2017; Creech and Moynier, 2019). The ${ }^{53} \mathrm{Mn}-{ }^{53} \mathrm{Cr}$ and ${ }^{87} \mathrm{Rb}-{ }^{87} \mathrm{Sr}$ isotope systematics of meteorites and terrestrial samples are consistent with a volatility-dependent, gas-solid fractionation during first few Myr of the solar system (e.g., Shukolyukov and Lugmair, 2006, Trinquier et al., 2008; Hans et al., 2013; Moynier et al. 2012), which might be prior to the dissipation of the nebular gas $\left(\sim t_{0}+5 \mathrm{Myr}\right.$; Wang et al. 2017).

There is negligible evidence for post-accretionary MVE losses in the chemical compositions of these planets. The bulk Earth and Mars, together with chondrites, show negligible evidence of evaporative losses in ratios of Na, Mn and Ti (Fig. 9 and Section A.1.1; O'Neill and Palme, 2008; Siebert et al. 2018), which have distinct relative volatilities during condensation and evaporation. Values of $\mathrm{Mn} / \mathrm{Na}$ and $\mathrm{Na} / \mathrm{Ti}$ in the bulk Earth, Mars and chondrites are consistent with an incomplete nebular condensation, in which earlier condensates are removed from a nebular gas before a completion of more volatile species (e.g., Larimer, 1967; Larimer and Anders, 1967) (cf. O'Neill and Palme. 2008). The plot of $\mathrm{Mn} / \mathrm{Na}$ versus $\mathrm{Na} / \mathrm{Ti}$ indicates that a formation of precursors of Earth and Mars at higher temperatures than their isotopically linked counterparts (enstatite and ordinary chondrites, respectively), which is also suggested by the former's higher $\mathrm{Mg} / \mathrm{Si}$ (i.e., olivine/pyroxene), $\mathrm{Al} / \mathrm{Si}$, and $\mathrm{Al} / \mathrm{Mg}$ ratios (Kerridge, 1979; Larimer, 1979, Dauphas et al., 2015, Morbidelli et al., 2020).

Collectively, the compositions of rocky planets, as compared to their chondritic relatives, likely 
reflects volatility-dependent chemical fractionation in the protoplanetary disk, rather than the postaccretionary losses of MVE. In contrast, small differentiated asteroids (e.g., parent bodies of Eucrite and Angrite) show clear evidence for preferential loss of MVE (Fig. 9, O'Neill and Palme, 2008) and heavy isotope enrichment (e.g., Paniello et al., 2012b; Pringle et al., 2017; Tian et al., 2019), which are the hallmarks of evaporative losses during or after accretion. Volatile elements might have escaped from these small bodies during and/or after their accretion, due to their weak gravity field.

\subsection{The building blocks of the terrestrial planets}

The planetary building blocks appeared to be made up of high-temperature materials, dominantly chondrules, which are silicate droplets formed by transient heating events within first few Myr of the solar system evolution (Connelly et al., 2012; Bollard et al., 2017), and are an essential component of chondrites (e.g., Scott and Krot, 2014, Russell et al., 2018). MVE composition of chondrules provides a record of incomplete nebular condensation rather than evaporation processes (Humayun and Clayton, 1995, Alexander et al., 2000, 2008, Galy et al., 2000; Pringle et al., 2017). The refractory element enrichment and MVE depletion in the BSE and BSM are comparable to those observed for chondrules from carbonaceous chondrites (Fig. 10, Hewins and Herzberg, 1996; Mahan et al. 2018). Significantly, mass-dependent Ca (Huang et al. 2010; Magna et al. 2015; Amsellem et al. 2017; Simon et al. 2017, Bermingham et al., 2018) and Mg (Bizzarro et al., 2004; Young and Galy, 2004; Wiechert and Halliday, 2007; Bouvier et al., 2013, Olsen et al., 2016, Hin et al. 2017) isotopic compositions of chondrules, BSE and BSM also suggest that they inherited fractionated isotopic signatures from similar precursor materials, which have experienced high-temperature gas-solid fractionation processes.

Recent theoretical models of planetary growth favor formation of terrestrial planets via accretion of chondrule-sized pebbles (e.g., Johansen et al., 2015a b; Levison et al. 2015). These models predict a rapid accretion of Mars-sized bodies under the presence of a nebular disk. Thus, Mars, with a $\tau_{\text {Mars }}^{\text {accretion }}$ of $\sim 2$ Myr (Dauphas and Pourmand, 2011, Kruijer et al., 2017b, Bouvier et al. 2018) (cf. Marchi et al. 2020), formed within the nebular disk lifetime ( 5 Myr; Wang et al., 2017),

whereas Earth is suggested to have $\tau_{\text {Earth }}^{\text {accretion }} \geq 30$ Myr (e.g., Kleine et al., 2009), which documents its accretion stretched beyond the lifetime of the nebular disk.

Differences in planetary MVE abundances (Fig. A.3 likely reflect aspects of their accretion histories and sizes. Chondrites, the least MVE-depleted bodies' materials, contain fine-grained, volatile-rich matrix that accounts for the largest fraction of the inventory of volatiles (e.g., Alexander, 2005, 2019a b; Bland et al. 2005, Zanda et al., 2018). Although a relationship between chondrules and matrix remains poorly understood, their coexistence in the protoplanetary disk before planetesimal accretion is accepted (e.g., Hezel et al.,2018a; Zanda et al., 2018). Some carbonaceous chondritic asteroids accreted more chondrules and less matrix, resulting in more MVE-depleted compositions (Figs. 11B and A.4). According to the pebble accretion model (Johansen et al. 
2015a b; Levison et al. 2015), planetesimal growth starts off by preferentially accreting the smallest particles, and as the body grows, it prefers to accrete larger and larger size particles. This mechanism would lead to a growing planetesimal having a larger chondrule/matrix ratio, and becoming more MVE-depleted as its mass increases. Thus, small chondritic asteroids likely co-accreted chondrules and matrix, whereas Mars, with its intermediate volatile depletion, size and accretion timescale, likely accreted a greater fraction of chondrules to matrix (Fig. 11). Finally, the Earth's prolonged accretion history was dominated by chondrule accretion, resulting in its significant MVE-depleted composition. The MVE depletion scales with size of the chondritic parent body and planet (Fig. 11), implying an accretion driven process from an undepleted nebula (i.e., CI (solar) composition). Exceptions are small differentiated bodies (e.g., the Moon and Vesta) that experienced post-nebular volatile loss due to internal or impact-induced heating (Section 3.1). Thus, the chondrule-driven planetary growth plays a critical role in establishing the planetary MVE-depleted characteristics.

In contrast, enstatite and ordinary chondrites, whose isotopic composition and redox state are most related to Earth and Mars, respectively (e.g., Trinquier et al., 2007, 2009, Warren, 2011; Dauphas, 2017; Fig. 2B), do not show a clear refractory enrichment nor MVE depletion (Figs. 2A, 11 and A.4). In addition, chondrules from these NC chondrites are less depleted in MVE than the BSE and BSM (Fig. A.5). Thus, the chondrule-driven MVE-depletion scenario discussed above cannot be applied to the NC chondrites we have in our collections. These observations indicate that the NC chondrites represent refractory-poor, volatile-rich counterparts of the inner rocky planets. Morbidelli et al. (2020) showed that the low $\mathrm{Mg} / \mathrm{Si}$ and $\mathrm{Al} / \mathrm{Si}$ solids, which are comparable to those of NC chondrites (Fig. 22A), condense after removal of early-formed, high-temperature condensates from the system.

Differences in the timing of planetary accretion might also be important in establishing their relative abundances of MVE. Chronology of meteorites combined with thermal modeling of asteroids (Sugiura and Fujiya, 2014, Kruijer et al., 2017a, Zhu et al., 2020) indicates that the undifferentiated NC planetesimals accreted 1-2 Myr after formation of differentiated NC bodies (i.e., iron meteorite parent bodies and terrestrial planets). The variation in the absolute ages of chondrules (Connelly et al., 2012; Bollard et al., 2017), occurrence of relict grains (Jones, 1994; Weisberg et al. 2011; Tenner et al., 2018) and igneous rims (Krot and Wasson, 1995) in chondrules, and the presence of compound chondrules (Wasson et al., 1995) indicate that chondrule formation was a repeated event. Thus, the longer chondrules remained in the accretionary disk, the more opportunities it has being recycled by later events. Ordinary chondrite chondrules records an admixing of MVE-rich CC-like materials to MVE-poor chondrule precursors into the NC reservoir (Mahan et al. 2018, Schiller et al., 2018; Bollard et al., 2019). Additions of MVE-rich materials and repeated chondrule recycling produce younger chondrules with higher MVE abundance (Mahan et al., 2018). Thus, terrestrial planets, which are dominated by earlier materials that experienced fewer recycle events and MVE addition, are more depleted in MVE as compared to the NC chondrites, which accreted the younger MVE-enriched chondrules.

In contrast, chondrule formation scenarios predict less frequent chondrule formation/recycle 
events in the outer solar system (e.g., Morris et al., 2012, Johnson et al., 2015, Sanders and Scott, 2018, Pilipp et al. 1998). This prediction is consistent with chemical and isotopic signatures of CC chondrules (e.g., Hewins and Zanda, 2012; Tenner et al., 2018, Mahan et al., 2018). Consequently, the $\mathrm{CC}$ chondrules could have preserved their MVE depletion until the accretion of CC chondritic asteroids, and thus are chemically comparable to the early $\mathrm{NC}$ materials which formed the inner rocky planets.

This chondrule-rich accretion model for the terrestrial planets reveals the limited ability to reach greater levels of enrichment in refractory elements (Figs. 2 $\mathrm{A}$ and $10 \mathrm{~B}$ ), which is a concern for planetary compositional models promoting high refractory element abundance (Section 2.1). To reach higher levels of refractory element enrichment beyond that seen in $\mathrm{CV}$ chondrites and their chondrules, larger amounts of refractory inclusions are needed, which is inconsistent with chondritic REE ratios of the BSE (Stracke et al., 2012, Dauphas and Pourmand, 2015).

\subsection{Formation models of the terrestrial planets}

\subsubsection{Previous models of the Earth's accretion and Moon formation}

Depletion of moderately to highly siderophile and chalcophile elements in the BSE is consistent with Earth's initial accretion from highly reduced, volatile-depleted materials, that was later oxidized by volatile-rich additions (e.g., Wänke, 1981, Wänke et al., 1984, Wänke and Dreibus, 1988; O'Neill, 1991b; Rubie et al. 2011, 2015). Support for this temporal evolution in volatile accretion is found in multiple radiogenic isotope systems (e.g., $\mathrm{Rb}-\mathrm{Sr}, \mathrm{U}-\mathrm{Pb}, \mathrm{Ag}-\mathrm{Pd}, \mathrm{I}-\mathrm{Pu}-\mathrm{Xe}$; Halliday and Porcelli, 2001; Albarede, 2009; Schönbächler et al. 2010, Mukhopadhyay, 2012, Ballhaus et al. 2013, Maltese and Mezger 2020), metal-silicate partitioning behaviors of elements such as W, Mo, S and C (e.g., Wade et al., 2012, Li et al., 2016, Suer et al., 2017, Tsuno et al., 2018, Ballhaus et al. 2017), and $N$-body simulations of planetary formation (e.g., Raymond et al. 2006; Morbidelli et al. 2012). However, the degree of volatile element depletion in the pre-impact proto-Earth remains unconstrained.

The two-component accretion models for the growth of Earth envisage mixing of highly reduced, volatile-depleted materials with oxidized, volatile-rich, "CI-chondritic" materials in some proportion, not well defined, but generally conceived their mass ratios to be in the range of 60:40 to 90:10 (Wänke et al., 1984, Wänke and Dreibus, 1988, O’Neill, 1991b). Some mass estimates of the late oxidized addition are comparable to a Mars-sized, Moon-forming impactor (e.g., Canup and Asphaug, 2001, Canup, 2004, 2008). The impactor's composition has often been assumed to be CI-chondritic (e.g., O’Neill, 1991a|b; Maltese and Mezger, 2020).

However, the CI-chondritic impactor model has been multiply challenged. The common MVE depletion in rocky differentiated bodies in the solar system (e.g., sub-solar K/Th ratios; Section 3.1) might indicate a similar MVE depletion in the Mars-sized impactor. In addition, the CI-like impactor model requires a significant volatile depletion in the proto-Earth, perhaps at levels seen in 
angrites and calcium-aluminum-rich inclusions (CAIs), which show heavy $\mathrm{Mg}$ - and Si-isotope enrichment and significant depletion of moderately volatile elements (e.g., Grossman et al., 2000, 2008, Pringle et al. 2014) due to significant evaporative losses of the major and more volatile elements by impact-induced or transient nebular heating events (e.g., Stolper and Paque, 1986, Richter et al., 2002, Pringle et al. 2014, Yoshizaki et al., 2019, Young et al., 2019). However, such isotopic signatures are not recognized for Earth (Section 3.1). Furthermore, models predicting compositional zoning in the protoplanetary disk have a region of CI-like material accreting at $\geq 15 \mathrm{AU}$ (Desch et al., 2018), where it is predicted that the disk mass is too low to form a Mars-sized body.

Compositional similarities of Earth and Moon in multiple isotope systems set strict constraints on the nature of both the impactor and proto-Earth, that is, they are derived from a similar NC isotopic reservoir that appears to be restricted to inner solar system sources (e.g., Wiechert et al. 2001 . Trinquier et al. 2009, Warren, 2011; Zhang et al., 2012, Greenwood et al., 2018; Dauphas, 2017 Kruijer et al., 2017a). This observation is consistent with dynamical simulations which predict low probabilities of a Moon-forming impactor originating from $>10$ AU (e.g., Jackson et al., 2018). Thus, these constraints exclude the isotopically distinct CI chondrite as an impactor candidate. In contrast, recent $\mathrm{Mo}$ and $\mathrm{O}$ isotopic data from a broad range of $\mathrm{NC}$ and $\mathrm{CC}$ materials challenge this exclusion and find support for a CC-like impactor and/or vigorous mixing of proto-Earth and impactor, requesting further constraints to reveal the origin of the Earth-Moon system (Young et al. 2016, Budde et al. 2019; Cano et al., 2020). Furthermore, the recently-proposed synestia model (Lock et al. 2018) has the Moon forming in a vapor cloud surrounding Earth. This vapor cloud was produced by a large impact, resulting in a well-mixed, chemically equilibrated proto-earth and the vapor cloud.

\subsubsection{Mars-like Moon-forming giant impactor model}

Here we propose a model for the origin of the Moon. Our model is a modification of the original Wänke et al.(1984)'s model and later modified by O'Neill (1991a b). In our version of this model, we envision the Earth's formational history in 4 steps and use a differentiated Mars-like composition (Yoshizaki and McDonough, 2020), instead of CI composition, for the giant impactor. Figs. 12 and 13 show the details of our model: Fig. 12 specifically highlights the differences between our model and those previously presented. Our model starts with

1. the accretion of the proto-Earth (reduced and volatile-depleted) accompanied by continuous core-mantle differentiation ( $\sim 90 \%$ of Earth's mass),

2. followed by a late-stage Moon-forming giant impact event (30-100 Myr after $t_{0}$; Kleine et al. 2009 ) that adds the final $\sim 10 \%$ mass (oxidized and volatile-enriched) to Earth and forms a protolunar accretion disk,

3. subsequently, the mantle loses a Fe-Ni $( \pm \mathrm{O})$ sulfide liquid (sulfide matte; O'Neill, 1991b) to the core ( $\sim 0.5 \%$ BSE mass), 
4. and finally, the BSE receives the addition of ( $~ 0.5 \%$ of the BSE mass) a late accretion component that brings the highly siderophile and chalcophile elements in chondritic proportions and highly volatile gases and fluids (see Section A.5 for details of the modeling).

In this scenario, the bulk proto-Earth already contains $\geq 80 \%$ of the present-day Earth's budgets of most of the MVE (e.g., K/Th 3200; Rb/Sr 0.026; Table A.2), since a Mars-like impactor contributes only a limited amount of additional MVE (Fig. 13). The addition of MVE by the impactor leads to sulfur saturation in the magma ocean, generating an Fe-Ni $( \pm \mathrm{O})$ sulfide liquid (postimpact sulfide matte; O'Neill, 1991b; Rubie et al., 2016). The sulfide matte precipitates through a crystallizing mantle into the core due to its high immiscibility, low wetting angle, and high density (Gaetani and Grove, 1999, Rose and Brenan, 2001). Assuming that the sulfide matte, with a present-day mantle sulfide-like composition (Lorand and Conquéré, 1983), extracted all S from the post-impact Earth's mantle; its mass is estimated to be $\sim 0.5 \mathrm{wt} \%$ of the present-day Earth's silicate mantle (Section A.5).

The siderophile and chalcophile element abundances of the BSE are reproduced when 10-15\% of a planetary mass is added by the impactor and most of the impactor's core equilibrates with the proto-Earth's mantle (Fig. 13 and Section A.5). In this scenario, the bulk proto-Earth contains $\geq 80 \%$ of the present-day Earth's budget of most of the MVE (e.g., K/Th $\sim 3200$; $\mathrm{Rb} / \mathrm{Sr} \sim 0.026$; Table A.2, with the Mars-like impactor contributing a limited amount of MVE (Fig. 13). We envision the proto-Earth as having a MVE abundance comparable to that of chondrules (Figs. 10 and $11 B$ ). Thus, the proto-Earth's composition is consistent with the chondrule-rich accretion scenario (Section 3.2) and requires no need for a post-accretionary loss of MVE from the proto-Earth before the Moon-forming event (Section 3.1).

The mass fraction of the impactor contributing to the lunar composition provides a critical constraint on the lunar formation models. The lunar mantle is depleted in nominally lithophile $\mathrm{V}, \mathrm{Cr}$ and Mn (Dreibus and Wänke, 1979). Such lunar mantle depletion can be achieved by high- $T$ or S-rich conditions during lunar core formation, but these conditions seem unlikely (Steenstra et al. 2016). If a Mars-sized impactor with no $\mathrm{V}, \mathrm{Cr}$ or Mn-depletion in its mantle contributed $>70 \%$ of Moon, as predicted by the canonical giant impact models (Canup and Asphaug, 2001, Canup. 2004, 2008), $\geq 40 \%$ of evaporative losses of $\mathrm{Mn}$ and $\mathrm{Cr}$ are needed to produce their depletion in the lunar mantle (Fig. 14). Such significant evaporation of these elements is inconsistent with their least volatile nature among MVE (Gellissen et al., 2019; Sossi et al., 2019). Thus, the proto-Earth's $\mathrm{V}, \mathrm{Cr}$ and Mn-depleted mantle should be a primary source of the Moon-forming materials, as supported by their isotopic similarities (e.g., Wiechert et al., 2001; Warren, 2011; Zhang et al., 2012, Greenwood et al. 2018). A recent geochemical model of Earth's Moon formation and differentiation prefers a present-day BSE-like MVE composition for the bulk proto-Moon (i.e., lunar source materials before gas-melt fractionation; Righter, 2019), which is consistent with the proto-Earth's MVE abundance and its large contribution to the lunar source materials (Fig. 14 and Table A.2). The proto-Earth origin of the Moon is also consistent with recent particle hydrodynamic collision 
simulations (Hosono et al. 2019) which showed that a terrestrial magma ocean might be a source of lunar building blocks.

\subsubsection{Mars' accretion and core formation}

Our compositional estimate of Mars requires a much simpler formation history as compared to Earth's multi-stage formation scenario. The lack of depletion in nominally lithophile elements in the BSM (V, Cr, and Mn; Fig. 4) is consistent with its accretion under uniformly oxidized and low- $T$ conditions (e.g., Wood et al., 2009). Mars might have experienced a large impact(s) that produced its hemispheric crustal dichotomy and possibly Martian moons (e.g., Marinova et al., 2008, Canup and Salmon, 2018), but estimates of a putative small impactor ( $\sim .1 \%$ of the Mars' mass; Canup and Salmon, 2018) would result in negligible changes in its bulk composition. The $0.5-1 \%$ mass addition of chondritic late accretion material provides highly siderophile and chalcophile elements to the Martian mantle (Tait and Day, 2018, Yoshizaki and McDonough, 2020).

Righter and Chabot (2011) and Yang et al. (2015) estimated Martian core formation happening at $14 \pm 3 \mathrm{GPa}$ and $2100 \pm 200 \mathrm{~K}$ based on its previous compositional models. Following the approaches of Righter and Chabot (2011) and Yang et al. (2015), the Martian siderophile element distribution of Yoshizaki and McDonough (2020) can be modeled by single stage $P-T$ and redox conditions (Fig. A.8), whereas there is no unique solution for Martian core formation (Fig. A.9.

The simple formation history of Mars, combined with its rapid and early accretion (Dauphas and Pourmand, 2011, Kruijer et al., 2017b, Bouvier et al., 2018, Marchi et al., 2020), is consistent with its status as a planetary embryo. Given compositional and redox state gradients in the protoplanetary disk, Mars might record the chemical characteristics of nebular materials in the Mars' orbit in the first few years of the solar system, whereas Earth might have incorporated oxidized materials from greater heliocentric distance in its later accretion stage (Section 3.3.2: Rubie et al., 2015). The Mars' status as a planetary embryo suggest that a Mars-sized body commonly has a Mars-like composition, supporting the Mars-like Moon-forming impactor scenario (Section 3.3.2).

\subsection{Conditions for a habitable planet formation}

The early $\tau_{\text {Mars }}^{\text {accretion }}$ age implies that Mars underwent global-scale silicate melting and rapid core formation due to heating from short-lived ${ }^{26} \mathrm{Al}$ and ${ }^{60} \mathrm{Fe}$ (Fig. A.12, Dauphas and Pourmand 2011, McDonough et al. 2020). The peak radiogenic heating occurs at about 1 to $5 \mathrm{Myr}$ after $t_{0}$, well within the time scale for Mars accretion. With $\tau_{\text {Mars }}^{\text {accretion }}=2 \mathrm{Myr}$, the radiogenic energy supplied by ${ }^{26} \mathrm{Al}$ is comparable to Mars' gravitational binding energy $\left(\sim 7 \times 10^{29} \mathrm{~J}\right.$ and $\sim 10^{30} \mathrm{~J}$, respectively). During the first $10 \mathrm{Myr}$, radiogenic heating $\left({ }^{26} \mathrm{Al},{ }^{60} \mathrm{Fe}\right.$ and ${ }^{40} \mathrm{~K}$, in order of significance) is comparable to the planet's primordial energy and is a major control on its thermal evolution. 
Mars has the attributes needed for a rocky planet to be biologically available in its early history (e.g., Ehlmann et al., 2016), and it has a higher bulk heat production than Earth's (3.9 vs 3.3 $\mathrm{pW} / \mathrm{kg}$; Table 1). Nonetheless, it has rapidly lost much of its primordial energy (i.e., accretion and core differentiation) due to its larger surface to volume ratio (a factor of 2) and smaller core size (i.e., reduced bottom heating), and it is in waning stages of limited fuel resources (Parro et al. 2017; Yoshizaki and McDonough, 2020). Basal heating of the Martian mantle by its core enhances its thermal evolution, while the transfer of hydrogen from the adjacent ringwoodite to the core (Shibazaki et al. 2009, Yoshizaki and McDonough, 2020) reduces the lifetime of the dynamo (O'Rourke and Shim 2019). Collectively, these processes likely contributed to dynamo termination at $\sim 4 \mathrm{Ga}$ and loss of the protective magnetosphere (Acuña et al., 1999; Arkani-Hamed, 2004; Lillis et al. 2008). This magnetosphere shields the planet from atmospheric losses, enhances its surface UV radiation, and leads to dramatic climate changes (Ehlmann et al., 2016).

Volatile elements may play a critical role in establishing the amount of light elements in and solidus of the core. The amount of water and other volatile species in the planet's interior and surface may potentially create the appropriate conditions for the initiation of plate tectonics (e.g., Albarede, 2009, Ehlmann et al. 2016). Likewise, the heat-producing elements and a reduced core solidus keep the metallic core convecting and lead to the creation of a magnetic field, which shields a planet's surface from cosmic rays. Together, heat-producing and volatile elements regulate a planet's cooling history, drive crustal differentiation, and make it habitable (Ehlmann et al., 2016). The simple formation history of Mars (Section 3.3.3, Rubie et al. 2015) emphasizes the uniqueness of Earth, the sole habitable planet in our solar system. In turn, the Earth-Mars comparison indicates that high-temperature nebular chemical processes and timescales of planetary accretion are essential in making habitable planets.

Depletion in volatile elements appears to be a common feature of the terrestrial planets (Fig. 3 Surkov et al., 1987, Peplowski et al., 2011), and may likely be so for rocky exoplanets (Harrison et al. 2018, 2021). The relationship between the planetary volatile depletion, size, accretion timescale and abundance of chondrules (Fig. 11) predict accretion timescales of Venus and Mercury of 30-100 Myr and 2-10 Myr, respectively, based on their Earth- and Mars-like K/Th ratios, respectively (Surkov et al., 1987, Peplowski et al. 2011). The predicted ages of Mercury and Venus provide a foundation for future investigation of their thermal history and habitability.

Venus and Earth are quite similar in their physical and chemical properties (size, bulk K/Th ratio, Mg\# in basalt and possibly MOI; e.g., Surkov et al., 1987; Dumoulin et al., 2017), but their present-day surface conditions are distinct. Venus does not show a clear evidence for a giant impact, and its size and K/Th ratio ( $\sim 3000$; Surkov et al. 1987) are comparable to those of the proto-Earth $(\mathrm{K} / \mathrm{Th} \sim 3200$; Table A.2). Therefore, the present-day Venus might be comparable to the preimpact proto-Earth. Further observational, cosmochemical and theoretical investigations of Venus may provide useful insights into the pre- and post-formational history of Earth, the only habitable planet in the today's solar system. 


\section{Conclusions}

The refractory element enhancement and volatile depletion of Earth and Mars were established by a nebular chemical fractionation. Post-accretionary losses of moderately volatile elements are negligible. The degree of volatile element depletion correlates with the abundance of accreted chondrules, planetary size, and their accretion timescale. The present-day bulk silicate Earth composition is consistent with a Moon-forming impactor having a Mars-like size and composition. Planetary chemistry, which is related to many factors including the building block composition, the timing, duration and sequence of accretion and its differentiation history, play an essential role in making a planet habitable.

\section{Acknowledgments}

We thank many our colleagues who have listened to various versions of this project and given feedback, especially Eiji Ohtani, Nick Schmerr, Beda Roskovec, Ondřej Šrámek, Sarah StewartMukhopadhyay, Kevin Righter, and Henri Samuel. We also thank Attilio Rivoldini for helpful comments. We greatly appreciate Hugh O'Neill, Bernard Wood, and an anonymous referee for their constructive reviews, which helped improve the manuscript. We thank the journal editor Astrid Holzheid for editorial efforts. TY acknowledges supports from the Japanese Society for the Promotion of Science (JP18J20708) and GP-EES and DIARE research grants. WFM gratefully acknowledges NSF support (EAR1650365).

\section{Author contributions}

TY and WFM proposed and conceived various portions of this study and together calculated the compositional models of planets. The manuscript was jointly written by TY and WFM and they read and approved the final manuscript.

\section{Competing interests}

The authors declare no competing interests.

\section{Additional information}

Correspondence and requests for materials should be addressed to TY.

\section{Data and materials availability}

Materials used in this study are available within the paper or supplementary materials. 
Table 1: Physical and chemical properties of Earth and Mars. Modeled values are in normal and reference values in italic fonts.

\begin{tabular}{|c|c|c|c|c|c|c|}
\hline Observation & Unit & Crust & Mantle & Core & Bulk planet & Reference value \\
\hline \multicolumn{7}{|l|}{ Earth } \\
\hline Mass $\sqrt{\mathrm{a} b}$ & $\mathrm{~kg}$ & $3.12 \times 10^{22}$ & $4.00 \times 10^{24}$ & $1.94 \times 10^{24}$ & $5.972 \times 10^{24}$ & $5.97218(60) \times 10^{24}$ \\
\hline Mean density & $\mathrm{kg} / \mathrm{m}^{3}$ & 2800 & 4400 & 11870 & 5514 & $5514(2)$ \\
\hline Moment of inertid & - & $1 \%$ & $88 \%$ & $11 \%$ & 0.3308 & $0.330690(9)$ \\
\hline \multirow{2}{*}{ Heat production $(\mathrm{K}, \mathrm{Th}, \mathrm{U})^{\mathrm{bdeff}}$} & TW & 7.3 & 12.6 & 0 & 19.9 & $46(3 \mathrm{~g}$ \\
\hline & $\mathrm{pW} / \mathrm{kg}$ & 232 & 3.1 & 0 & 3.3 & - \\
\hline \multicolumn{7}{|l|}{ Mars } \\
\hline Mass & $\mathrm{kg}$ & $2.56 \times 10^{22}$ & $5.01 \times 10^{23}$ & $1.17 \times 10^{23}$ & $6.419 \times 10^{23}$ & $6.417(3) \times 10^{23}$ \\
\hline Mean density ${ }^{\text {1] }}$ & $\mathrm{kg} / \mathrm{m}^{3}$ & 3010 & 3640 & 6910 & 3936 & $3935(1)$ \\
\hline Moment of inertia & - & $7 \%$ & $89 \%$ & $4 \%$ & 0.3638 & $0.3639(1)$ \\
\hline \multirow{2}{*}{ Heat production $(\mathrm{K}, \mathrm{Th}, \mathrm{U})^{\mathrm{j} \mathrm{kT}}$} & TW & 1.3 & 1.3 & 0 & 2.5 & $2.7(2 \mathrm{~g}$ \\
\hline & $\mathrm{pW} / \mathrm{kg}$ & 49 & 2.5 & 0 & 3.9 & - \\
\hline
\end{tabular}

\begin{tabular}{|c|c|c|c|c|c|c|c|c|c|c|c|}
\hline \multirow[b]{2}{*}{ wt $\%$} & \multicolumn{2}{|c|}{ Mantle + crus } & \multirow[b]{2}{*}{ wt $\%$} & \multicolumn{2}{|c|}{ Core $\mathrm{dlk}^{\mathrm{d}}$} & \multirow[b]{2}{*}{ wt $\%$} & \multicolumn{2}{|c|}{ Bulk plane $e^{\mathrm{dI} / \mathrm{m}}$} & \multicolumn{3}{|c|}{ Chondrit $\mathrm{e}^{\mathrm{⿴囗}}$} \\
\hline & Earth & Mars & & Earth & Mars & & Earth & Mars & $\mathrm{EH}$ & $\mathrm{L}$ & $\overline{\mathrm{CI}}$ \\
\hline $\mathrm{SiO}_{2}$ & 44.9 & 45.5 & $\mathrm{Fe}$ & 85.5 & 79.5 & $\mathrm{O}$ & 29.7 & 36.3 & 30.0 & 35.8 & 29.9 \\
\hline $\mathrm{TiO}_{2}$ & 0.20 & 0.17 & $\mathrm{Ni}$ & 5.1 & 7.4 & $\mathrm{Fe}$ & 32.0 & 23.7 & 31.0 & 22.7 & 27.7 \\
\hline $\mathrm{Al}_{2} \mathrm{O}_{3}$ & 4.44 & 3.59 & $\mathrm{O}$ & 2 & 5.2 & $\mathrm{Mg}$ & 15.4 & 15.3 & 11.3 & 15.7 & 14.3 \\
\hline $\mathrm{MnO}$ & 0.14 & 0.37 & $\mathrm{~S}$ & 1.8 & 6.6 & $\mathrm{Si}$ & 16.1 & 17.4 & 17.8 & 19.5 & 16.0 \\
\hline $\mathrm{FeO}$ & 8.06 & 14.7 & $\mathrm{H}$ & 0.06 & 0.9 & $\mathrm{Ni}$ & 1.82 & 1.4 & 1.87 & 1.27 & 1.58 \\
\hline $\mathrm{MgO}$ & 37.8 & 31.0 & Co & 0.25 & 0.33 & $\mathrm{Ca}$ & 1.71 & 1.69 & 0.91 & 1.38 & 1.36 \\
\hline $\mathrm{CaO}$ & 3.54 & 2.88 & $\mathrm{P}$ & 0.20 & 0.33 & $\mathrm{Al}$ & 1.59 & 1.56 & 0.86 & 1.29 & 1.26 \\
\hline $\mathrm{Na}_{2} \mathrm{O}$ & 0.36 & 0.59 & $\mathrm{Si}$ & 4 & 0 & $S$ & 0.59 & 1.2 & 6.2 & 2.3 & 8.0 \\
\hline $\mathrm{K}_{2} \mathrm{O}$ & 0.034 & 0.043 & $\mathrm{Cr}$ & 0.75 & 0 & & & & & & \\
\hline $\mathrm{P}_{2} \mathrm{O}_{5}$ & 0.021 & 0.17 & & & & Total & 99.0 & 98.5 & 100 & 100 & 100 \\
\hline $\mathrm{NiO}$ & 0.25 & 0.046 & Total & 99.7 & 100.2 & & & & & & \\
\hline $\mathrm{Cr}_{2} \mathrm{O}_{3}$ & 0.15 & 0.88 & & & & $\mathrm{Mg} / \mathrm{Si}$ & 0.96 & 0.88 & 0.63 & 0.81 & 0.89 \\
\hline & & & & & & $\mathrm{Al} / \mathrm{Si}$ & 0.10 & 0.09 & 0.05 & 0.07 & 0.08 \\
\hline $\mathrm{K}(\mathrm{ppm})$ & 280 & 360 & & & & $\mathrm{Fe} / \mathrm{Si}$ & 2.0 & 1.4 & 1.7 & 1.2 & 1.7 \\
\hline Th (ppb) & 76 & 68 & & & & & & & & & \\
\hline $\mathrm{U}(\mathrm{ppb})$ & 20 & 18 & & & & & & & & & \\
\hline Total & 100.2 & 99.9 & & & & & & & & & \\
\hline
\end{tabular}

${ }^{\mathrm{a}}$ Chambat et al. (2010). $\quad{ }^{\mathrm{b}}$ Wipperfurth et al. (2020). $\quad{ }^{\mathrm{c}}$ Dziewonski and Anderson $(1981)$.

${ }^{\mathrm{d}}$ McDonough (2014). $\quad$ e Jaupart et al. (2015). $\quad{ }^{\mathrm{f}}$ Rudnick and Gao (2014). $\quad{ }^{\mathrm{g}}$ Global surface heat loss.

${ }^{\mathrm{h}}$ Konopliv et al. (2016). $\quad{ }^{\mathrm{T}}$ Rivoldini et al.(2011). $\quad{ }^{\mathrm{J}}$ Taylor and McLennan (2009). $\quad{ }^{\mathrm{k}}$ Yoshizaki and McDonough (2020).

${ }^{1}$ Parro et al. (2017). ${ }^{\mathrm{m}}$ This study. ${ }^{\mathrm{n}}$ Alexander (2019a b) (Volatile-free, normalized to total $=100 \mathrm{wt} \%$ ). 

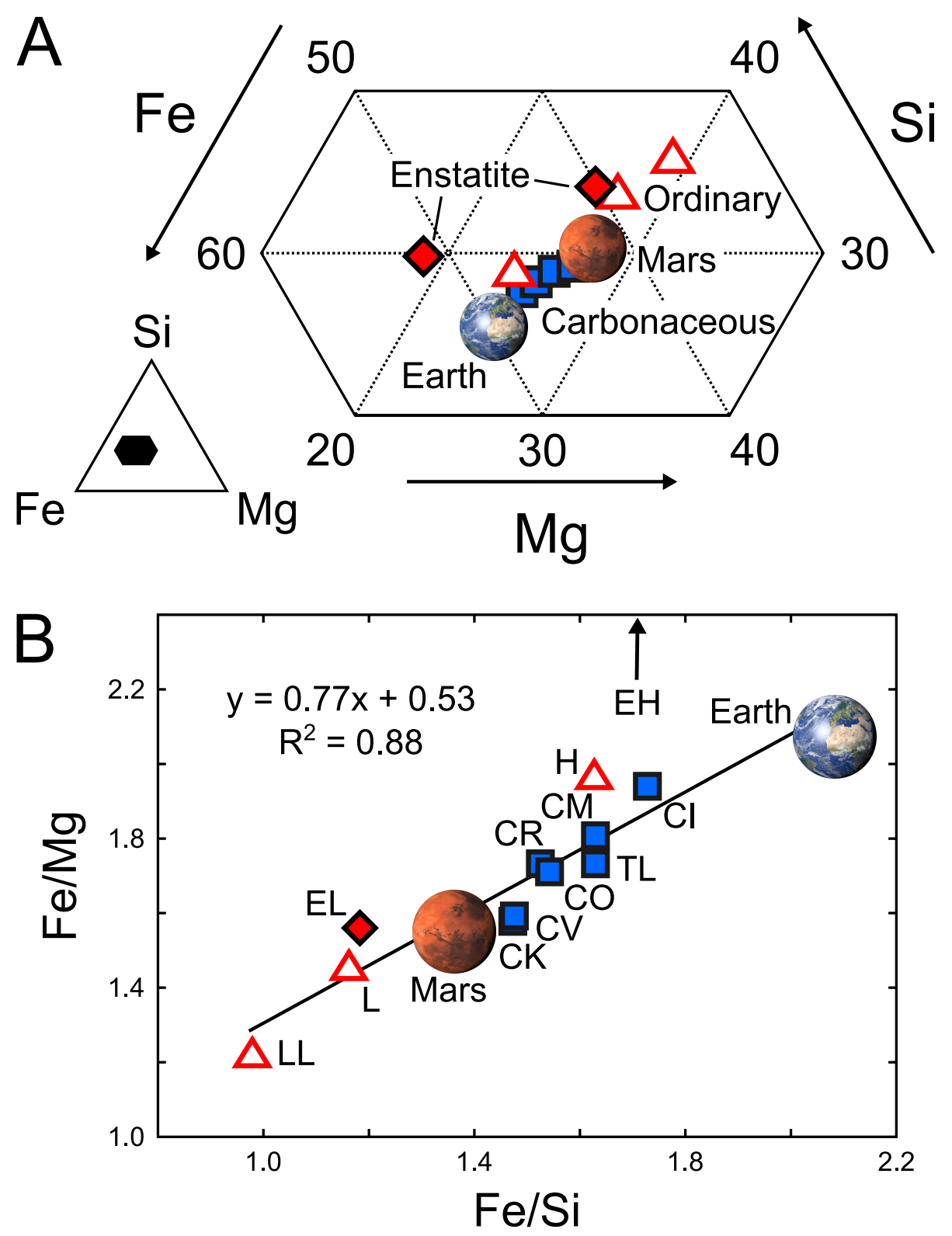

Fig. 1: (A) Ternary plot and (B) scatter ratio plot of major elements Si, Fe and $\mathrm{Mg}$ in bulk Earth (McDonough, 2014), bulk Mars (Yoshizaki and McDonough, 2020) and chondritic meteorites (Alexander, 2019a b). The regression line for chondrites (except for sulfide-rich EH) is also shown in the lower panel. TL-Tagish Lake. 

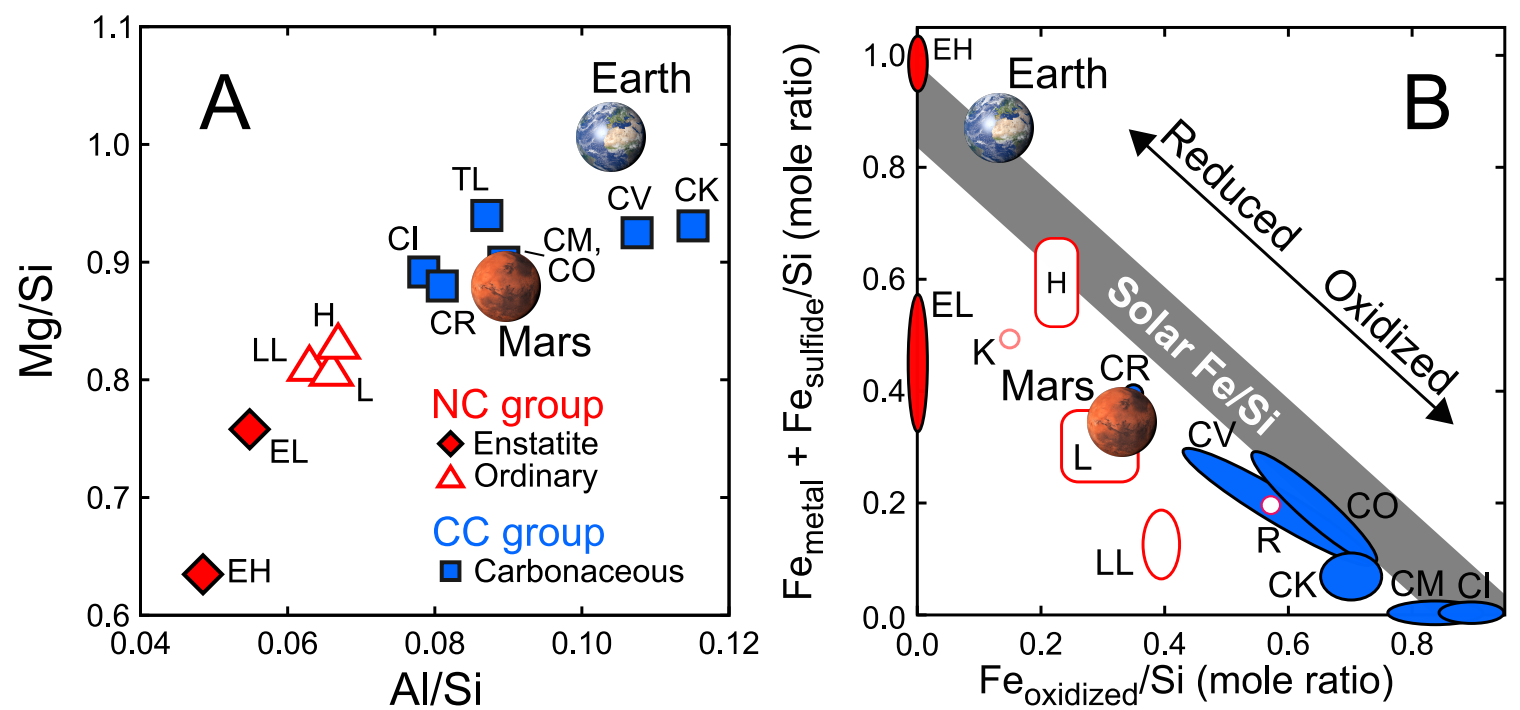

Fig. 2: (A) Weight ratios of $\mathrm{Al} / \mathrm{Si}$ vs $\mathrm{Mg} / \mathrm{Si}$ values for planets and chondrites. Earth and Mars show higher RLE abundances (i.e., $\mathrm{Al}$ ) and $\mathrm{Mg} / \mathrm{Si}$ value (i.e., olivine/pyroxene ratio) compared to enstatite and ordinary chondrites, which are respectively their isotopically identified relatives. (B) The Urey-Craig diagram (after Urey and Craig, 1953) illustrates relative redox condition for Earth, Mars, and chondrites. Chondrite classification (non-carbonaceous (NC; red) vs carbonaceous (CC; blue) groups) follows Warren (2011) and Kruijer et al. (2017a). TL-Tagish Lake. Data sources are as in Fig. 1. 


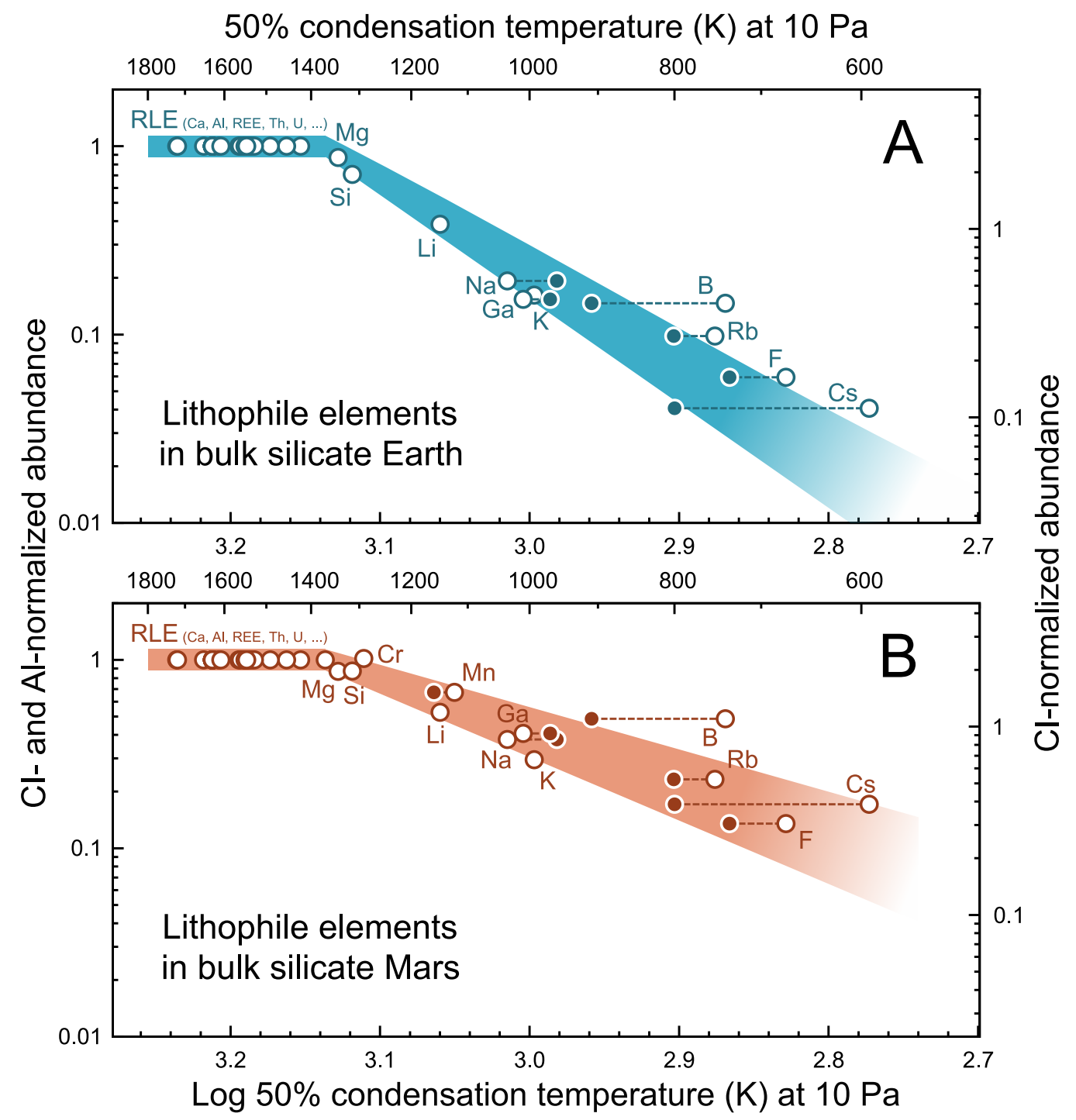

Fig. 3: Lithophile element abundances in the bulk silicate Earth and Mars normalized to CI abundances and refractory lithophile element $\mathrm{Al}$. The scale of right ordinate shows the CI-normalized abundances. The values are plotted against $50 \%$ condensation temperature $(\mathrm{K})$ of elements at $10 \mathrm{~Pa}$ (open; Wood et al. 2019) and (filled; Lodders, 2003). CI abundance is from Lodders (2020). Other data sources are as in Fig. 1 


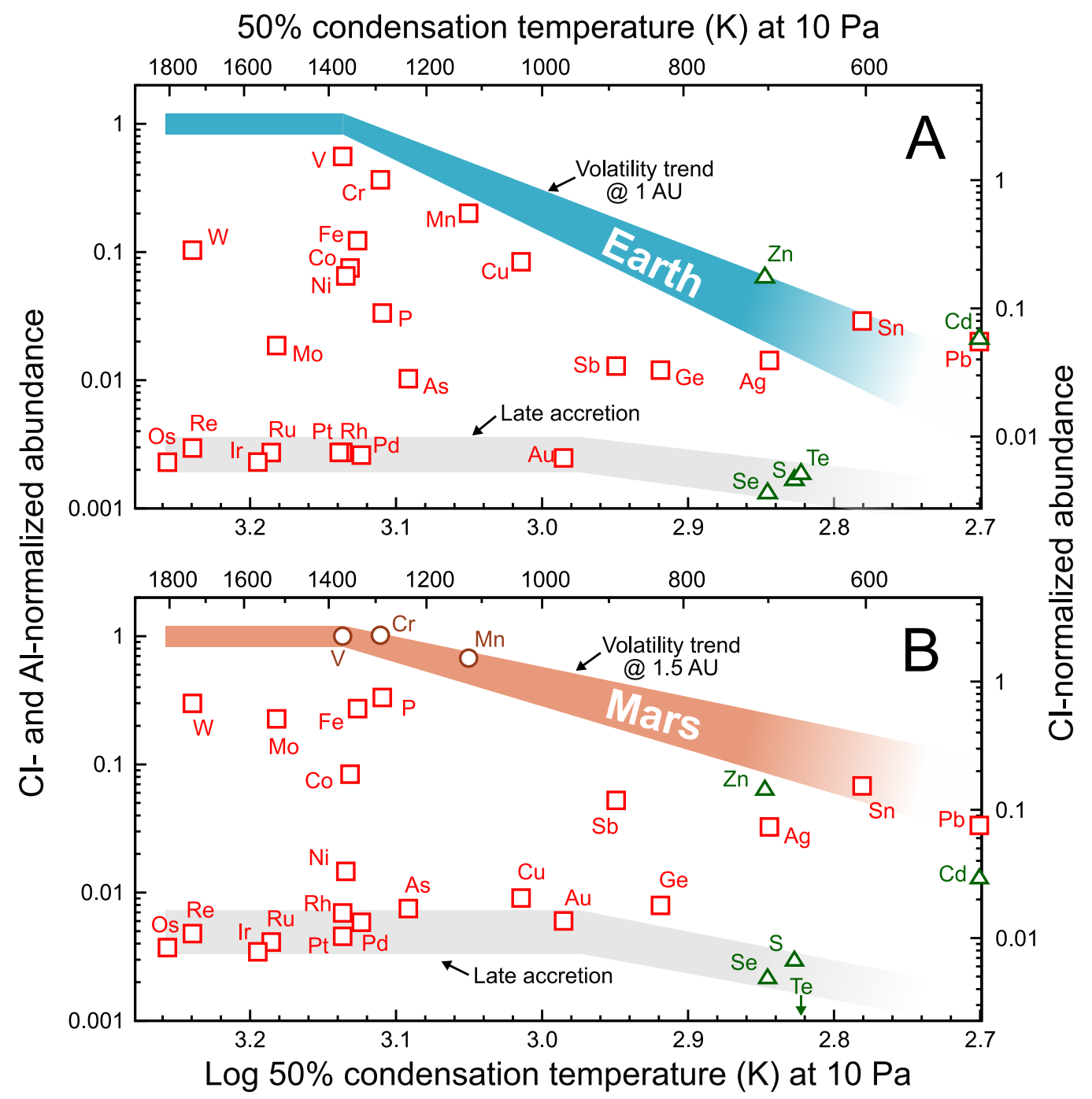

Fig. 4: Siderophile (red square) and chalcophile (green triangle) element abundances in the bulk silicate Earth and Mars plotted against 50\% condensation temperature (K) of elements at $10 \mathrm{~Pa}$ (Wood et al., 2019). The values for y axes follow the same convention as Fig. 3. Also shown are time-integrated planetary volatility trends at $1 \mathrm{AU}$ (Earth) and 1.5 AU (Mars) defined by lithophile elements (Fig. 3). Data sources are as in Fig. 1. 


\section{Earth}
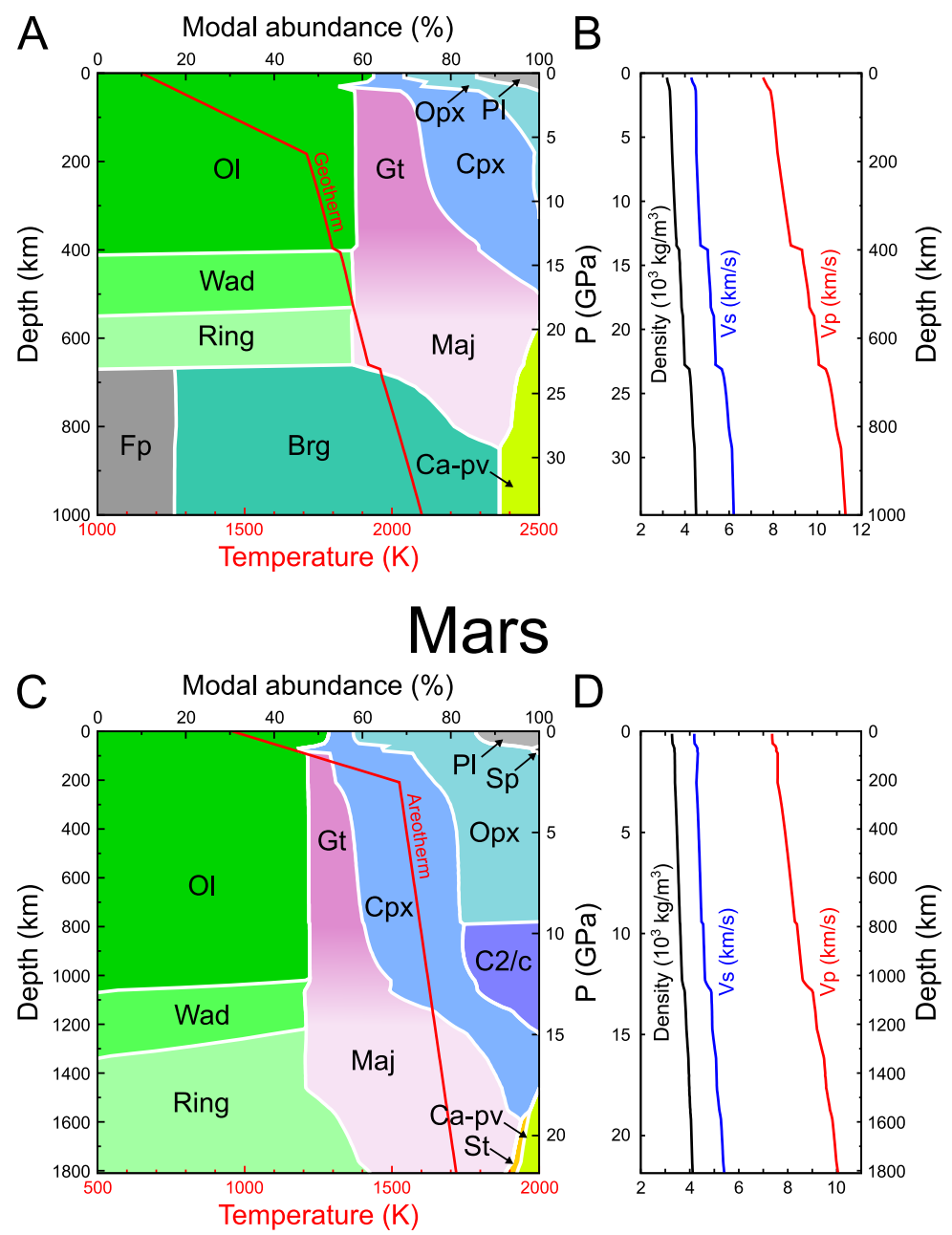

Fig. 5: Mineralogy and physical properties of planetary mantles. (A, C) Phase transitions and (B, D) P- and S-wave velocities and density from surface to the core-mantle boundary in the Earth's and Martian mantle. Red lines show temperature profile in the mantle. Figures for Earth are based on the mantle compositional model of McDonough (2014) and model geotherm from Katsura et al.(2010). Figures for Mars are reprinted from T. Yoshizaki and W.F. McDonough (2020) The composition of Mars, Geochimica et Cosmochimica Acta 273, 137-162, Copyright (2020), with permission from Elsevier. Abbreviations: Brg-bridgmanite; Ca-pv-Ca-perovskite; $\mathrm{Cpx}$-clinopyroxene; C2/chigh-pressure clinopyroxene; Fp-ferropericlase; Gt-garnet; Ol-olivine; Opx-orthopyroxene; $\mathrm{Pl}$ plagioclase; Ring-ringwoodite; Sp-spinel; St-stishovite; Wad-wadsleyite. 


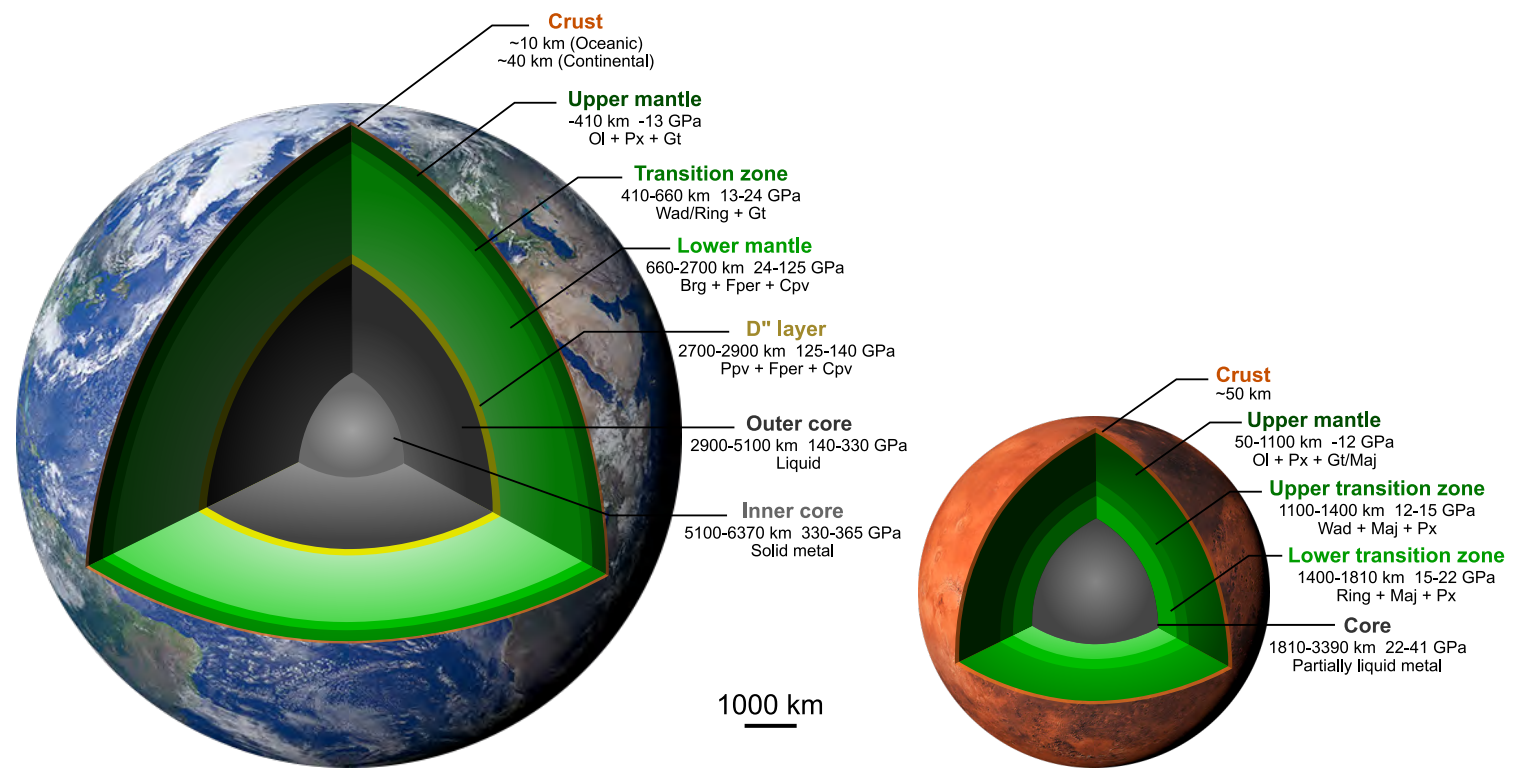

Fig. 6: Interior structure of Earth and Mars. Abbreviations: Ol-olivine; Px-pyroxene; Gt-garnet; Wad-wadsleyite; Ring-ringwoodite; Brg-bridgmanite; Cpv-Ca-perovskite; Ppv-post-perovskite; Fper-ferropericlase. The Mars figure is reprinted from T. Yoshizaki and W.F. McDonough (2020) The composition of Mars, Geochimica et Cosmochimica Acta 273, 137-162, Copyright (2020), with permission from Elsevier. 


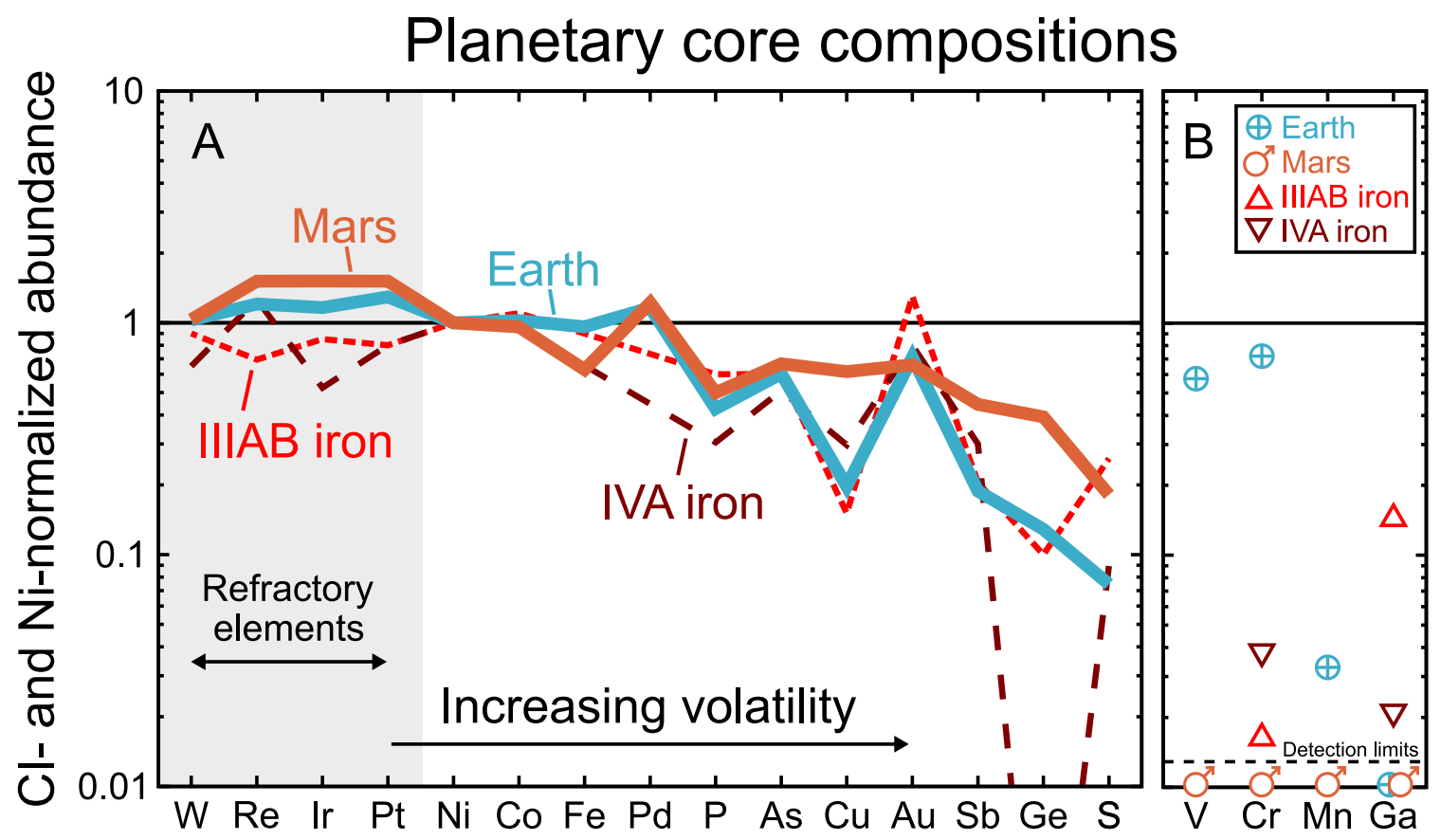

Fig. 7: Composition of metallic cores of Earth (McDonough, 2014), Mars (Yoshizaki and McDonough, 2020) and NC-group iron meteorite parent bodies (Wasson and Richardson, 2001; Chabot, 2018). (A) Siderophile and chalcophile element and (B) nominally lithophile element abundances. Elemental abundances are normalized to $\mathrm{CI}$ chondrite composition and Ni. Elements are arranged by their $50 \%$ nebular condensation temperatures (Wood et al., 2019), while W and Re are replaced to highlight chondritic highly siderophile element abundance in planetary cores. Type IIIAB and IVA iron meteorites have fractional crystallization (i.e., magmatic) origin and are isotopically classified as NC group meteorites (Burkhardt et al., 2011, Kruijer et al., 2017a, Poole et al. 2017). 

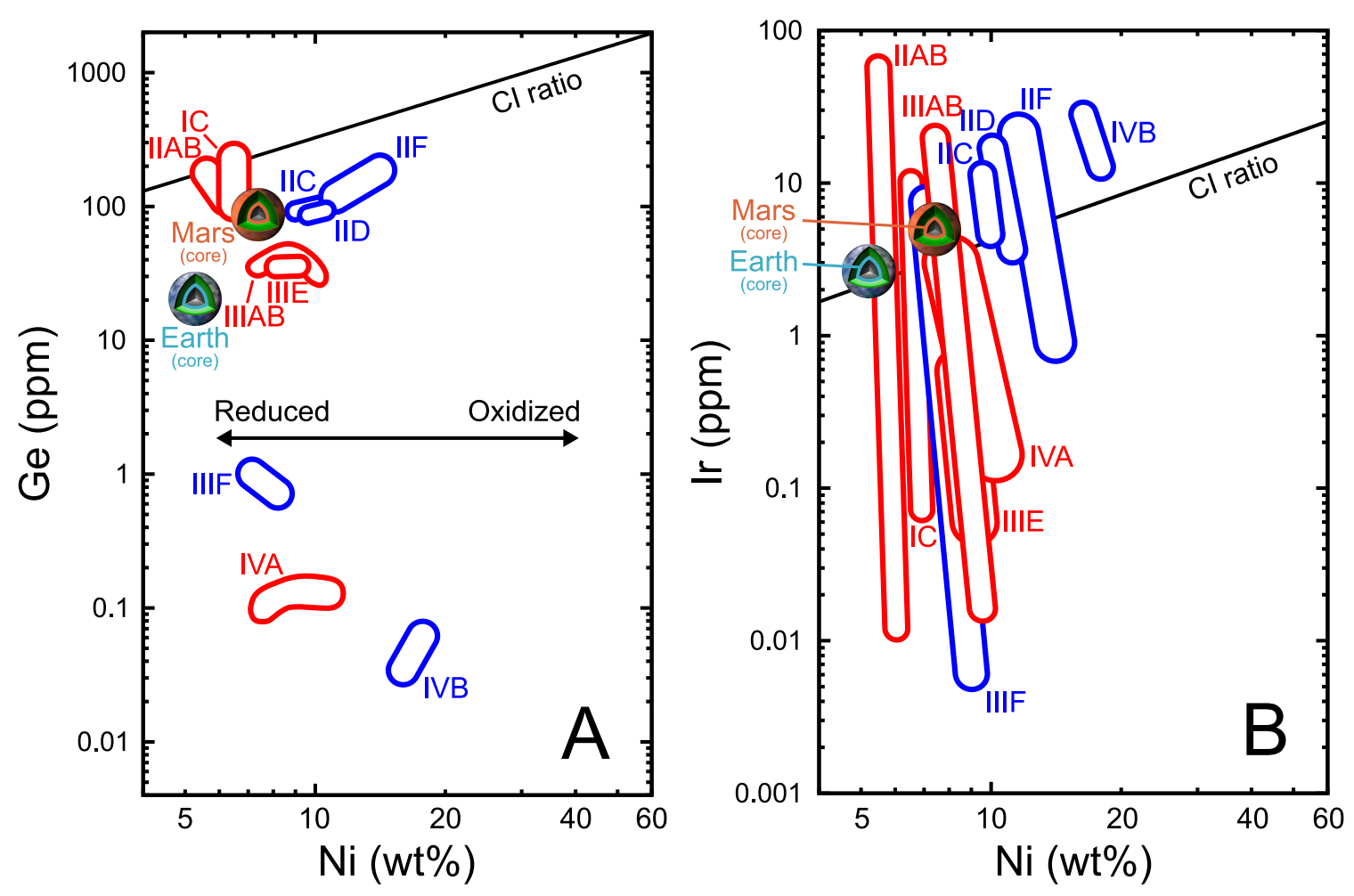

Fig. 8: Composition of metallic cores of Earth (McDonough, 2014), Mars (Yoshizaki and McDonough, 2020) and fractionally crystallized (i.e., magmatic) iron meteorites (Goldstein et al. 2009). (A) Ge versus Ni. (B) Ir versus Ni. Iron meteorites are classified into non-carbonaceous (NC: in red) and carbonaceous (CC: in blue) groups based on their Mo and W isotopic compositions (Burkhardt et al., 2011, Kruijer et al., 2017a; Poole et al., 2017). Silicate-bearing (non-magmatic) iron groups are not shown. The IIG iron meteorites are also excluded from the plot because isotopic data to classify them into $\mathrm{NC}$ or $\mathrm{CC}$ group are not available. $\mathrm{CI}$ chondritic ratios are from Lodders (2020). 


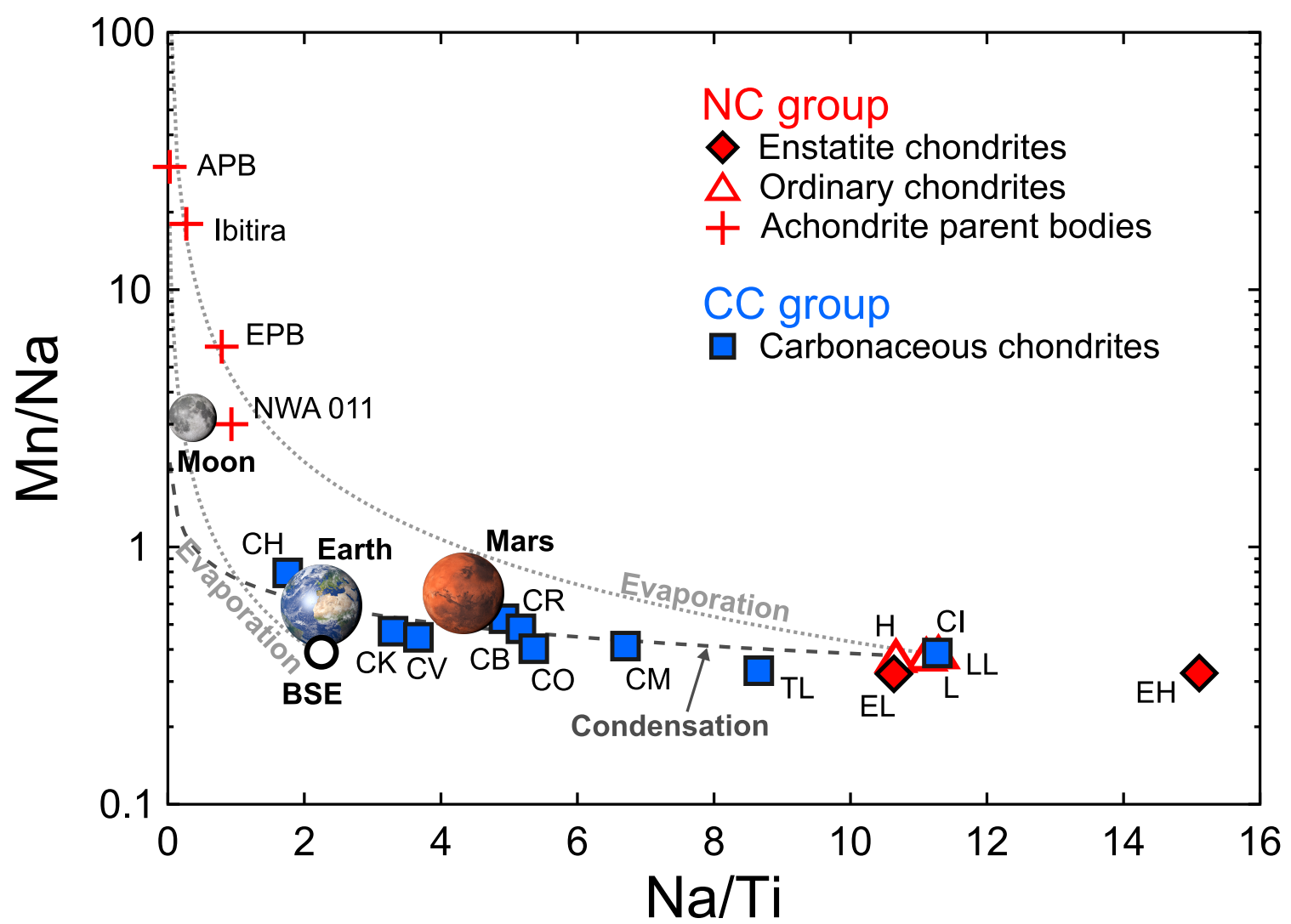

Fig. 9: $\mathrm{Na} / \mathrm{Ti}$ vs $\mathrm{Mn} / \mathrm{Na}$ in chondrites (Alexander, 2019a b), differentiated asteroids (O'Neill and Palme, 2008), Moon (Dauphas et al., 2014), Earth (this study; McDonough, 2014, Siebert et al. 2018) and Mars (Yoshizaki and McDonough, 2020). Dark gray line shows incomplete condensation from a gas of CI composition. Light gray lines correspond to evaporative loss of $\mathrm{Na}$ and $\mathrm{Mn}$ from CI and the bulk silicate Earth (BSE) compositions, respectively. See Section A.1.1 for details of model calculations. 

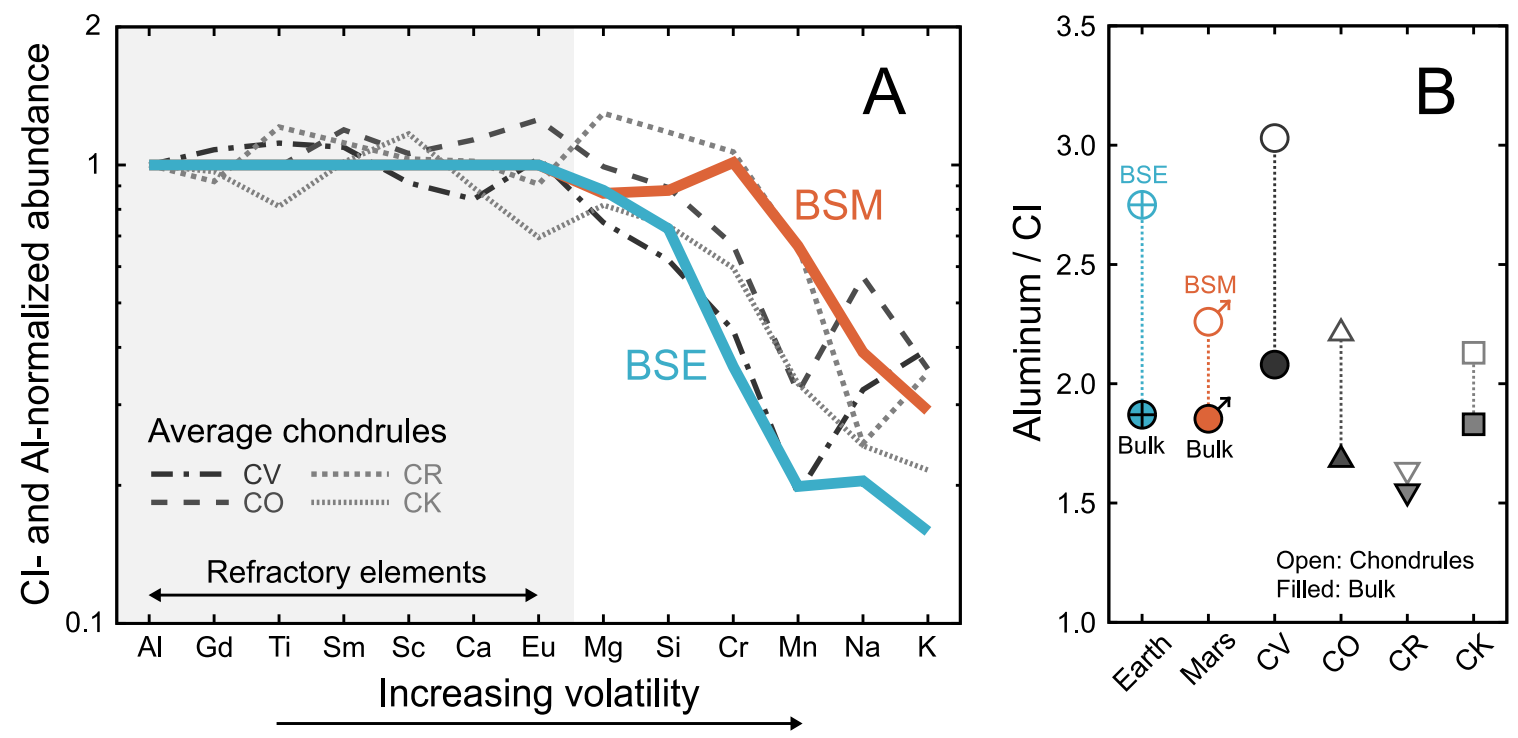

Fig. 10: Lithophile element composition of Earth, Mars, and carbonaceous chondrites and their components. (A) Lithophile element abundance in the bulk silicate Mars (BSM), bulk silicate Earth (BSE) and bulk chondrules from carbonaceous chondrites. Elemental abundances are normalized to $\mathrm{CI}$ chondrite composition and $\mathrm{Al}$. Elements are arranged by their $50 \%$ nebular condensation temperatures. (B) CI-normalized Al abundances in the BSE, BSM, bulk planets, bulk chondrules and bulk chondrites. Chemical composition of chondrules is from Hezel et al. (2018b) and MetBase (1994-2017). Other data sources are as in Fig. 1. 


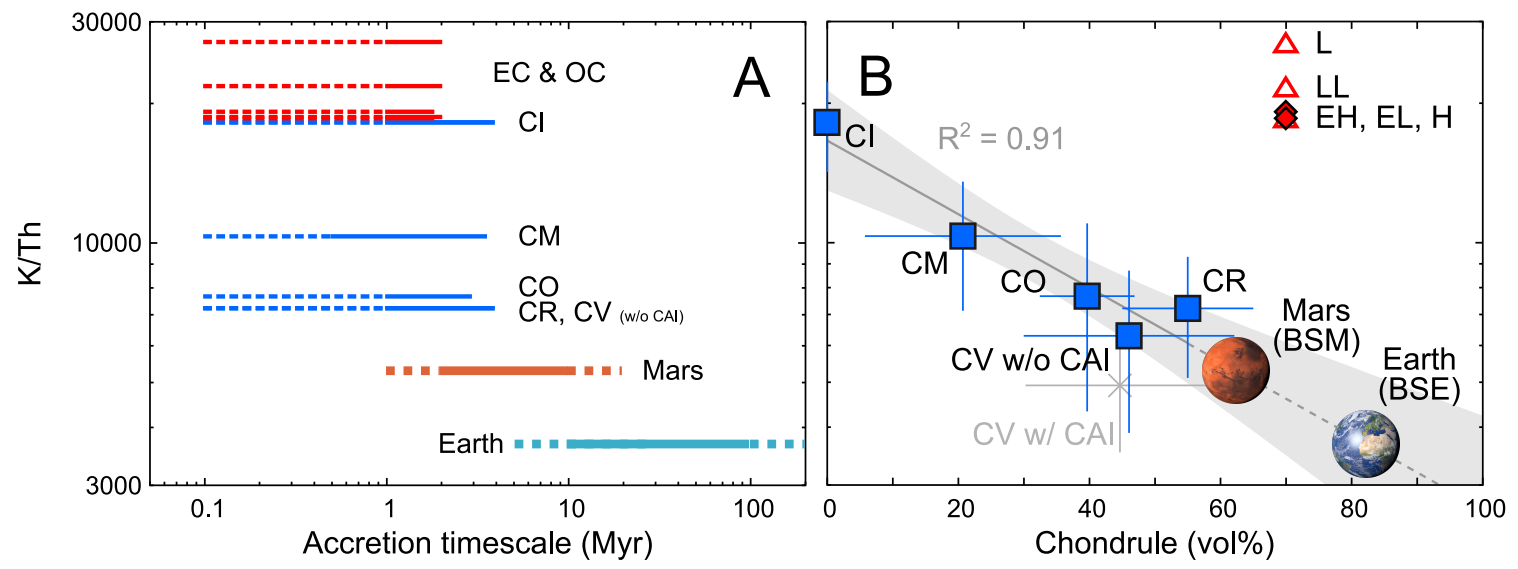

Fig. 11: (A) Accretion timescale (Myr) vs K/Th ratio of chondrites and terrestrial planets. Duration of accretion of chondritic asteroids is based on the $\mathrm{Pb}-\mathrm{Pb}$, Hf-W and $\mathrm{Al}-\mathrm{Mg}$ ages of chondrules (Amelin et al., 2002, Amelin and Krot, 2007, Connelly et al., 2008, 2012, Connelly and Bizzarro, 2009, Bollard et al. 2017, 2019; Villeneuve et al., 2009; Nagashima et al., 2017; Schrader et al. 2017, Kita et al., 2013, Pape et al. 2019, Budde et al., 2016, 2018), Mn-Cr ages of asteroidal secondary alteration products (Fujiya et al., 2012; Doyle et al., 2015), and thermal modeling of asteroids (Sugiura and Fujiya, 2014). Accretion timescales of Earth and Mars are defined based on Kruijer et al. (2017b, 2020), Kleine et al. (2009), Dauphas and Pourmand (2011), Kruijer et al. (2017b), and Connelly et al. (2019). (B) Abundance of chondrules (vol\%) vs K/Th value of chondrites. Error bars (shown only for carbonaceous chondrites) represent 2 standard deviations, and gray area corresponds to the $95 \%$ confidence interval of the linear regression. The abundances of chondrules in chondrites are based on McSween (1977a), McSween (1977b), McSween (1979) and Scott and Krot (2014). The amounts of chondrules in Earth and Mars are estimated based on their K/Th values and extrapolation of the carbonaceous chondritic trend. See Section A.4 for a method to calculate the CAI-free bulk CV composition. 

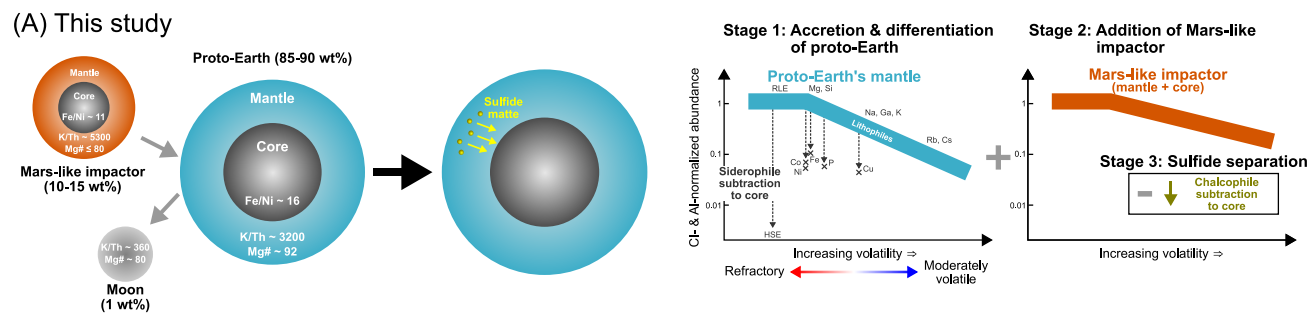

(B) O'Neill (1991)
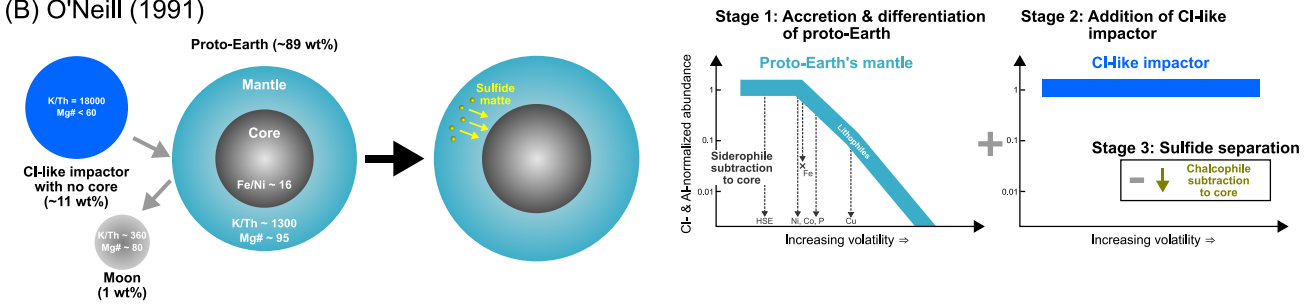

(C) Wänke et al. (1984)
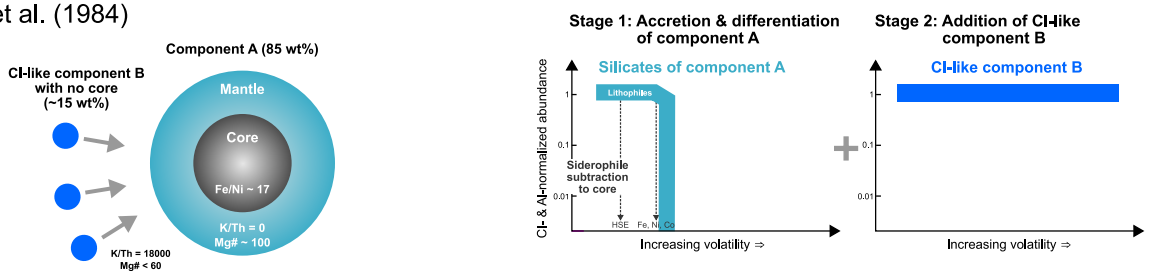

Fig. 12: A cartoon summarizing three models of the Earth's accretion: (A) this study; (B) O'Neill (1991b); and (C) Wänke et al. (1984). The later models envisage Earth's formation as composed of four stages: (1) accretion and differentiation of a proto-Earth, (2) addition of a giant impactor to the proto-Earth's mantle, (3) loss of a sulfide matte from this mantle, and (4) late accretion of volatile-rich chondritic materials (not shown). 


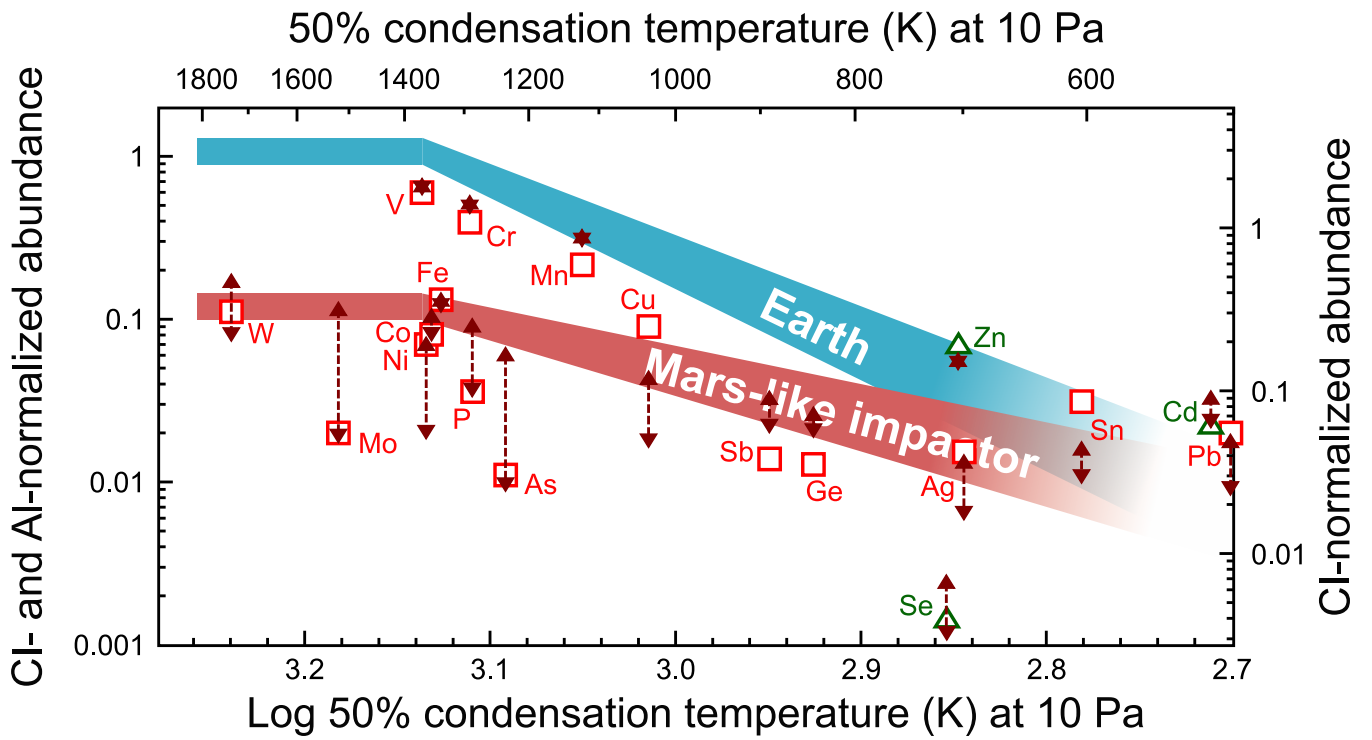

Fig. 13: Siderophile (red square) and chalcophile (green triangle) element abundances in the BSE, and a model BSE composition after the sulfide matte subtraction (dark red arrow) predicted by a Mars-like (i.e., size and composition) Moon-forming impactor scenario. The dark red arrows represent the model compositional range based on sulfide-silicate partition coefficients of elements (Table A.1). Highly siderophile and chalcophile elements are not shown, as their abundances in the present-day BSE can be explained by the late addition of volatile-rich materials (Step 4). Also shown are the Mars-like impactor's contribution (red band) in the present-day Earth composition (blue band). The values for $\mathrm{x}$ and $\mathrm{y}$ axes follow the same conventions as Fig. 4 


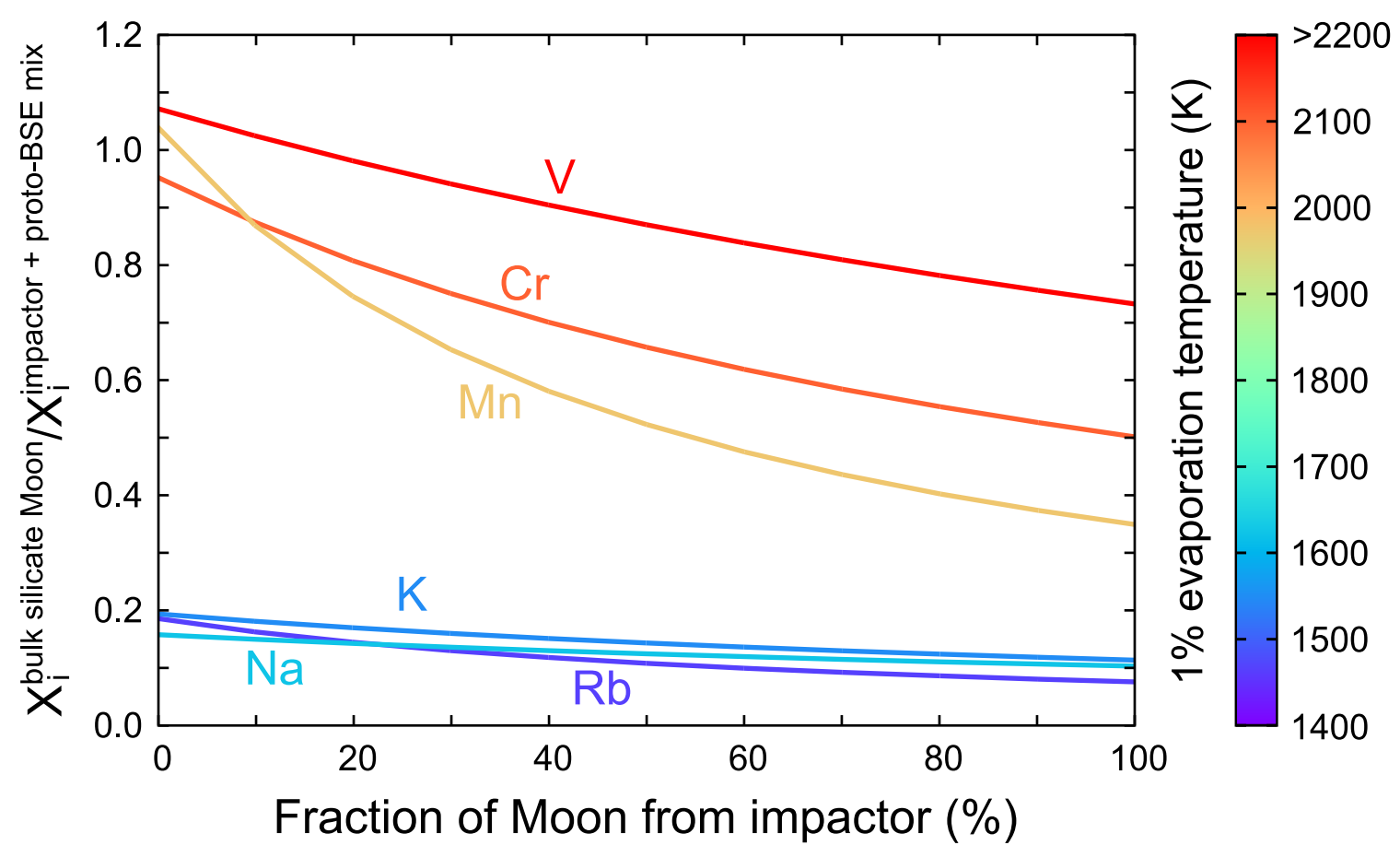

Fig. 14: Abundances of moderately volatile elements $\left(X_{\mathrm{i}}\right)$ in bulk silicate Moon and mixture of the Mars-like Moon-forming impactor's mantle and proto-BSE, plotted against mass fraction of the

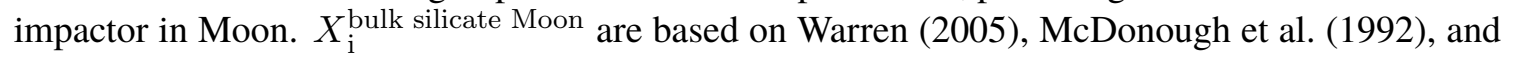
O'Neill (1991a). Colors of curves correspond 1\% evaporation temperatures of elements from a silicate melt at $\log f_{\mathrm{O}_{2}}=-10$ at 1 bar (Sossi et al., 2019). 


\section{References}

Acuña, M.H., Connerney, J.E., Ness, N.F., Lin, R.P., Mitchell, D., Carlson, C.W., McFadden, J., Anderson, K.A., Rème, H., Mazelle, C., Vignes, D., Wasilewski, P., Cloutier, P., 1999. Global distribution of crustal magnetization discovered by the Mars Global Surveyor MAG/ER experiment. Science 284, 790-793. doi:10.1126/science.284.5415.790

Albarede, F., 2009. Volatile accretion history of the terrestrial planets and dynamic implications. Nature 461, 1227-1233. doi:10.1038/nature08477.

Alexander, C.M.O'D., 2005. Re-examining the role of chondrules in producing the elemental fractionations in chondrites. Meteoritics \& Planetary Science Archives 40, 943-965. doi:10.1111/ j.1945-5100.2005.tb00166.x.

Alexander, C.M.O'D., 2019a. Quantitative models for the elemental and isotopic fractionations in chondrites: The carbonaceous chondrites. Geochimica et Cosmochimica Acta 254, 277-309. doi:10.1016/j.gca.2019.02.008

Alexander, C.M.O'D., 2019b. Quantitative models for the elemental and isotopic fractionations in the chondrites: The non-carbonaceous chondrites. Geochimica et Cosmochimica Acta 254, 246-276. doi:10.1016/j.gca.2019.01.026

Alexander, C.M.O'D., Bowden, R., Fogel, M.L., Howard, K.T., Herd, C.D.K., Nittler, L.R., 2012. The provenances of asteroids, and their contributions to the volatile inventories of the terrestrial planets. Science 337, 721-723. doi:10.1126/science.1223474.

Alexander, C.M.O’D., Grossman, J.N., Ebel, D.S., Ciesla, F.J., 2008. The formation conditions of chondrules and chondrites. Science 320,1617-1619. doi:10.1126/science.1156561.

Alexander, C.M.O'D., Grossman, J.N., Wang, J., Zanda, B., Bourot-Denise, M., Hewins, R.H., 2000. The lack of potassium-isotopic fractionation in Bishunpur chondrules. Meteoritics \& Planetary Science 35, 859-868. doi:10.1111/j.1945-5100.2000.tb01469.x

Allègre, C.J., Poirier, J.P., Humler, E., Hofmann, A.W., 1995. The chemical composition of the Earth. Earth and Planetary Science Letters 134, 515-526. doi:10.1016/0012-821X (95) 00123-T.

Amelin, Y., Krot, A., 2007. Pb isotopic age of the Allende chondrules. Meteoritics \& Planetary Science 42, 1321-1335. doi:10.1111/j.1945-5100.2007.tb00577.x.

Amelin, Y., Krot, A.N., Hutcheon, I.D., Ulyanov, A.A., 2002. Lead isotopic ages of chondrules and calcium-aluminum-rich inclusions. Science 297, 1678-1683. doi $10.1126 /$ science. 1073950

Amsellem, E., Moynier, F., Pringle, E.A., Bouvier, A., Chen, H., Day, J.M.D., 2017. Testing the chondrule-rich accretion model for planetary embryos using calcium isotopes. Earth and Planetary Science Letters 469, 75-83. doi:10.1016/j.epsl.2017.04.022 
Anders, E., Owen, T., 1977. Mars and Earth: Origin and abundance of volatiles. Science 198, 453-465. doi:10.1126/science.198.4316.453.

Arkani-Hamed, J., 2004. Timing of the Martian core dynamo. Journal of Geophysical Research: Planets 109, E03006. doi:10.1029/2003JE002195.

Ballhaus, C., Fonseca, R.O.C., Münker, C., Rohrbach, A., Nagel, T., Speelmanns, I.M., Helmy, H.M., Zirner, A., Vogel, A.K., Heuser, A., 2017. The great sulfur depletion of Earth's mantle is not a signature of mantle-core equilibration. Contributions to Mineralogy and Petrology 172, 68. doi:10.1007/s00410-017-1388-3

Ballhaus, C., Laurenz, V., Münker, C., Fonseca, R.O.C., Albarède, F., Rohrbach, A., Lagos, M., Schmidt, M.W., Jochum, K.P., Stoll, B., Weis, U., Helmy, H.M., 2013. The U/Pb ratio of the Earth's mantle-A signature of late volatile addition. Earth and Planetary Science Letters 362, 237-245. doi:10.1016/j.epsl.2012.11.049

Banerdt, W.B., Smrekar, S.E., Banfield, D., Giardini, D., Golombek, M., Johnson, C.L., Lognonné, P., Spiga, A., Spohn, T., Perrin, C., Stähler, S.C., Antonangeli, D., Asmar, S., Beghein, C., Bowles, N., Bozdag, E., Chi, P., Christensen, U., Clinton, J., Collins, G.S., Daubar, I., Dehant, V., Drilleau, M., Fillingim, M., Folkner, W., Garcia, R.F., Garvin, J., Grant, J., Grott, M., Grygorczuk, J., Hudson, T., Irving, J.C.E., Kargl, G., Kawamura, T., Kedar, S., King, S., Knapmeyer-Endrun, B., Knapmeyer, M., Lemmon, M., Lorenz, R., Maki, J.N., Margerin, L., McLennan, S.M., Michaut, C., Mimoun, D., Mittelholz, A., Mocquet, A., Morgan, P., Mueller, N.T., Murdoch, N., Nagihara, S., Newman, C., Nimmo, F., Panning, M., Pike, W.T., Plesa, A.C., Rodriguez, S., Rodriguez-Manfredi, J.A., Russell, C.T., Schmerr, N., Siegler, M., Stanley, S., Stutzmann, E., Teanby, N., Tromp, J., van Driel, M., Warner, N., Weber, R., Wieczorek, M., 2020. Initial results from the InSight mission on Mars. Nature Geoscience 13, 1-7. doi:10.1038/s41561-020-0544-y

Baratoux, D., Toplis, M.J., Monnereau, M., Gasnault, O., 2011. Thermal history of Mars inferred from orbital geochemistry of volcanic provinces. Nature 472, 338-341. doi $10.1038 /$ nature09903.

Baratoux, D., Toplis, M.J., Monnereau, M., Sautter, V., 2013. The petrological expression of early Mars volcanism. Journal of Geophysical Research: Planets 118, 59-64. doi 10.1029/ 2012JE004234.

Becker, H., Horan, M.F., Walker, R.J., Gao, S., Lorand, J.P., Rudnick, R.L., 2006. Highly siderophile element composition of the Earth's primitive upper mantle: constraints from new data on peridotite massifs and xenoliths. Geochimica et Cosmochimica Acta 70, 4528-4550. doi: $10.1016 /$ j.gca.2006.06.004 
Bermingham, K.R., Gussone, N., Mezger, K., Krause, J., 2018. Origins of mass-dependent and mass-independent $\mathrm{Ca}$ isotope variations in meteoritic components and meteorites. Geochimica et Cosmochimica Acta 226, 206-223. doi $10.1016 /$ j.gca.2018.01.034

Bertka, C.M., Fei, Y., 1997. Mineralogy of the Martian interior up to core-mantle boundary pressures. Journal of Geophysical Research: Solid Earth 102, 5251-5264. doi:10.1029/96JB03270

Bizzarro, M., Baker, J.A., Haack, H., 2004. Mg isotope evidence for contemporaneous formation of chondrules and refractory inclusions. Nature 431, 275-278. doi:10.1038/nature02882.

Blanchard, I., Siebert, J., Borensztajn, S., Badro, J., 2017. The solubility of heat-producing elements in Earth's core. Geochemical Perspectives Letters 5, 1-5. doi:10.7185/geochemlet.1737.

Bland, P.A., Alard, O., Benedix, G.K., Kearsley, A.T., Menzies, O.N., Watt, L.E., Rogers, N.W., 2005. Volatile fractionation in the early solar system and chondrule/matrix complementarity. Proceedings of the National Academy of Sciences of the United States of America 102, 1375513760. doi:10.1073/pnas.0501885102.

van Boekel, R.J.H.M., Min, M., Leinert, C., Waters, L.B.F.M., Richichi, A., Chesneau, O., Dominik, C., Jaffe, W., Dutrey, A., Graser, U., , Henning, T., de Jong, J., Köhler, R., de Koter, A., Lopez, B., Malbet, F., Morel, S., Paresce, F., Perrin, G., Preibisch, T., Przygodda, F., Schöller, M., Wittkowski, M., 2004. The building blocks of planets within the 'terrestrial' region of protoplanetary disks. Nature 432, 479-482. doi:10.1038/nature03088

Bollard, J., Connelly, J.N., Whitehouse, M.J., Pringle, E.A., Bonal, L., Jørgensen, J.K., Nordlund, Å., Moynier, F., Bizzarro, M., 2017. Early formation of planetary building blocks inferred from $\mathrm{Pb}$ isotopic ages of chondrules. Science Advances 3, e1700407. doi:10.1126/sciadv 1700407

Bollard, J., Kawasaki, N., Sakamoto, N., Olsen, M., Itoh, S., Larsen, K., Wielandt, D., Schiller, M., Connelly, J.N., Yurimoto, H., Bizzarroa, M., 2019. Combined U-corrected $\mathrm{Pb}-\mathrm{Pb}$ dating and ${ }^{26} \mathrm{Al}-{ }^{26} \mathrm{Mg}$ systematics of individual chondrules-Evidence for a reduced initial abundance of ${ }^{26} \mathrm{Al}$ amongst inner Solar System chondrules. Geochimica et Cosmochimica Acta 260, 62-83. doi:10.1016/j.gca.2019.06.025

Bouvier, A., Vervoort, J.D., Patchett, P.J., 2008. The Lu-Hf and Sm-Nd isotopic composition of CHUR: Constraints from unequilibrated chondrites and implications for the bulk composition of terrestrial planets. Earth and Planetary Science Letters 273, 48-57. doi:10.1016/j.epsl. 2008.06 .010 .

Bouvier, A., Wadhwa, M., Simon, S.B., Grossman, L., 2013. Magnesium isotopic fractionation in chondrules from the Murchison and Murray CM2 carbonaceous chondrites. Meteoritics \& Planetary Science 48, 339-353. doi:10.1111/maps. 12059 
Bouvier, L.C., Costa, M.M., Connelly, J.N., Jensen, N.K., Wielandt, D., Storey, M., Nemchin, A.A., Whitehouse, M.J., Snape, J.F., Bellucci, J.J., Moynier, F., Agranier, A., Gueguen, B., Schönbächler, M., Bizzarro, M., 2018. Evidence for extremely rapid magma ocean crystallization and crust formation on Mars. Nature 558, 586-589. doi:10.1038/s41586-018-0222-z

Bouwman, J., Henning, T., Hillenbrand, L.A., Meyer, M.R., Pascucci, I., Carpenter, J., Hines, D., Kim, J.S., Silverstone, M.D., Hollenbach, D., Wolf, S., 2008. The formation and evolution of planetary systems: Grain growth and chemical processing of dust in T Tauri systems. The Astrophysical Journal 683, 479-498. doi:10.1086/587793.

Bouwman, J., Lawson, W.A., Juhász, A., Dominik, C., Feigelson, E.D., Henning, T., Tielens, A.G.G.M., Waters, L.B.F.M., 2010. The protoplanetary disk around the M4 star RECX 5: witnessing the influence of planet formation? The Astrophysical Journal Letters 723, L243-L247. doi:10.1088/2041-8205/723/2/L243.

Brandon, A.D., Puchtel, I.S., Walker, R.J., Day, J.M.D., Irving, A.J., Taylor, L.A., 2012. Evolution of the martian mantle inferred from the ${ }^{187} \mathrm{Re}-{ }^{187} \mathrm{Os}$ isotope and highly siderophile element abundance systematics of shergottite meteorites. Geochimica et Cosmochimica Acta 76, 206 235. doi: $10.1016 / \mathrm{j} \cdot$ gca.2011.09.047.

Breuer, D., Moore, W.B., 2015. Dynamics and Thermal History of the Terrestrial Planets, the Moon, and Io, in: Schubert, G. (Ed.), Treatise on Geophysics (Second Edition). Elsevier, Oxford, pp. 255-305. doi:10.1016/B978-0-444-53802-4.00173-1.

Breuer, D., Spohn, T., 2003. Early plate tectonics versus single-plate tectonics on Mars: Evidence from magnetic field history and crust evolution. Journal of Geophysical Research: Planets 108, 5072. doi:10.1029/2002JE001999

Budde, G., Burkhardt, C., Kleine, T., 2019. Molybdenum isotopic evidence for the late accretion of outer Solar System material to Earth. Nature Astronomy 3, 736-741. doi $10.1038 /$ s41550-019-0779-y.

Budde, G., Kleine, T., Kruijer, T.S., Burkhardt, C., Metzler, K., 2016. Tungsten isotopic constraints on the age and origin of chondrules. Proceedings of the National Academy of Sciences 113, 2886-2891. doi:10.1073/pnas.1524980113.

Budde, G., Kruijer, T.S., Kleine, T., 2018. Hf-W chronology of CR chondrites: Implications for the timescales of chondrule formation and the distribution of ${ }^{26} \mathrm{Al}$ in the solar nebula. Geochimica et Cosmochimica Acta 222, 284-304. doi $10.1016 /$ j.gca.2017.10.014

Burkhardt, C., Borg, L.E., Brennecka, G.A., Shollenberger, Q.R., Dauphas, N., Kleine, T., 2016. A nucleosynthetic origin for the Earth's anomalous ${ }^{142} \mathrm{Nd}$ composition. Nature 537, 394-398. doi:10.1038/nature18956. 
Burkhardt, C., Kleine, T., Oberli, F., Pack, A., Bourdon, B., Wieler, R., 2011. Molybdenum isotope anomalies in meteorites: Constraints on solar nebula evolution and origin of the Earth. Earth and Planetary Science Letters 312, 390-400. doi:10.1016/j.epsl.2011.10.010

Cano, E.J., Sharp, Z.D., Shearer, C.K., 2020. Distinct oxygen isotope compositions of the Earth and Moon. Nature Geoscience 13, 270-274. doi:10.1038/s41561-020-0550-0.

Canup, R., Salmon, J., 2018. Origin of Phobos and Deimos by the impact of a Vesta-to-Ceres sized body with Mars. Science Advances 4, eaar6887. doi:10.1126/sciadv. aar6887.

Canup, R.M., 2004. Simulations of a late lunar-forming impact. Icarus 168, 433-456. doi:10. 1016/j.icarus.2003.09.028

Canup, R.M., 2008. Accretion of the Earth. Philosophical Transactions of the Royal Society A: Mathematical, Physical and Engineering Sciences 366, 4061-4075. doi:10.1098/rsta. 2008. 0101

Canup, R.M., Asphaug, E., 2001. Origin of the Moon in a giant impact near the end of the Earth's formation. Nature 412, 708-712. doi:10.1038/35089010.

Caro, G., Bourdon, B., 2010. Non-chondritic Sm/Nd ratio in the terrestrial planets: Consequences for the geochemical evolution of the mantle-crust system. Geochimica et Cosmochimica Acta 74, 3333-3349. doi:10.1016/j.gca.2010.02.025.

Chabot, N.L., 2018. Composition of metallic cores in the early Solar System, in: Lunar and Planetary Science Conference, p. 1532.

Chambat, F., Ricard, Y., Valette, B., 2010. Flattening of the Earth: further from hydrostaticity than previously estimated. Geophysical Journal International 183, 727-732. doi: $10.1111 / \mathrm{j}$. 1365-246X.2010.04771.x.

Cockell, C., Bush, T., Bryce, C., Direito, S., Fox-Powell, M., Harrison, J., Lammer, H., Landenmark, H., Martin-Torres, J., Nicholson, N., Noack, L., O’Malley-James, J., Payler, S., Rushby, A., Samuels, T., Schwendner, P., Wadsworth, J., Zorzano, M., 2016. Habitability: a review. Astrobiology 16, 89-117. doi:10.1089/ast.2015.1295

Connelly, J.N., Amelin, Y., Krot, A.N., Bizzarro, M., 2008. Chronology of the solar system's oldest solids. The Astrophysical Journal Letters 675, L121-L124. doi:10.1086/533586

Connelly, J.N., Bizzarro, M., 2009. Pb-Pb dating of chondrules from CV chondrites by progressive dissolution. Chemical Geology 259, 143-151. doi:10.1016/j.chemgeo.2008.11.003.

Connelly, J.N., Bizzarro, M., Krot, A.N., Nordlund, A., Wielandt, D., Ivanova, M.A., 2012. The absolute chronology and thermal processing of solids in the solar protoplanetary disk. Science 338, 651-655. doi:10.1126/science.1226919. 
Connelly, J.N., Schiller, M., Bizzarro, M., 2019. Pb isotope evidence for rapid accretion and differentiation of planetary embryos. Earth and Planetary Science Letters 525, 115722. doi:10.1016/ j.epsl.2019.115722

Corgne, A., Keshav, S., Fei, Y., McDonough, W.F., 2007. How much potassium is in the Earth's core? New insights from partitioning experiments. Earth and Planetary Science Letters 256, 567-576. doi:10.1016/j.epsl.2007.02.012

Creech, J.B., Moynier, F., 2019. Tin and zinc stable isotope characterisation of chondrites and implications for early Solar System evolution. Chemical Geology 511, 81-90. doi:10.1016/j. chemgeo.2019.02.028

Dauphas, N., 2017. The isotopic nature of the Earth's accreting material through time. Nature 541, 521-524. doi:10.1038/nature20830.

Dauphas, N., Burkhardt, C., Warren, P.H., Fang-Zhen, T., 2014. Geochemical arguments for an Earth-like Moon-forming impactor. Philosophical Transactions of the Royal Society A: Mathematical, Physical and Engineering Sciences 372, 20130244. doi:10.1098/rsta.2013.0244.

Dauphas, N., Poitrasson, F., Burkhardt, C., Kobayashi, H., Kurosawa, K., 2015. Planetary and meteoritic $\mathrm{Mg} / \mathrm{Si}$ and $\delta^{30} \mathrm{Si}$ variations inherited from solar nebula chemistry. Earth and Planetary Science Letters 427, 236-248. doi:10.1016/j.epsl.2015.07.008.

Dauphas, N., Pourmand, A., 2011. Hf-W-Th evidence for rapid growth of Mars and its status as a planetary embryo. Nature 473, 489-492. doi:10.1038/nature10077.

Dauphas, N., Pourmand, A., 2015. Thulium anomalies and rare earth element patterns in meteorites and Earth: Nebular fractionation and the nugget effect. Geochimica et Cosmochimica Acta 163, 234-261. doi:10.1016/j.gca.2015.03.037

Day, J.M.D., Brandon, A.D., Walker, R.J., 2016. Highly siderophile elements in Earth, Mars, the Moon, and asteroids. Reviews in Mineralogy and Geochemistry 81, 161-238. doi:10.2138/ rmg.2016.81.04.

Desch, S.J., Kalyaan, A., Alexander, C.M.O'D., 2018. The effect of Jupiter's formation on the distribution of refractory elements and inclusions in meteorites. The Astrophysical Journal Supplement Series 238, 11. doi:10.3847/1538-4365/aad95f

Doyle, P.M., Jogo, K., Nagashima, K., Krot, A.N., Wakita, S., Ciesla, F.J., Hutcheon, I.D., 2015. Early aqueous activity on the ordinary and carbonaceous chondrite parent bodies recorded by fayalite. Nature Communications 6, 7444. doi:10.1038/ncomms8444.

Dreibus, G., Wänke, H., 1979. On the chemical composition of the Moon and the Eucrite parent body and a comparison with the composition of the Earth, the case of Mn, Cr, and V, in: Lunar and Planetary Science Conference, pp. 315-317. 
Dreibus, G., Wänke, H., 1987. Volatiles on Earth and Mars: A comparison. Icarus 71, 225-240. doi: $10.1016 / 0019-1035(87) 90148-5$.

Dumoulin, C., Tobie, G., Verhoeven, O., Rosenblatt, P., Rambaux, N., 2017. Tidal constraints on the interior of Venus. Journal of Geophysical Research: Planets 122, 1338-1352. doi:10.1002/ 2016JE005249.

Dziewonski, A.M., Anderson, D.L., 1981. Preliminary reference Earth model. Physics of the Earth and Planetary Interiors 25, 297-356. doi:10.1016/0031-9201(81)90046-7.

Ehlmann, B.L., Anderson, F.S., Andrews-Hanna, J., Catling, D.C., Christensen, P.R., Cohen, B.A., Dressing, C.D., Edwards, C.S., Elkins-Tanton, L.T., Farley, K.A., Fassett, C.I., Fischer, W.W., Fraeman, A.A., Golombek, M.P., Hamilton, V.E., Hayes, A.G., Herd, C.D., Horgan, B., Hu, R., Jakosky, B.M., Johnson, J.R., Kasting, J.F., Kerber, L., Kinch, K.M., Kite, E.S., Knutson, H.A., Lunine, J.I., Mahaffy, P.R., Mangold, N., McCubbin, F.M., Mustard, J.F., Niles, P.B., QuantinNataf, C., Rice, M.S., Stack, K.M., Stevenson, D.J., Stewart, S.T., Toplis, M.J., Usui, T., Weiss, B.P., Werner, S.C., Wordsworth, R.D., Wray, J.J., Yingst, R.A., Yung, Y.L., Zahnle, K.J., 2016. The sustainability of habitability on terrestrial planets: Insights, questions, and needed measurements from Mars for understanding the evolution of Earth-like worlds. Journal of Geophysical Research: Planets 121, 1927-1961. doi:10.1002/2016JE005134.

Filiberto, J., 2017. Geochemistry of Martian basalts with constraints on magma genesis. Chemical Geology 466, 1-14. doi $10.1016 / \mathrm{j}$. chemgeo.2017.06.009

Filiberto, J., Dasgupta, R., 2011. Fe ${ }^{2+}-\mathrm{Mg}$ partitioning between olivine and basaltic melts: Applications to genesis of olivine-phyric shergottites and conditions of melting in the Martian interior. Earth and Planetary Science Letters 304, 527-537. doi:10.1016/j .eps1.2011.02.029

Frost, D.J., 2003. The structure and sharpness of $(\mathrm{Mg}, \mathrm{Fe})_{2} \mathrm{SiO}_{4}$ phase transformations in the transition zone. Earth and Planetary Science Letters 216, 313-328. doi:10.1016/S0012-821X (03) 00533-8.

Fujiya, W., Sugiura, N., Hotta, H., Ichimura, K., Sano, Y., 2012. Evidence for the late formation of hydrous asteroids from young meteoritic carbonates. Nature Communications 3, 1-6. doi:10. $1038 /$ ncomms 1635 .

Gaetani, G.A., Grove, T.L., 1999. Wetting of mantle olivine by sulfide melt: implications for Re/Os ratios in mantle peridotite and late-stage core formation. Earth and Planetary Science Letters 169, 147-163. doi:10.1016/S0012-821X(99)00062-X.

Galy, A., Young, E.D., Ash, R.D., O’Nions, R.K., 2000. The formation of chondrules at high gas pressures in the solar nebula. Science 290, 1751-1753. doi:10.1126/science.290.5497. 1751. 
Gast, P.W., 1960. Limitations on the composition of the upper mantle. Journal of Geophysical Research 65, 1287-1297. doi:10.1029/JZ065i004p01287.

Gellissen, M., Holzheid, A., Kegler, P., Palme, H., 2019. Heating experiments relevant to the depletion of $\mathrm{Na}, \mathrm{K}$ and $\mathrm{Mn}$ in the Earth and other planetary bodies. Geochemistry 79, 125540. doi: $10.1016 / j$.chemer.2019.125540.

Genova, A., Goossens, S., Lemoine, F.G., Mazarico, E., Neumann, G.A., Smith, D.E., Zuber, M.T., 2016. Seasonal and static gravity field of Mars from MGS, Mars Odyssey and MRO radio science. Icarus 272, 228-245. doi $10.1016 / \mathrm{j}$. icarus.2016.02.050

Goldstein, J.I., Scott, E.R.D., Chabot, N.L., 2009. Iron meteorites: Crystallization, thermal history, parent bodies, and origin. Geochemistry 69, 293-325. doi:10.1016/j.chemer.2009.01.002.

Goodrich, C.A., Herd, C.D.K., Taylor, L.A., 2003. Spinels and oxygen fugacity in olivine-phyric and lherzolitic shergottites. Meteoritics \& Planetary Science 38, 1773-1792. doi:10.1111/j . 1945-5100.2003.tb00014.x.

Greenwood, R.C., Barrat, J.A., Miller, M.F., Anand, M., Dauphas, N., Franchi, I.A., Sillard, P., Starkey, N.A., 2018. Oxygen isotopic evidence for accretion of Earth's water before a high-energy Moon-forming giant impact. Science Advances 4, eaao5928. doi:10.1126/sciadv . aao5928.

Grossman, L., Ebel, D.S., Simon, S.B., Davis, A.M., Richter, F.M., Parsad, N.M., 2000. Major element chemical and isotopic compositions of refractory inclusions in C3 chondrites: The separate roles of condensation and evaporation. Geochimica et Cosmochimica Acta 64, 2879-2894. doi:10.1016/S0016-7037(00)00396-3.

Grossman, L., Simon, S.B., Rai, V.K., Thiemens, M.H., Hutcheon, I.D., Williams, R.W., Galy, A., Ding, T., Fedkin, A.V., Clayton, R.N., Mayeda, T.K., 2008. Primordial compositions of refractory inclusions. Geochimica et Cosmochimica Acta 72, 3001-3021. doi $10.1016 /$ j.gca. 2008.04 002 .

Halliday, A.N., Porcelli, D., 2001. In search of lost planets-The paleocosmochemistry of the inner solar system. Earth and Planetary Science Letters 192, 545-559. doi:10.1016/ S0012-821X(01) 00479-4.

Hans, U., Kleine, T., Bourdon, B., 2013. Rb-Sr chronology of volatile depletion in differentiated protoplanets: BABI, ADOR and ALL revisited. Earth and Planetary Science Letters 374, 204 214. doi:10.1016/j.epsl.2013.05.029.

Harrison, J.H., Shorttle, O., Bonsor, A., 2021. Evidence for post-nebula volatilisation in an exoplanetary body. Earth and Planetary Science Letters 554, 116694. doi:10.1016/j . epsl . 2020 . 116694 
Harrison, J.H.D., Bonsor, A., Madhusudhan, N., 2018. Polluted white dwarfs: constraints on the origin and geology of exoplanetary material. Monthly Notices of the Royal Astronomical Society 479, 3814-3841. doi $10.1093 / \mathrm{mnras} / \mathrm{sty} 1700$

Hart, S.R., Zindler, A., 1986. In search of a bulk-Earth composition. Chemical Geology 57, 247 267. doi:10.1016/0009-2541(86)90053-7.

Herd, C.D.K., 2019. Reconciling redox: making spatial and temporal sense of oxygen fugacity variations in martian igneous rocks, in: Lunar and Planetary Science Conference, p. 2746.

Herd, C.D.K., Borg, L.E., Jones, J.H., Papike, J.J., 2002. Oxygen fugacity and geochemical variations in the martian basalts: Implications for martian basalt petrogenesis and the oxidation state of the upper mantle of Mars. Geochimica et Cosmochimica Acta 66, 2025-2036. doi:10.1016/S0016-7037(02)00828-1.

Herd, C.D.K., Papike, J.J., Brearley, A.J., 2001. Oxygen fugacity of martian basalts from electron microprobe oxygen and TEM-EELS analyses of Fe-Ti oxides. American Mineralogist 86, 10151024. doi:10.2138/am-2001-8-908

Hewins, R.H., Herzberg, C.T., 1996. Nebular turbulence, chondrule formation, and the composition of the Earth. Earth and Planetary Science Letters 144, 1-7. doi:10.1016/0012-821X(96) 00159-8.

Hewins, R.H., Zanda, B., 2012. Chondrules: Precursors and interactions with the nebular gas. Meteoritics \& Planetary Science 47, 1120-1138. doi:10.1111/j.1945-5100.2012.01376.x

Hezel, D.C., Bland, P., Palme, H., Jacquet, E., Bigolski, J., 2018a. Composition of chondrules and matrix and their complementary relationship in chondrites, in: Russell, S.S., Connolly, Jr., H.C., Krot, A.N. (Eds.), Chondrules and the Protoplanetary Disk. Cambridge University Press, Cambridge. chapter 4, pp. 91-121. doi:10.1017/9781108284073.004

Hezel, D.C., Harak, M., Libourel, G., 2018b. What we know about elemental bulk chondrule and matrix compositions: Presenting the ChondriteDB Database. Chemie der Erde-Geochemistry 78, 1-14. doi:10.1016/j.chemer.2017.05.003.

Hin, R.C., Coath, C.D., Carter, P.J., Nimmo, F., Lai, Y.J., von Strandmann, P.A.E.P., Willbold, M., Leinhardt, Z.M., Walter, M.J., Elliott, T., 2017. Magnesium isotope evidence that accretional vapour loss shapes planetary compositions. Nature 549, 511-515. doi:10.1038/nature23899

Hosono, N., Karato, S.i., Makino, J., Saitoh, T.R., 2019. Terrestrial magma ocean origin of the Moon. Nature Geoscience 12, 418-423. doi:10.1038/s41561-019-0354-2.

Huang, S., Farkaš, J., Jacobsen, S.B., 2010. Calcium isotopic fractionation between clinopyroxene and orthopyroxene from mantle peridotites. Earth and Planetary Science Letters 292, 337-344. doi:10.1016/j.epsl.2010.01.042. 
Humayun, M., Clayton, R.N., 1995. Potassium isotope cosmochemistry: Genetic implications of volatile element depletion. Geochimica et Cosmochimica Acta 59, 2131-2148. doi 10.1016/ 0016-7037(95)00132-8

Humayun, M., Nemchin, A., Zanda, B., Hewins, R.H., Grange, M., Kennedy, A., Lorand, J.P., Göpel, C., Fieni, C., Pont, S., Deldicque, D., 2013. Origin and age of the earliest Martian crust from meteorite NWA 7533. Nature 503, 513-516. doi:10.1038/nature12764.

Jackson, A.P., Gabriel, T.S.J., Asphaug, E.I., 2018. Constraints on the pre-impact orbits of Solar system giant impactors. Monthly Notices of the Royal Astronomical Society 474, 2924-2936. doi:10.1093/mnras/stx2901.

Jagoutz, E., Palme, H., Baddenhausen, H., Blum, K., Cendales, M., Dreibus, G., Spettel, B., Lorenz, V., Wänke, H., 1979. The abundances of major, minor and trace elements in the earth's mantle as derived from primitive ultramafic nodules, in: Lunar and Planetary Science Conference Proceedings, pp. 2031-2050.

Jaupart, C., Labrosse, S., Lucazeau, F., Mareschal, J.C., 2015. Temperatures, heat, and energy in the mantle of the earth, in: Schubert, G. (Ed.), Treatise on Geophysics (Second Edition). Elsevier, Oxford. volume 7, pp. 223-270. doi:10.1016/B978-0-444-53802-4.00126-3.

Javoy, M., 1995. The integral enstatite chondrite model of the Earth. Geophysical Research Letters 22, 2219-2222. doi:10.1029/95GL02015

Javoy, M., Kaminski, E., Guyot, F., Andrault, D., Sanloup, C., Moreira, M., Labrosse, S., Jambon, A., Agrinier, P., Davaille, A., Jaupart, C., 2010. The chemical composition of the Earth: Enstatite chondrite models. Earth and Planetary Science Letters 293, 259-268. doi $10.1016 / \mathrm{j}$.epsl. 2010.02 .033

Johansen, A., Jacquet, E., Cuzzi, J.N., Morbidelli, A., Gounelle, M., 2015a. New paradigms for asteroid formation, in: Michel, P., DeMeo, F., Bottke, W., Dotson, R. (Eds.), Asteroids IV. University of Arizona Press, Tucson. volume 47, pp. 471-492. doi:10.2458/azu_uapress_ 9780816532131-ch025.

Johansen, A., Mac Low, M.M., Lacerda, P., Bizzarro, M., 2015b. Growth of asteroids, planetary embryos, and Kuiper belt objects by chondrule accretion. Science Advances 1, e1500109. doi:10 . 1126/sciadv. 1500109

Johnson, B.C., Minton, D.A., Melosh, H.J., Zuber, M.T., 2015. Impact jetting as the origin of chondrules. Nature 517, 339-341. doi:10.1038/nature14105

Jones, R.H., 1994. Relict grains in chondrules: Evidence for chondrule recycling, in: Hewins, R.H., Jones, R.H., Scott, E.R.D. (Eds.), Chondrules and the Protoplanetary Disk, pp. 163-172. 
Kato, C., Moynier, F., 2017. Gallium isotopic evidence for extensive volatile loss from the Moon during its formation. Science Advances 3, e1700571. doi:10.1126/sciadv.1700571

Katsura, T., Yoneda, A., Yamazaki, D., Yoshino, T., Ito, E., 2010. Adiabatic temperature profile in the mantle. Physics of the Earth and Planetary Interiors 183, 212-218. doi:10.1016/j . pepi. 2010.07 .001 .

Kerridge, J., 1979. Fractionation of refractory lithophile elements among chondritic meteorites, in: Lunar and Planetary Science Conference Proceedings, pp. 989-996.

Kessler-Silacci, J., Augereau, J., Dullemond, C.P., Geers, V., Lahuis, F., Evans II, N.J., van Dishoeck, E.F., Blake, G.A., Boogert, A.C.A., Brown, J., Jorgensen, J.K., Knez, C., Pontoppidan, K.M., 2006. C2D Spitzer IRS spectra of disks around T Tauri stars. I. Silicate emission and grain growth. The Astrophysical Journal 639, 275. doi:10.1086/499330

Khan, A., Liebske, C., Rozel, A., Rivoldini, A., Nimmo, F., Connolly, J.A.D., Plesa, A.C., Giardini, D., 2018. A geophysical perspective on the bulk composition of Mars. Journal of Geophysical Research: Planets 123, 575-611. doi:10.1002/2017JE005371

Kiefer, W.S., 2003. Melting in the Martian mantle: Shergottite formation and implications for present-day mantle convection on Mars. Meteoritics \& Planetary Science 38, 1815-1832. doi: $10.1111 / j .1945-5100.2003 . t b 00017 . x$

Kimura, K., Lewis, R.S., Anders, E., 1974. Distribution of gold and rhenium between nickel-iron and silicate melts: implications for the abundance of siderophile elements on the Earth and Moon. Geochimica et Cosmochimica Acta 38, 683-701. doi 10.1016/0016-7037(74)90144-6.

Kita, N.T., Yin, Q.Z., MacPherson, G.J., Ushikubo, T., Jacobsen, B., Nagashima, K., Kurahashi, E., Krot, A.N., Jacobsen, S.B., 2013. ${ }^{26} \mathrm{Al}-{ }^{26} \mathrm{Mg}$ isotope systematics of the first solids in the early solar system. Meteoritics \& Planetary Science 48, 1383-1400. doi:10.1111/maps.12141.

Kleine, T., Touboul, M., Bourdon, B., Nimmo, F., Mezger, K., Palme, H., Jacobsen, S.B., Yin, Q.Z., Halliday, A.N., 2009. Hf-W chronology of the accretion and early evolution of asteroids and terrestrial planets. Geochimica et Cosmochimica Acta 73, 5150-5188. doi $10.1016 / \mathrm{j}$. gca.2008.11.047.

Konopliv, A.S., Park, R.S., Folkner, W.M., 2016. An improved JPL Mars gravity field and orientation from Mars orbiter and lander tracking data. Icarus 274, 253-260. doi:10.1016/j. icarus . 2016.02 .052

Krot, A.N., Wasson, J.T., 1995. Igneous rims on low-FeO and high-FeO chondrules in ordinary chondrites. Geochimica et Cosmochimica Acta 59, 4951-4966. doi:10.1016/0016-7037(95) $00337-1$. 
Kruijer, T.S., Burkhardt, C., Budde, G., Kleine, T., 2017a. Age of Jupiter inferred from the distinct genetics and formation times of meteorites. Proceedings of the National Academy of Sciences 114, 6712-6716. doi:10.1073/pnas.1704461114.

Kruijer, T.S., Kleine, T., Borg, L.E., 2020. The great isotopic dichotomy of the early Solar System. Nature Astronomy 4, 32-40. doi:10.1038/s41550-019-0959-9.

Kruijer, T.S., Kleine, T., Borg, L.E., Brennecka, G.A., Irving, A.J., Bischoff, A., Agee, C.B., 2017 b. The early differentiation of Mars inferred from Hf-W chronometry. Earth and Planetary Science Letters 474, 345-354. doi: $10.1016 / j$.epsl.2017.06.047.

Larimer, J.W., 1967. Chemical fractionations in meteorites-I. Condensation of the elements. Geochimica et Cosmochimica Acta 31, 1215-1238. doi:10.1016/S0016-7037(67)80013-9.

Larimer, J.W., 1979. The condensation and fractionation of refractory lithophile elements. Icarus 40, 446-454. doi:10.1016/0019-1035(79)90038-1.

Larimer, J.W., Anders, E., 1967. Chemical fractionations in meteorites-II. Abundance patterns and their interpretation. Geochimica et Cosmochimica Acta 31, 1239-1270. doi:10.1016/ S0016-7037(67)80014-0.

Laurenz, V., Rubie, D.C., Frost, D.J., Vogel, A.K., 2016. The importance of sulfur for the behavior of highly-siderophile elements during Earth's differentiation. Geochimica et Cosmochimica Acta 194, 123-138. doi:10.1016/j.gca.2016.08.012.

Levison, H.F., Kretke, K.A., Walsh, K.J., Bottke, W.F., 2015. Growing the terrestrial planets from the gradual accumulation of submeter-sized objects. Proceedings of the National Academy of Sciences 112, 14180-14185. doi 10.1073/pnas.1513364112.

Li, Y., Dasgupta, R., Tsuno, K., Monteleone, B., Shimizu, N., 2016. Carbon and sulfur budget of the silicate Earth explained by accretion of differentiated planetary embryos. Nature Geoscience 9, 781-785. doi:10.1038/ngeo2801.

Lillis, R.J., Frey, H.V., Manga, M., 2008. Rapid decrease in Martian crustal magnetization in the Noachian era: Implications for the dynamo and climate of early Mars. Geophysical Research Letters 35, L14203. doi:10.1029/2008GL034338.

Lock, S.J., Stewart, S.T., Petaev, M.I., Leinhardt, Z., Mace, M.T., Jacobsen, S.B., Cuk, M., 2018. The origin of the Moon within a terrestrial synestia. Journal of Geophysical Research: Planets 123, 910-951. doi:10.1002/2017JE005333.

Lodders, K., 2003. Solar system abundances and condensation temperatures of the elements. The Astrophysical Journal 591, 1220-1247. doi $10.1086 / 375492$ 
Lodders, K., 2020. Solar Elemental Abundances, in: Read, P. (Ed.), Oxford Research Encyclopedia of Planetary Science. Oxford University Press, Oxford, pp. 1-68. doi:10.1093/acrefore/ 9780190647926.013 .145

Longhi, J., Knittle, E., Holloway, J.R., Wänke, H., 1992. The bulk composition, mineralogy and internal structure of Mars, in: Kieffer, H.H., Jakosky, B.M., Snyder, C.W., Matthews, M.S. (Eds.), Mars. University of Arizona Press, Tuscon, pp. 184-208.

Lorand, J.P., Conquéré, F., 1983. Contribution à l'étude des sulfures dans les enclaves de lherzolite à spinelle des basaltes alcalins (Massif Central et Languedoc, France). Bulletin de Minéralogie 106, 585-606. doi:10.3406/bulmi.1983.7737.

Magna, T., Gussone, N., Mezger, K., 2015. The calcium isotope systematics of Mars. Earth and Planetary Science Letters 430, 86-94. doi:10.1016/j.epsl.2015.08.016.

Mahan, B., Moynier, F., Siebert, J., Gueguen, B., Agranier, A., Pringle, E.A., Bollard, J., Connelly, J.N., Bizzarro, M., 2018. Volatile element evolution of chondrules through time. Proceedings of the National Academy of Sciences 115, 8547-8552. doi:10.1073/pnas. 1807263115

Maltese, A., Mezger, K., 2020. The Pb isotope evolution of Bulk Silicate Earth: Constraints from its accretion and early differentiation history. Geochimica et Cosmochimica Acta 271, 179-193. doi: $10.1016 /$ j.gca.2019.12.021

Marchi, S., Walker, R.J., Canup, R.M., 2020. A compositionally heterogeneous martian mantle due to late accretion. Science Advances 6, eaay2338. doi:10.1126/sciadv . aay2338.

Marinova, M.M., Aharonson, O., Asphaug, E., 2008. Mega-impact formation of the Mars hemispheric dichotomy. Nature 453, 1216-1219. doi:10.1038/nature07070

Marty, B., 2012. The origins and concentrations of water, carbon, nitrogen and noble gases on Earth. Earth and Planetary Science Letters 313, 56-66. doi:10.1016/j.epsl.2011.10.040

McCanta, M.C., Elkins-Tanton, L., Rutherford, M.J., 2009. Expanding the application of the Euoxybarometer to the lherzolitic shergottites and nakhlites: Implications for the oxidation state heterogeneity of the Martian interior. Meteoritics \& Planetary Science 44, 725-745. doi: 10. 1111/j.1945-5100.2009.tb00765.x

McDonough, W.F., 2014. Compositional model for the Earth's core, in: Holland, H.D., Turekian, K.K. (Eds.), Treatise on Geochemistry (Second Edition). Elsevier, Oxford. volume 3, pp. 559577. doi:10.1016/B978-0-08-095975-7.00215-1

McDonough, W.F., 2016. The composition of the lower mantle and core, in: Terasaki, H., Fischer, R.A. (Eds.), Deep Earth. American Geophysical Union (AGU). chapter 12, pp. 145-159. doi:10. 1002/9781118992487.ch12. 
McDonough, W.F., Sun, S.s., 1995. The composition of the Earth. Chemical Geology 120, 223253. doi:10.1016/0009-2541(94)00140-4.

McDonough, W.F., Sun, S.s., Ringwood, A.E., Jagoutz, E., Hofmann, A.W., 1992. Potassium, rubidium, and cesium in the Earth and Moon and the evolution of the mantle of the Earth. Geochimica et Cosmochimica Acta 56, 1001-1012. doi:10.1016/0016-7037(92)90043-I

McDonough, W.F., Šrámek, O., Wipperfurth, S.A., 2020. Radiogenic power and geoneutrino luminosity of the Earth and other terrestrial bodies through time. Geochemistry, Geophysics, Geosystems 21, e2019GC008865. doi:10.1029/2019GC008865

McGovern, P.J., Solomon, S.C., Smith, D.E., Zuber, M.T., Simons, M., Wieczorek, M.A., Phillips, R.J., Neumann, G.A., Aharonson, O., Head, J.W., 2002. Localized gravity/topography admittance and correlation spectra on Mars: Implications for regional and global evolution. Journal of Geophysical Research: Planets 107, 19-1-19-25. doi:10.1029/2002JE001854.

McKenzie, D., Barnett, D.N., Yuan, D.N., 2002. The relationship between Martian gravity and topography. Earth and Planetary Science Letters 195, 1-16. doi:10.1016/S0012-821X(01) $00555-6$.

McSween, Jr., H.Y., 1977a. Carbonaceous chondrites of the Ornans type: A metamorphic sequence. Geochimica et Cosmochimica Acta 41, 477-491. doi 10.1016/0016-7037(77)90286-1.

McSween, Jr., H.Y., 1977b. Petrographic variations among carbonaceous chondrites of the Vigarano type. Geochimica et Cosmochimica Acta 41, 1777-1790. doi:10.1016/0016-7037(77) 90210-1.

McSween, Jr., H.Y., 1979. Alteration in CM carbonaceous chondrites inferred from modal and chemical variations in matrix. Geochimica et Cosmochimica Acta 43, 1761-1770. doi:10. 1016/0016-7037(79)90024-3.

MetBase, 1994-2017. Meteorite Information Database. URL: http://www.metbase.org geoPlatform UG, Germany. Accessed: 2019-11-3.

Morbidelli, A., Libourel, G., Palme, H., Jacobson, S.A., Rubie, D.C., 2020. Subsolar Al/Si and $\mathrm{Mg} / \mathrm{Si}$ ratios of non-carbonaceous chondrites reveal planetesimal formation during early condensation in the protoplanetary disk. Earth and Planetary Science Letters 538, 11622. doi: $10.1016 /$ j.epsl.2020.116220.

Morbidelli, A., Lunine, J.I., O’Brien, D.P., Raymond, S.N., Walsh, K.J., 2012. Building terrestrial planets. Annual Review of Earth and Planetary Sciences 40, 251-275. doi 10.1146/ annurev-earth-042711-105319.

Morgan, J.W., Anders, E., 1980. Chemical composition of Earth, Venus, and Mercury. Proceedings of the National Academy of Sciences 77, 6973-6977. doi:10.1073/pnas.77.12.6973 
Morris, M.A., Boley, A.C., Desch, S.J., Athanassiadou, T., 2012. Chondrule formation in bow shocks around eccentric planetary embryos. The Astrophysical Journal 752, 27. doi:10.1088/ $0004-637 \mathrm{X} / 752 / 1 / 27$

Moynier, F., Day, J.M.D., Okui, W., Yokoyama, T., Bouvier, A., Walker, R.J., Podosek, F.A., 2012. Planetary-scale strontium isotopic heterogeneity and the age of volatile depletion of early Solar System materials. The Astrophysical Journal 758, 45. doi $10.1088 / 0004-637 \mathrm{X} / 758 / 1 / 45$

Mukhopadhyay, S., 2012. Early differentiation and volatile accretion recorded in deep-mantle neon and xenon. Nature 486, 101-104. doi:10.1038/nature11141.

Nagashima, K., Krot, A.N., Komatsu, M., 2017. ${ }^{26} \mathrm{Al}-{ }^{26} \mathrm{Mg}$ systematics in chondrules from Kaba and Yamato 980145 CV3 carbonaceous chondrites. Geochimica et Cosmochimica Acta 201, 303-319. doi:10.1016/j.gca.2016.10.030

Nebel, O., Mezger, K., van Westrenen, W., 2011. Rubidium isotopes in primitive chondrites: Constraints on Earth's volatile element depletion and lead isotope evolution. Earth and Planetary Science Letters 305, 309-316. doi:10.1016/j.gca.2010.04.061.

Norris, C.A., Wood, B.J., 2017. Earth's volatile contents established by melting and vaporization. Nature 549, 507-510. doi:10.1038/nature23645.

Ohtani, E., Ringwood, A.E., 1984. Composition of the core, I. Solubility of oxygen in molten iron at high temperatures. Earth and Planetary Science Letters 71, 85-93. doi 10.1016/ 0012-821X (84) 90054-2

Olsen, M.B., Wielandt, D., Schiller, M., Van Kooten, E.M.M.E., Bizzarro, M., 2016. Magnesium and ${ }^{54} \mathrm{Cr}$ isotope compositions of carbonaceous chondrite chondrules-Insights into early disk processes. Geochimica et Cosmochimica Acta 191, 118-138. doi:10.1016/j.gca.2016.07. 011.

O'Neill, H.S.C., 1991a. The origin of the Moon and the early history of the Earth-A chemical model. Part 1: The Moon. Geochimica et Cosmochimica Acta 55, 1135-1157. doi 10.1016/ 0016-7037(91)90168-5

O'Neill, H.S.C., 1991b. The origin of the Moon and the early history of the Earth-A chemical model. Part 2: The Earth. Geochimica et Cosmochimica Acta 55, 1159-1172. doi 10.1016/ 0016-7037(91)90169-6

O'Neill, H.S.C., Canil, D., Rubie, D.C., 1998. Oxide-metal equilibria to $2500{ }^{\circ} \mathrm{C}$ and $25 \mathrm{GPa}$ : Implications for core formation and the light component in the Earth's core. Journal of Geophysical Research: Solid Earth 103, 12239-12260. doi:10.1029/97JB02601.

O'Neill, H.S.C., Palme, H., 2008. Collisional erosion and the non-chondritic composition of the terrestrial planets. Philosophical Transactions of the Royal Society of London A: Mathematical, Physical and Engineering Sciences 366, 4205-4238. doi:10.1098/rsta.2008.0111. 
O'Rourke, J.G., Shim, S.H., 2019. Hydrogenation of the Martian core by hydrated mantle minerals with implications for the early dynamo. Journal of Geophysical Research: Planets 124, 34223441. doi:10.1029/2019JE005950

Palme, H., O'Neill, H.S.C., 2014. Cosmochemical estimates of mantle composition, in: Holland, H.D., Turekian, K.K. (Eds.), Treatise on Geochemistry (Second Edition). Elsevier, Oxford. volume 3, pp. 1-39. doi:10.1016/B978-0-08-095975-7.00201-1.

Paniello, R.C., Day, J.M.D., Moynier, F., 2012a. Zinc isotopic evidence for the origin of the Moon. Nature 490, 376-379. doi:10.1038/nature11507.

Paniello, R.C., Moynier, F., Beck, P., Barrat, J.A., Podosek, F.A., Pichat, S., 2012b. Zinc isotopes in HEDs: Clues to the formation of 4-Vesta, and the unique composition of Pecora Escarpment 82502. Geochimica et Cosmochimica Acta 86, 76-87. doi:10.1016/j.gca.2012.01.045.

Pape, J., Mezger, K., Bouvier, A.S., Baumgartner, L.P., 2019. Time and duration of chondrule formation: Constraints from ${ }^{26} \mathrm{Al}-{ }^{26} \mathrm{Mg}$ ages of individual chondrules. Geochimica et Cosmochimica Acta 244, 416-436. doi:10.1016/j.gca.2018.10.017

Parro, L.M., Jiménez-Díaz, A., Mansilla, F., Ruiz, J., 2017. Present-day heat flow model of Mars. Scientific Reports 7, 45629. doi:10.1038/srep45629

Peplowski, P.N., Evans, L.G., Hauck, S.A., McCoy, T.J., Boynton, W.V., Gillis-Davis, J.J., Ebel, D.S., Goldsten, J.O., Hamara, D.K., Lawrence, D.J., McNutt, R.L., Nittler, L.R., Solomon, S.C., Rhodes, E.A., Sprague, A.L., Starr, R.D., Stockstill-Cahill, K.R., 2011. Radioactive elements on Mercury's surface from MESSENGER: Implications for the planet's formation and evolution. Science 333, 1850-1852. doi:10.1126/science.1211576.

Pilipp, W., Hartquist, T.W., Morfill, G.E., Levy, E., 1998. Chondrule formation by lightning in the Protosolar Nebula? Astronomy and Astrophysics 331, 121-146.

Poitrasson, F., Halliday, A.N., Lee, D.C., Levasseur, S., Teutsch, N., 2004. Iron isotope differences between Earth, Moon, Mars and Vesta as possible records of contrasted accretion mechanisms. Earth and Planetary Science Letters 223, 253-266. doi 10.1016/j.eps1.2004.04.032

Poole, G.M., Rehkämper, M., Coles, B.J., Goldberg, T., Smith, C.L., 2017. Nucleosynthetic molybdenum isotope anomalies in iron meteorites-new evidence for thermal processing of solar nebula material. Earth and Planetary Science Letters 473, 215-226. doi:10.1016/j .eps1.2017.05. 001.

Prettyman, T.H., Yamashita, N., Reedy, R.C., McSween, Jr., H.Y., Mittlefehldt, D.W., Hendricks, J.S., Toplis, M.J., 2015. Concentrations of potassium and thorium within Vesta's regolith. Icarus 259, 39-52. doi:10.1016/j.icarus.2015.05.035. 
Pringle, E.A., Moynier, F., 2017. Rubidium isotopic composition of the Earth, meteorites, and the Moon: Evidence for the origin of volatile loss during planetary accretion. Earth and Planetary Science Letters 473, 62-70. doi:10.1016/j.epsl.2017.05.033

Pringle, E.A., Moynier, F., Beck, P., Paniello, R., Hezel, D.C., 2017. The origin of volatile element depletion in early solar system material: Clues from $\mathrm{Zn}$ isotopes in chondrules. Earth and Planetary Science Letters 468, 62-71. doi:10.1016/j.epsl.2017.04.002.

Pringle, E.A., Moynier, F., Savage, P.S., Badro, J., Barrat, J.A., 2014. Silicon isotopes in angrites and volatile loss in planetesimals. Proceedings of the National Academy of Sciences 111, 1702917032. doi:10.1073/pnas.1418889111.

Putirka, K., 2016. Rates and styles of planetary cooling on Earth, Moon, Mars, and Vesta, using new models for oxygen fugacity, ferric-ferrous ratios, olivine-liquid $\mathrm{Fe}-\mathrm{Mg}$ exchange, and mantle potential temperature. American Mineralogist 101, 819-840. doi:10.2138/am-2016-5402.

Raymond, S.N., Quinn, T., Lunine, J.I., 2006. High-resolution simulations of the final assembly of Earth-like planets I. Terrestrial accretion and dynamics. Icarus 183, 265-282. doi:10.1016/j. icarus.2006.03.011.

Richter, F.M., Davis, A.M., Ebel, D.S., Hashimoto, A., 2002. Elemental and isotopic fractionation of Type B calcium-, aluminum-rich inclusions: Experiments, theoretical considerations, and constraints on their thermal evolution. Geochimica et Cosmochimica Acta 66, 521-540. doi:10.1016/S0016-7037(01)00782-7.

Righter, K., 2019. Volatile element depletion of the Moon-The roles of precursors, post-impact disk dynamics, and core formation. Science Advances 5, eaau7658. doi:10.1126/sciadv . aau7658

Righter, K., Chabot, N.L., 2011. Moderately and slightly siderophile element constraints on the depth and extent of melting in early Mars. Meteoritics \& Planetary Science 46, 157-176. doi:10. $1111 / j .1945-5100.2010 .01140 . x$

Righter, K., Danielson, L.R., Pando, K.M., Williams, J., Humayun, M., Hervig, R.L., Sharp, T.G., 2015. Highly siderophile element (HSE) abundances in the mantle of Mars are due to core formation at high pressure and temperature. Meteoritics \& Planetary Science 50, 604-631. doi:10.1111/maps.12393.

Righter, K., Humayun, M., Danielson, L., 2008. Partitioning of palladium at high pressures and temperatures during core formation. Nature Geoscience 1, 321-323. doi:10.1038/ngeo180

Righter, K., Pando, K., Humayun, M., Waeselmann, N., Yang, S., Boujibar, A., Danielson, L.R., 2018. Effect of silicon on activity coefficients of siderophile elements ( $\mathrm{Au}, \mathrm{Pd}, \mathrm{Pt}, \mathrm{P}, \mathrm{Ga}, \mathrm{Cu}$, $\mathrm{Zn}$, and $\mathrm{Pb}$ ) in liquid $\mathrm{Fe}$ : Roles of core formation, late sulfide matte, and late veneer in shaping terrestrial mantle geochemistry. Geochimica et Cosmochimica Acta 232, 101-123. doi:10. $1016 / \mathrm{j} \cdot \mathrm{gca} .2018 .04 .011$. 
Righter, K., Pando, K., Ross, D.K., Righter, M., Lapen, T.J., 2019. Effect of silicon on activity coefficients of $\mathrm{Bi}, \mathrm{Cd}, \mathrm{Sn}$, and $\mathrm{Ag}$ in liquid $\mathrm{Fe}-\mathrm{Si}$, and implications for differentiation and core formation. Meteoritics \& Planetary Science 54, 1379-1394. doi:10.1111/maps.13285.

Righter, K., Sutton, S.R., Danielson, L., Pando, K., Newville, M., 2016. Redox variations in the inner solar system with new constraints from vanadium XANES in spinels. American Mineralogist 101, 1928-1942. doi $10.2138 / \mathrm{am}-2016-5638$

Ringwood, A.E., 1966. Chemical evolution of the terrestrial planets. Geochimica et Cosmochimica Acta 30, 41-104. doi:10.1016/0016-7037(66)90090-1.

Ringwood, A.E., 1975. Composition and Petrology of the Earth's Mantle. MacGraw-Hill, New York.

Rivoldini, A., Van Hoolst, T., Verhoeven, O., Mocquet, A., Dehant, V., 2011. Geodesy constraints on the interior structure and composition of Mars. Icarus 213, 451-472. doi: $10.1016 / \mathrm{j}$. icarus.2011.03.024

Rose, L.A., Brenan, J.M., 2001. Wetting properties of $\mathrm{Fe}-\mathrm{Ni}-\mathrm{Co}-\mathrm{Cu}-\mathrm{Os}$ melts against olivine: Implications for sulfide melt mobility. Economic Geology 96, 145-157. doi:10.2113/gsecongeo . 96.1 .145 .

Rubie, D.C., Frost, D.J., Mann, U., Asahara, Y., Nimmo, F., Tsuno, K., Kegler, P., Holzheid, A., Palme, H., 2011. Heterogeneous accretion, composition and core-mantle differentiation of the Earth. Earth and Planetary Science Letters 301, 31-42. doi:10.1016/j .epsl.2010.11.030

Rubie, D.C., Jacobson, S.A., Morbidelli, A., O'Brien, D.P., Young, E.D., de Vries, J., Nimmo, F., Palme, H., Frost, D.J., 2015. Accretion and differentiation of the terrestrial planets with implications for the compositions of early-formed Solar System bodies and accretion of water. Icarus 248, 89-108. doi $10.1016 / \mathrm{j}$. icarus.2014.10.015

Rubie, D.C., Laurenz, V., Jacobson, S.A., Morbidelli, A., Palme, H., Vogel, A.K., Frost, D.J., 2016. Highly siderophile elements were stripped from Earth's mantle by iron sulfide segregation. Science 353,1141-1144. doi:10.1126/science .aaf6919

Rudnick, R.L., Gao, S., 2014. Composition of the continental crust, in: Holland, H.D., Turekian, K.K. (Eds.), Treatise on Geochemistry (Second Edition). Elsevier, Oxford, pp. 1-51. doi:10. 1016/B978-0-08-095975-7.00301-6

Russell, S.S., Connolly, Jr., H.C., Krot, A.N. (Eds.), 2018. Chondrules: Records of Protoplanetary Disk Processes. volume 22. Cambridge University Press, Cambridge. doi:10.1017/ 9781108284073

Sanders, I.S., Scott, E.R.D., 2018. Making Chondrules by Splashing Molten Planetesimals, in: Russell, S.S., Connolly Jr., H.C., Krot, A.N. (Eds.), Chondrules: Records of Protoplanetary Disk 
Processes. Cambridge University Press. Cambridge Planetary Science. chapter 14, p. 361-374. doi: $10.1017 / 9781108284073.014$

Sargent, B.A., Forrest, W.J., Tayrien, C., McClure, M.K., Li, A., Basu, A.R., Manoj, P., Watson, D.M., Bohac, C.J., Furlan, E., Kim, K.H., Green, J.D., Sloan, G.C., 2008. Silica in protoplanetary disks. The Astrophysical Journal 690, 1193. doi:10.1088/0004-637X/690/2/1193.

Schiller, M., Bizzarro, M., Fernandes, V.A., 2018. Isotopic evolution of the protoplanetary disk and the building blocks of Earth and the Moon. Nature 555, 507-510. doi:10.1038/nature25990

Schönbächler, M., Carlson, R.W., Horan, M.F., Mock, T.D., Hauri, E.H., 2010. Heterogeneous accretion and the moderately volatile element budget of Earth. Science 328, 884-887. doi:10 . $1126 /$ science.1186239.

Schrader, D.L., Nagashima, K., Krot, A.N., Ogliore, R.C., Yin, Q.Z., Amelin, Y., Stirling, C.H., Kaltenbach, A., 2017. Distribution of ${ }^{26} \mathrm{Al}$ in the $\mathrm{CR}$ chondrite chondrule-forming region of the protoplanetary disk. Geochimica et Cosmochimica Acta 201, 275-302. doi:10.1016/j.gca. 2016.06 .023

Scott, E.R.D., Krot, A.N., 2014. Chondrites and their Components, in: Holland, H.D., Turekian, K.K. (Eds.), Treatise on Geochemistry (Second Edition). Elsevier, Oxford. volume 1, pp. 65-137. doi:10.1016/B978-0-08-095975-7.00104-2.

Shearer, C.K., Burger, P.V., Sutton, S.R., Papike, J.J., McCubbin, F., 2011. REE crystal chemistry of phosphates in extraterrestrial basalts at different oxygen fugacities: Direct determination of europium valence state in merrillite-whitlockite, in: Lunar and Planetary Science Conference, $p$. 1143.

Shibazaki, Y., Ohtani, E., Terasaki, H., Suzuki, A., Funakoshi, K.i., 2009. Hydrogen partitioning between iron and ringwoodite: Implications for water transport into the Martian core. Earth and Planetary Science Letters 287, 463-470. doi:10.1016/j.epsl.2009.08.034.

Shukolyukov, A., Lugmair, G.W., 2006. Manganese-chromium isotope systematics of carbonaceous chondrites. Earth and Planetary Science Letters 250, 200-213. doi $10.1016 / \mathrm{j}$.epsl. 2006.07 .036 .

Siebert, J., Sossi, P.A., Blanchard, I., Mahan, B., Badro, J., Moynier, F., 2018. Chondritic Mn/Na ratio and limited post-nebular volatile loss of the Earth. Earth and Planetary Science Letters 485, 130-139. doi:10.1016/j.epsl.2017.12.042

Simon, J.I., Jordan, M.K., Tappa, M.J., Schauble, E.A., Kohl, I.E., Young, E.D., 2017. Calcium and titanium isotope fractionation in refractory inclusions: tracers of condensation and inheritance in the early solar protoplanetary disk. Earth and Planetary Science Letters 472, 277-288. doi:10. 1016/j.epsl.2017.05.002. 
Smrekar, S.E., Lognonné, P., Spohn, T., Banerdt, W.B., Breuer, D., Christensen, U., Dehant, V., Drilleau, M., Folkner, W., Fuji, N., Garcia, R.F., Giardini, D., Golombek, M., Grott, M., Gudkova, T., Johnson, C., Khan, A., Langlais, B., Mittelholz, A., Mocquet, A., Myhill, R., Panning, M., Perrin, C., Pike, T., Plesa, A.C., Rivoldini, A., Samuel, H., Stähler, S.C., van Driel, M., Van Hoolst, T., Verhoeven, O., Weber, R., Wieczorek, M., 2019. Pre-mission InSights on the interior of Mars. Space Science Reviews 215, 3. doi:10.1007/s11214-018-0563-9.

Sossi, P.A., Klemme, S., O’Neill, H.S.C., Berndt, J., Moynier, F., 2019. Evaporation of moderately volatile elements from silicate melts: Experiments and theory. Geochimica et Cosmochimica Acta 260, 204-231. doi $10.1016 /$ j.gca.2019.06.021.

Sossi, P.A., Nebel, O., Anand, M., Poitrasson, F., 2016. On the iron isotope composition of Mars and volatile depletion in the terrestrial planets. Earth and Planetary Science Letters 449, 360-371. doi: $10.1016 / \mathrm{j}$. epsl.2016.05.030.

Sossi, P.A., Nebel, O., O’Neill, H.S.C., Moynier, F., 2018. Zinc isotope composition of the Earth and its behaviour during planetary accretion. Chemical Geology 477, 73-84. doi:10.1016/j. chemgeo.2017.12.006

Steenstra, E.S., Rai, N., Knibbe, J.S., Lin, Y.H., van Westrenen, W., 2016. New geochemical models of core formation in the Moon from metal-silicate partitioning of 15 siderophile elements. Earth and Planetary Science Letters 441, 1-9. doi: $10.1016 /$ j .epsl.2016.02.028

Stolper, E., Paque, J.M., 1986. Crystallization sequences of Ca-Al-rich inclusions from Allende: The effects of cooling rate and maximum temperature. Geochimica et Cosmochimica Acta 50, 1785-1806. doi:10.1016/0016-7037(86)90139-0

Stracke, A., Palme, H., Gellissen, M., Münker, C., Kleine, T., Birbaum, K., Günther, D., Bourdon, B., Zipfel, J., 2012. Refractory element fractionation in the Allende meteorite: Implications for solar nebula condensation and the chondritic composition of planetary bodies. Geochimica et Cosmochimica Acta 85, 114-141. doi:10.1016/j.gca.2012.02.006.

Suer, T.A., Siebert, J., Remusat, L., Menguy, N., Fiquet, G., 2017. A sulfur-poor terrestrial core inferred from metal-silicate partitioning experiments. Earth and Planetary Science Letters 469, 84-97. doi:10.1016/j.epsl.2017.04.016.

Sugiura, N., Fujiya, W., 2014. Correlated accretion ages and $\varepsilon^{54} \mathrm{Cr}$ of meteorite parent bodies and the evolution of the solar nebula. Meteoritics \& Planetary Science 49, 772-787. doi $10.1111 /$ maps.12292.

Surkov, Y.A., Kirnozov, F.F., Glazov, V.N., Dunchenko, A.G., Tatsy, L.P., Sobornov, O.P., 1987. Uranium, thorium, and potassium in the Venusian rocks at the landing sites of Vega 1 and 2. Journal of Geophysical Research: Solid Earth 92, E537-E540. doi:10.1029/JB092iB04p0E537. 
Tait, K.T., Day, J.M.D., 2018. Chondritic late accretion to Mars and the nature of shergottite reservoirs. Earth and Planetary Science Letters 494, 99-108. doi:10.1016/j.eps1.2018.04.040.

Taylor, G.J., 2013. The bulk composition of Mars. Chemie der Erde-Geochemistry 73, 401-420. doi:10.1016/j.chemer.2013.09.006.

Taylor, G.J., Boynton, W., Brückner, J., Wänke, H., Dreibus, G., Kerry, K., Keller, J., Reedy, R., Evans, L., Starr, R., Squyres, S., Karunatillake, S., Gasnault, O., Maurice, S., d’Uston, C., Englert, P., Dohm, J., Baker, V., Hamara, D., Janes, D., Sprague, A., Kim, K., Drake, D., 2006. Bulk composition and early differentiation of Mars. Journal of Geophysical Research: Planets 111, E03S10. doi:10.1029/2005JE002645.

Taylor, S.R., McLennan, S., 2009. Planetary Crusts: Their Composition, Origin and Evolution. volume 10. Cambridge University Press, Cambridge. doi:10.1017/CB09780511575358

Tenner, T.J., Ushikubo, T., Nakashima, D., Schrader, D.L., Weisberg, M.K., Kimura, M., Kita, N.T., 2018. Oxygen isotope characteristics of chondrules from recent studies by secondary ion mass spectrometry, in: Russell, S.S., Connolly Jr., H.C., Krot, A.N. (Eds.), Chondrules: Records of Protoplanetary Disk Processes. Cambridge University Press. Cambridge Planetary Science. chapter 8, p. 196-246. doi:10.1017/9781108284073.008

Tian, Z., Chen, H., Fegley Jr., B., Lodders, K., Barrat, J.A., Day, J.M.D., Wang, K., 2019. Potassium isotopic compositions of howardite-eucrite-diogenite meteorites. Geochimica et Cosmochimica Acta 266, 611-632. doi $10.1016 / \mathrm{j} \cdot$ gca.2019.08.012

Trinquier, A., Birck, J.L., Allegre, C.J., 2007. Widespread ${ }^{54} \mathrm{Cr}$ heterogeneity in the inner solar system. The Astrophysical Journal 655, 1179. doi:10.1086/510360.

Trinquier, A., Birck, J.L., Allègre, C.J., Göpel, C., Ulfbeck, D., 2008. ${ }^{53} \mathrm{Mn}-{ }^{53} \mathrm{Cr}$ systematics of the early Solar System revisited. Geochimica et Cosmochimica Acta 72, 5146-5163. doi:10. 1016/j.gca.2008.03.023.

Trinquier, A., Elliott, T., Ulfbeck, D., Coath, C., Krot, A.N., Bizzarro, M., 2009. Origin of nucleosynthetic isotope heterogeneity in the solar protoplanetary disk. Science 324, 374-376. doi:10.1126/science.1168221

Tsuno, K., Grewal, D.S., Dasgupta, R., 2018. Core-mantle fractionation of carbon in Earth and Mars: The effects of sulfur. Geochimica et Cosmochimica Acta 238, 477-495. doi: $10.1016 / \mathrm{j}$. gca.2018.07.010.

Turcotte, D., Schubert, G., 2014. Geodynamics (3rd Edition). Cambridge University Press, Cambridge. doi:10.1017/cbo9780511843877.

Turcotte, D.L., Paul, D., White, W.M., 2001. Thorium-uranium systematics require layered mantle convection. Journal of Geophysical Research: Solid Earth 106, 4265-4276. doi $10.1029 /$ 2000JB900409. 
Urey, H.C., Craig, H., 1953. The composition of the stone meteorites and the origin of the meteorites. Geochimica et Cosmochimica Acta 4, 36-82. doi:10.1016/0016-7037 (53) 90064-7

Villeneuve, J., Chaussidon, M., Libourel, G., 2009. Homogeneous distribution of ${ }^{26} \mathrm{Al}$ in the solar system from the Mg isotopic composition of chondrules. Science 325, 985-988. doi $10.1126 /$ science.1173907.

Wade, J., Wood, B.J., Tuff, J., 2012. Metal-silicate partitioning of Mo and W at high pressures and temperatures: evidence for late accretion of sulphur to the Earth. Geochimica et Cosmochimica Acta 85, 58-74. doi:10.1016/j.gca.2012.01.010.

Wadhwa, M., 2001. Redox state of Mars' upper mantle and crust from Eu anomalies in shergottite pyroxenes. Science 291, 1527-1530. doi:10.1126/science.1057594.

Wadhwa, M., 2008. Redox conditions on small bodies, the Moon and Mars, in: MacPherson, G.J. (Ed.), Reviews in Mineralogy and Geochemistry. Mineralogical Society of America. volume 68, pp. 493-510. doi:10.2138/rmg. 2008.68.17

Walker, R.J., Bermingham, K., Liu, J., Puchtel, I.S., Touboul, M., Worsham, E.A., 2015. In search of late-stage planetary building blocks. Chemical Geology 411, 125-142. doi:10.1016/j. chemgeo.2015.06.028

Walsh, K.J., Morbidelli, A., Raymond, S.N., O’Brien, D.P., Mandell, A.M., 2011. A low mass for Mars from Jupiter's early gas-driven migration. Nature 475, 206-209. doi 10.1038/ nature10201.

Wang, H., Weiss, B.P., Bai, X.N., Downey, B.G., Wang, J., Wang, J., Suavet, C., Fu, R.R., Zucolotto, M.E., 2017. Lifetime of the solar nebula constrained by meteorite paleomagnetism. Science 355, 623-627. doi:10.1126/science.aaf5043.

Wang, Z., Becker, H., 2017. Chalcophile elements in Martian meteorites indicate low sulfur content in the Martian interior and a volatile element-depleted late veneer. Earth and Planetary Science Letters 463, 56-68. doi $10.1016 / \mathrm{j}$. epsl.2017.01.023

Wänke, H., 1981. Constitution of terrestrial planets. Philosophical Transactions of the Royal Society of London. Series A: Mathematical and Physical Sciences 303, 287-302. doi:10.1098/rsta. 1981.0203

Wänke, H., Dreibus, G., 1988. Chemical composition and accretion history of terrestrial planets. Philosophical Transactions of the Royal Society of London. Series A, Mathematical and Physical Sciences 325, 545-557. doi:10.1098/rsta.1988.0067.

Wänke, H., Dreibus, G., 1994. Chemistry and accretion history of Mars. Philosophical Transactions of the Royal Society of London. Series A, Mathematical and Physical Sciences 349, 285-293. doi:10.1098/rsta.1994.0132 
Wänke, H., Dreibus, G., Jagoutz, E., 1984. Mantle chemistry and accretion history of the Earth, in: Kröner, A., Hanson, G.N., Goodwin, A.M. (Eds.), Archaean Geochemistry. Springer, pp. 1-24. doi:10.1007/978-3-642-70001-9_1

Warren, P.H., 2005. "New" lunar meteorites: Implications for composition of the global lunar surface, lunar crust, and the bulk Moon. Meteoritics \& Planetary Science 40, 477-506. doi: 10 . 1111/j.1945-5100.2005.tb00395.x

Warren, P.H., 2008. A depleted, not ideally chondritic bulk Earth: The explosive-volcanic basalt loss hypothesis. Geochimica et Cosmochimica Acta 72, 2217-2235. doi:10.1016/j . gca. 2007. 11.038

Warren, P.H., 2011. Stable-isotopic anomalies and the accretionary assemblage of the Earth and Mars: A subordinate role for carbonaceous chondrites. Earth and Planetary Science Letters 311, 93-100. doi:10.1016/j.epsl.2011.08.047.

Wasserburg, G.J., MacDonald, G.J.F., Hoyle, F., Fowler, W.A., 1964. Relative contributions of uranium, thorium, and potassium to heat production in the Earth. Science 143, 465-467. doi: 10 . $1126 /$ science.143.3605.465

Wasserburg, G.J., Mazor, E., Zartman, R.E., 1963. Isotopic and chemical composition of some terrestrial natural gases, in: Geiss, J., Goldberg, E.D. (Eds.), Earth Science and Meteorites. NorthHolland Pub. Co., pp. 219-240.

Wasson, J.T., Kallemeyn, G.W., 1988. Compositions of chondrites. Philosophical Transactions of the Royal Society of London A: Mathematical, Physical and Engineering Sciences 325, 535-544. doi:10.1098/rsta.1988.0066

Wasson, J.T., Krot, A.N., Lee, M.S., Rubin, A.E., 1995. Compound chondrules. Geochimica et Cosmochimica Acta 59, 1847-1869. doi:10.1016/0016-7037(95)00087-G

Wasson, J.T., Richardson, J.W., 2001. Fractionation trends among IVA iron meteorites: Contrasts with IIIAB trends. Geochimica et Cosmochimica Acta 65, 951-970. doi 10.1016/ S0016-7037(00)00597-4.

Weisberg, M.K., Ebel, D.S., Connolly, H.C., Kita, N.T., Ushikubo, T., 2011. Petrology and oxygen isotope compositions of chondrules in E3 chondrites. Geochimica et Cosmochimica Acta 75, 6556-6569. doi:10.1016/j.gca.2011.08.040.

Wheeler, K.T., Walker, D., McDonough, W.F., 2011. Pd and Ag metal-silicate partitioning applied to Earth differentiation and core-mantle exchange. Meteoritics \& Planetary Science 46, 199-217. doi: $10.1111 / \mathrm{j} .1945-5100.2010 .01145 . \mathrm{x}$.

Wiechert, U., Halliday, A.N., 2007. Non-chondritic magnesium and the origins of the inner terrestrial planets. Earth and Planetary Science Letters 256, 360-371. doi:10.1016/j .epsl. 2007. 01.007 
Wiechert, U., Halliday, A.N., Lee, D.C., Snyder, G.A., Taylor, L.A., Rumble, D., 2001. Oxygen isotopes and the Moon-forming giant impact. Science 294, 345-348. doi:10.1126/science. 1063037

Wieczorek, M.A., Zuber, M.T., 2004. Thickness of the Martian crust: Improved constraints from geoid-to-topography ratios. Journal of Geophysical Research: Planets 109. doi $10.1029 /$ 2003JE002153.

Willig, M., Stracke, A., Beier, C., Salters, V.J.M., 2020. Constraints on mantle evolution from CeNd-Hf isotope systematics. Geochimica et Cosmochimica Acta 272, 36-53. doi:10.1016/j. gca.2019.12.029.

Wipperfurth, S.A., Guo, M., Šrámek, O., McDonough, W.F., 2018. Earth’s chondritic Th/U: Negligible fractionation during accretion, core formation, and crust-mantle differentiation. Earth and Planetary Science Letters 498, 196-202. doi:10.1016/j.epsl.2018.06.029

Wipperfurth, S.A., Šrámek, O., McDonough, W.F., 2020. Reference models for lithospheric geoneutrino signal. Journal of Geophysical Research: Solid Earth 125, e2019JB018433. doi:10.1029/2019JB018433.

Wombacher, F., Rehkämper, M., Mezger, K., Bischoff, A., Münker, C., 2008. Cadmium stable isotope cosmochemistry. Geochimica et Cosmochimica Acta 72, 646-667. doi:10.1016/j . gca.2007.10.024.

Wood, B.J., Smythe, D.J., Harrison, T., 2019. The condensation temperatures of the elements: A reappraisal. American Mineralogist 104, 844-856. doi:10.2138/am-2019-6852CCBY.

Wood, B.J., Wade, J., Kilburn, M.R., 2009. Core formation and the oxidation state of the Earth: Additional constraints from $\mathrm{Nb}, \mathrm{V}$ and $\mathrm{Cr}$ partitioning. Geochimica et Cosmochimica Acta 72, 1415-1426. doi:10.1016/j.gca.2007.11.036.

Yang, S., Humayun, M., Righter, K., Jefferson, G., Fields, D., Irving, A.J., 2015. Siderophile and chalcophile element abundances in shergottites: Implications for Martian core formation. Meteoritics \& Planetary Science 50, 691-714. doi:10.1111/maps.12384.

Yoder, C.F., Konopliv, A.S., Yuan, D.N., Standish, E.M., Folkner, W.M., 2003. Fluid core size of Mars from detection of the solar tide. Science 300, 299-303. doi $10.1126 /$ science. 1079645

Yoshizaki, T., McDonough, W.F., 2020. The composition of Mars. Geochimica et Cosmochimica Acta 273, 137-162. doi $10.1016 /$ j.gca.2020.01.011.

Yoshizaki, T., Nakashima, D., Nakamura, T., Park, C., Sakamoto, N., Ishida, H., Itoh, S., 2019. Nebular history of an ultrarefractory phase bearing CAI from a reduced type CV chondrite. Geochimica et Cosmochimica Acta 252, 39-60. doi:10.1016/j.gca.2019.02.034. 
Young, E.D., Galy, A., 2004. The isotope geochemistry and cosmochemistry of magnesium. Reviews in Mineralogy and Geochemistry 55, 197-230. doi:10.2138/gsrmg.55.1.197.

Young, E.D., Kohl, I.E., Warren, P.H., Rubie, D.C., Jacobson, S.A., Morbidelli, A., 2016. Oxygen isotopic evidence for vigorous mixing during the Moon-forming giant impact. Science 351, 493 496. doi:10.1126/science.aad0525

Young, E.D., Shahar, A., Nimmo, F., Schlichting, H.E., Schauble, E.A., Tang, H., Labidi, J., 2019. Near-equilibrium isotope fractionation during planetesimal evaporation. Icarus 323, 1-15. doi: $10.1016 /$ j. icarus. 2019.01.012.

Zanda, B., Lewin, É., Humayun, M., 2018. The chondritic assemblage, in: Russell, S.S., Connolly, Jr., H.C., Krot, A.N. (Eds.), Chondrules: Records of Protoplanetary Disk Processes. Cambridge University Press, Cambridge. volume 22. chapter 5, pp. 122-150. doi $10.1017 /$ 9781108284073.005 .

Zhang, J., Dauphas, N., Davis, A.M., Leya, I., Fedkin, A., 2012. The proto-Earth as a significant source of lunar material. Nature Geoscience 5, 251-255. doi:10.1038/ngeo1429

Zhu, K., Moynier, F., Schiller, M., Bizzarro, M., 2020. Dating and tracing the origin of enstatite chondrite chondrules with $\mathrm{Cr}$ isotopes. The Astrophysical Journal Letters 894, L26. doi:10. 3847/2041-8213/ab8dca.

Zuber, M.T., Solomon, S.C., Phillips, R.J., Smith, D.E., Tyler, G.L., Aharonson, O., Balmino, G., Banerdt, W.B., Head, J.W., Johnson, C.L., Lemoine, F.G., McGovern, P.J., Neumann, G.A., Rowlands, D.D., Zhong, S., 2000. Internal structure and early thermal evolution of Mars from Mars Global Surveyor topography and gravity. Science 287, 1788-1793. doi:10.1126/science. 287.5459 .1788 . 


\title{
Supplementary materials for Earth and Mars-distinct inner solar system products
}

\author{
Takashi Yoshizaki*1 and William F. McDonough ${ }^{1,2,3}$ \\ ${ }^{1}$ Department of Earth Science, Graduate School of Science, Tohoku University, Sendai, Miyagi \\ 980-8578, Japan \\ ${ }^{2}$ Department of Geology, University of Maryland, College Park, MD 20742, USA \\ ${ }^{3}$ Research Center for Neutrino Science, Tohoku University, Sendai, Miyagi 980-8578, Japan \\ (*Corresponding author. E-mail: takashiy@ tohoku.ac.jp)
}

February 3, 2021

\section{Appendix A Supplementary materials}

\section{A.1 Updates in planetary compositions}

Here we revise compositional models of Earth (McDonough and Sun, 1995; Palme and O'Neill, 2014, McDonough, 2014) and Mars (Yoshizaki and McDonough, 2020) for some elements based on recent literature (Braukmüller et al., 2018, Alexander, 2019a b; Wood et al. 2019; Lodders, 2020).

\section{A.1.1 Manganese in the bulk Earth and its core}

The BSE has a lower Mn/Na value than that predicted by a condensation model based on the BSE's $\mathrm{Na} / \mathrm{Ti}$ value (Fig. 9). This Mn depletion in the BSE reflects its partial incorporation into the metallic core (McDonough, 2014), which is consistent with moderately siderophile behavior of Mn under highly reduced condition in the proto-Earth (Siebert et al. 2018). Thus, the Mn abundance in the bulk Earth includes contributions from the core and the mantle.

The Mn abundance in the BSE is 1,050 ppm (McDonough and Sun, 1995; Palme and O'Neill, 2014). McDonough (2014) estimated Mn abundance of the bulk Earth and core of $800 \mathrm{ppm}$ and $300 \mathrm{ppm}$, respectively, based on a linear trend in a plot of $\mathrm{Na} / \mathrm{Ti}$ vs $\mathrm{Mn} / \mathrm{Na}$ among chondrites. This estimate gives core-mantle partition coefficient of $\mathrm{Mn}\left(D_{\mathrm{Mn}}^{\text {core-mantle }}\right)$ of $\sim 0.3$, lower than that predicted by high P-T experimental studies (e.g., Siebert et al., 2018). Recently, Siebert et al. (2011) re-evaluated the bulk Earth's bulk Mn content of 900-1300 ppm based on moderately siderophile behavior of Mn under Earth's core formation conditions.

Here we test if the ratios of $\mathrm{Na}, \mathrm{Mn}$ and Ti of Earth (McDonough and Sun, 1995, Palme and O'Neill. 2014; McDonough, 2014; Siebert et al., 2018), Mars (Yoshizaki and McDonough, 2020) and other small solar system bodies ('O'Neill and Palme, 2008, Wasson and Kallemeyn, 1988, Braukmüller et al. 2018) reflect incomplete condensation of a solar nebular gas or post-accretionary evaporative loss of moderately volatile elements (MVE). We modeled the incomplete condensation in 
the solar nebula, in which volatile depletion in condensates is strictly depending on the $50 \%$ condensation temperature of elements, following Cassen (1996) and Cassen (2001). We assume that a log of CI-normalized abundance of non-refractory elements in condensates shows a linear trend when plotted against the $50 \%$ condensation temperature of elements during a partial condensation. Thus, the composition of condensates is formulated as:

$$
\log \frac{C_{\mathrm{i}}^{\text {cond }}}{C_{\mathrm{i}}^{\mathrm{CI}}}= \begin{cases}-\left(\log T_{c}(\text { ref })-\log T_{c}(\mathrm{i})\right) \times f & \left(T_{c}(\mathrm{i})<T_{c}(\text { ref })\right) \\ 1 & \left(T_{c}(\mathrm{i}) \geq T_{c}(\text { ref })\right)\end{cases}
$$

where $C_{\mathrm{i}}^{\text {cond }}$ and $C_{\mathrm{i}}^{\mathrm{CI}}$ are abundances of an element $\mathrm{i}$ in a condensate and CI chondrite, respectively, $T_{c}(\mathrm{i})$ and $T_{c}$ (ref) are 50\% condensation temperatures of the element $i$ and vanadium, which has the lowest condensation temperature among refractory elements $(1370 \mathrm{~K}$ at $10 \mathrm{~Pa}$; Wood et al., 2019), respectively, and $f$ is a slope of the linear volatility trend in a $\log \left(C^{\text {cond }} / C^{\mathrm{CI}}\right)$ vs $\log T_{c}$ space (i.e., degree of volatile depletion in the condensate). Condensation temperature of elements from Wood et al. (2019) and CI abundance from Lodders (2020) are adopted in the calculation. The evaporative losses of elements from a high-temperature liquid were modeled using equations and thermochemical data from Sossi et al. (2019) and Chase (1998).

Our simplified calculation of incomplete condensation well reproduces a chemical composition of chondrites and Mars (Fig. 9). The bulk Earth composition (McDonough 2014) with the updated Mn abundance (Siebert et al., 2018) is consistent with the incomplete condensation model. In contrast, compositions of differentiated asteroids (e.g., parent bodies of angrites and eucrites) and Earth's moon are consistent with the evaporation from a CI and the BSE compositions, respectively. These observations, combined with a lack of heavy MVE isotope enrichment composition of terrestrial samples (e.g., K, Fe, Si, Mg, Zn, Cd; Humayun and Clayton, 1995, Poitrasson et al., 2004; Norman et al., 2006; Wombacher et al., 2008; Herzog et al., 2009; Paniello et al., 2012; Zambardi et al. 2013, Sossi et al., 2016, 2018), document that the bulk Earth's MVE abundance is established by a nebular condensation, rather than post-accretionary evaporative losses. With the bulk Earth's $\mathrm{Na} / \mathrm{Ti} \sim 2.2$ (McDonough, 2014), the incomplete condensation model predicts Mn abundance of $1070 \mathrm{ppm}$ and $1120 \mathrm{ppm}$ in the bulk Earth and its core, respectively, with the $D_{\mathrm{Mn}}^{\text {core-mantle }}$ of $\sim 1.1$, which are in agreement with the values predicted by Siebert et al. (2018). Thus, we update the Mn abundances in the bulk Earth and its core with these values.

\section{A.1.2 Sulfur in the bulk Earth and its core}

The $\mathrm{S}$ content in the bulk Earth is of particular interest when estimating a mass fraction of the postimpact sulfide matte. Sulfur is a moderately volatile, chalcophile element so that its abundances in the bulk Earth and core can be constrained by an abundance of lithophile element with similar volatility. Zinc abundance in the BSE has been used to constrain Earth's S content, since Zn does not show deviation from Earth's lithophile volatility trend and its condensation temperature is close to that of S (McDonough and Sun, 1995, Dreibus and Palme, 1996). 
McDonough (2014) estimated sulfur in the BSE at $250 \pm 50 \mathrm{ppm}$ and a bulk Earth with 6350 ppm, based on Earth's volatility trend and S abundance of CI chondrite of $5.40 \mathrm{wt} \%$. These estimates lead to the prediction of $1.9 \mathrm{wt} \% \mathrm{~S}$ in Earth's core. The authors used 50\% condensation temperatures of elements from Wasson (1985), in which $T_{c}$ of $\mathrm{S}$ and $\mathrm{Zn}$ (treated as lithophile) are $648 \mathrm{~K}$ and 660 $\mathrm{K}$, respectively.

Dreibus and Palme (1996) assumed a CI-like Zn/S value for Earth given a nearly similar $T_{c}$ of $\mathrm{S}$ and $\mathrm{Zn}$ (Wasson, 1985), and estimated $5600 \mathrm{ppm} \mathrm{S}$ in the bulk Earth. They used a lower and higher $\mathrm{S}$ abundance in the BSE (130 ppm) and CI chondrite $(5.9 \mathrm{wt} \%)$ than the values taken by McDonough (2014), which gives an estimate of $\sim 1.7 \mathrm{wt} \% \mathrm{~S}$ in the Earth's core.

Here we revise the $\mathrm{S}$ content of the bulk Earth and its core based on recently-revised $T_{c}$ (Wood et al. 2019) and CI abundance (Lodders, 2020). The updated $T_{c}(\mathrm{~S})$ and $T_{c}(\mathrm{Zn})$ are $672 \mathrm{~K}$ and 704 $\mathrm{K}$, respectively, with a difference of $32 \mathrm{~K}$, which is larger than that of the Wasson (1985)'s value. Thus, we consider that the $\mathrm{Zn} / \mathrm{S}$ value of the bulk Earth might not be chondritic if these elements are depleted in Earth based strictly on their relative volatilities. We use the $S$ abundance of $250 \mathrm{ppm}$ in the BSE (McDonough and Sun, 1995; Palme and O'Neill, 2014) and $5.36 \mathrm{wt} \%$ in CI chondrite (Lodders, 2020), and modeled a incomplete condensation of moderately volatile elements as we applied for Mn (Section A.1.1). With these values, we estimate S concentrations of $5900 \mathrm{ppm}$ in the bulk Earth, and $1.8 \mathrm{wt} \%$ in the core. The revised S abundance in Earth is used to estimate the mass of post-impact sulfide matte (Section 3.3.2).

\section{A.1.3 Sulfur in the Martian core}

The $\mathrm{S}$ content in the Martian core estimated by Yoshizaki and McDonough (2020) is much lower than that estimated by Wänke and Dreibus (1994) and Taylor (2013), who constrained the S content in the Martian core by assuming that moderately volatile elements are in chondritic abundances in the bulk Mars. However, the trend of depletion of moderately volatile elements in Mars is inconsistent with assumptions in (Yoshizaki and McDonough, 2020).

Physical models of Martian interior (e.g., Khan and Connolly, 2008, Rivoldini et al., 2011; Khan et al., 2018) based on available observations (mass, density, MOI and tidal Love number $k_{2}$ ) typically use the compositional model of the Martian mantle established by Wänke and Dreibus (1994). These studies generally predict a larger core (1700-1800 km in radius) with a high S concentration (15-20 wt\%), which are differ from the estimates by Yoshizaki and McDonough (2020) ( $r \sim 1600 \mathrm{~km} ; \leq 7 \mathrm{wt} \% \mathrm{~S}$ ). These geophysical models use the Mars' $k_{2}$ Love number to estimate its core $\mathrm{S}$ content. However, a deconvolution of the $k_{2}$ Love number requires an accurate knowledge of the degree of partial melting and hydration in the mantle, phase- and composition-dependent changes in elastic properties of mantle minerals, and grain size variation (e.g., Nimmo and Faul 2013, Khan et al., 2018). Thus, we use the planetary volatility trend to estimate the Mars' bulk and core S abundances (Yoshizaki and McDonough, 2020), following the practice used to constrain the S abundance in the Earth's core (Dreibus and Palme, 1996, McDonough, 2014). A direct seismic 
observation of Martian interior by NASA's ongoing InSight mission will place strong constraints on the size and light element inventory of the Martian core.

Core-mantle partitioning behaviors of refractory elements, which are sensitive to the $\mathrm{S}$ content of the metal (Righter, 2011; Wade et al., 2012), provide further constraints on the S concentration in the Martian core. The compositional model of Mars (Yoshizaki and McDonough, 2020) predict core-mantle $D$-value of $10 \pm 5.5$, based on the depletion of W in the BSM. Figs. A.10 and A.11 show the metal-silicate partitioning behavior of $\mathrm{W}$ at $\Delta \mathrm{IW}=-1.5$ for the Martian core models (Wänke and Dreibus, 1994; Taylor, 2013, Yang et al., 2015; Yoshizaki and McDonough, 2020), estimated based on a compilation of previous experimental constraints (Righter, 2011). Fig. A.10 shows that $\mathrm{S}$ become less siderophile as the $\mathrm{S}$ concentration in the metal increases. For a $\mathrm{S}$-rich core model (>20 wt \%; Taylor 2013), the $D$-value of $\mathrm{W}$ is much lower than the Martian compositional model (Fig. A.11C). Models with 10-15 wt\% S in the core (Wänke and Dreibus, 1994, Yang et al. $2015)$ requires $\sim 2500 \mathrm{~K}$ to explain the BSM's W depletion. The S-poor core composition $(\mathrm{S} \sim 7$ wt \%; Yoshizaki \& McDonough, 2020) is consistent with a BSM model forming at $>2300 \mathrm{~K}$. Thus, the predicted W abundance in the BSM is consistent with lower S models for the Martian core. We note that the temperature conditions required to explain the distribution of $\mathrm{W}$ in Mars decreases by $\sim 200 \mathrm{~K}$ if the $\log f_{\mathrm{O}_{2}}$ value decreased for 0.5 units in the $\Delta \mathrm{IW}$ space.

Similarly, the behavior of Mo is also sensitive to $S$ contents in a metal (Wade et al. 2012). Therefore, Mo is another useful element for constraining the $S$ abundance in the Martian core. Unfortunately, the Mo abundance in the BSM is currently poorly constrained. Yoshizaki and McDonough (2020) found no clear correlation of Mo with other elements in Martian meteorites. Yang et al. (2015) proposed the Mo abundance in the BSM based on Mo-Ce correlation in two Martian meteorites, which were not identified by Yoshizaki and McDonough (2020). Future constraints on the Mo abundance in the Martian mantle will provide important constraints on the light element composition of the Martian core.

\section{A.1.4 Halogens in Earth and Mars}

Abundances of heavy halogens $(\mathrm{Cl}, \mathrm{Br}$ and $\mathrm{I})$ in the $\mathrm{BSE}$ is enigmatic because of their large depletion in the BSE (McDonough and Sun, 1995, Palme and O'Neill, 2014), perhaps indicative of unique behaviors of these elements during and/or after the Earth's accretion (e.g., Kramers, 2003, Armytage et al., 2013; McDonough, 2014, Sharp and Draper, 2013; Zolotov and Mironenko, 2007; Clay et al., 2017, Jackson et al., 2018, Steenstra et al., 2020). The present bulk Earth model (McDonough, 2014) attributed this heavy halogen depletion to their incorporation into the core, and estimated core/mantle enrichment factors of 10-15 for these elements. Limited numbers of experimental studies suggest that iodine becomes siderophile during core formation Armytage et al. 2013; Jackson et al. 2018), whereas $\mathrm{Cl}$ does not show such a metal-loving behavior (Sharp and Draper. 2013).

Recently, Clay et al. (2017) proposed a lower halogen abundance for chondritic meteorites than 
previous estimates (e.g., Dreibus et al. 1979, Lodders, 2003). By normalizing the BSE abundance of halogens to their updated CI composition, Clay et al.(2017) showed that $\mathrm{Br}$ and I are plotted on the lithophile volatility trend and no need for any special processes of halogen fractionation. However, even if normalized to Clay et al. (2017)'s CI chondrite composition, the BSE's Cl abundance still shows a depletion from the volatility trend.

The CI abundances of heavy halogens proposed by Clay et al. (2017) has been challenged by Fegley et al. (2020), who showed that these updated CI abundances fall below a curve of nuclide abundance vs mass number. Lodders (2020) critically evaluated and updated the CI composition proposed by Clay et al. (2017) and brought it in line with previous estimates of the CI abundance (Dreibus et al., 1979; Lodders, 2003).

The revised 50\% condensation temperatures of the halogens (Fegley and Lodders, 2018; Wood et al. 2019) are lower than the previous values (Lodders. 2003). Consequently, using condensation temperatures from Fegley and Lodders (2018) and CI abundance from Lodders (2020), Fegley et al. (2020) showed that all the halogens plot on the Earth's volatility trend for the lithophile elements, thereby eliminating any need for any extra halogen fractionation (Fig. A.3A). We note that a hockeystick depletion pattern of MVE in the BSE (e.g., Braukmüller et al. 2019) is not observed when CI abundance from Lodders (2020) is used instead of that of Clay et al. (2017). In this case, the Earth's halogen budgets (i.e., $12 \mathrm{ppm} \mathrm{Cl}, 0.03 \mathrm{ppm} \mathrm{Br}$, and $0.01 \mathrm{ppm}$ I in the bulk Earth) are hosted in its silicate fraction, and there is no need for their incorporation into the core.

In contrast, a separate effort by Wood et al. (2019) derived higher $50 \%$ condensation temperatures for these elements compared to Fegley and Lodders (2018), which seem to be consistent with the halogen-bearing core model (Fig. A.3B). Thus, further analytical, experimental and theoretical efforts are needed to better constrain the abundance and distribution of heavy halogens in Earth.

Yoshizaki and McDonough (2020) estimated halogen abundances in the BSM and bulk Mars based on the CI abundance of these elements from Clay et al.(2017). Using CI chondritic abundance from Lodders (2020), and assuming that the heavy halogens are hosted in the Mars' silicate fraction, the BSM and bulk Mars heavy halogen abundances are updated as follows: $28 \mathrm{ppm} \mathrm{Cl}, 0.13 \mathrm{ppm}$ $\mathrm{Br}$, and $0.03 \mathrm{ppm} \mathrm{I}$ in the BSM; and $23 \mathrm{ppm} \mathrm{Cl}, 0.10 \mathrm{ppm} \mathrm{Br}$, and $0.02 \mathrm{ppm} \mathrm{I}$ in the bulk Mars. If the Martian core contained heavy halogens, the bulk Mars' halogen abundance might be $0.1-0.2 \times$ CI.

\section{A.2 Heat production in terrestrial planets}

Internal heat production of Mars is calculated using the BSM abundances of heat-producing elements (HPE) ${ }^{40} \mathrm{~K},{ }^{232} \mathrm{Th},{ }^{235} \mathrm{U}$ and ${ }^{238} \mathrm{U}$ (Yoshizaki and McDonough, 2020), and their standard decay constants (McDonough et al. 2020 and references therein). The Martian core contributes negligibly to the radiogenic heating of the planet as it is predicted to contain insignificant quantities 
of HPE. Heat production in the Martian crust is calculated for a crust with $3740 \mathrm{ppm} \mathrm{K}, 700 \mathrm{ppb}$ Th and $180 \mathrm{ppb} \mathrm{U}$ (Taylor and McLennan, 2009). Abundances of HPE in the Martian mantle are based on mass-balance considerations

$$
X_{\mathrm{Mm}}^{\mathrm{i}}=\frac{X_{\mathrm{Mc}}^{\mathrm{i}} \times M_{\mathrm{Mc}}-X_{\mathrm{BSM}}^{\mathrm{i}} \times M_{\mathrm{BSM}}}{M_{\mathrm{Mm}}}
$$

where $X_{\mathrm{j}}^{\mathrm{i}}$ is concentration of HPE $\mathrm{i}\left({ }^{40} \mathrm{~K},{ }^{232} \mathrm{Th},{ }^{235} \mathrm{U}\right.$ and $\left.{ }^{238} \mathrm{U}\right)$ in the reservoir $\mathrm{j}(\mathrm{Mm}, \mathrm{Mc}$, and BSM are Martian mantle, Martian crust and the bulk silicate Mars, respectively) and $M_{\mathrm{j}}$ is mass of reservoir j (Table 1). For $X_{\mathrm{BSM}}$ of $360 \mathrm{ppm} \mathrm{K,} 68 \mathrm{ppb}$ Th and $18 \mathrm{ppb} \mathrm{U}$ (Yoshizaki and McDonough. 2020) and $X_{\mathrm{Mc}}$ from Taylor and McLennan (2009), Eq. (A.2) yields $190 \mathrm{ppm} \mathrm{K,} 36 \mathrm{ppb}$ Th and 10 ppb $U$ in the Martian mantle. Martian planetary Urey ratio $(U r)$ is given by

$$
U r_{\mathrm{Mars}}=\frac{H_{\mathrm{BSM}}}{4 \pi R^{2} F}
$$

where $H_{\mathrm{BSM}}$ is heat production in the bulk silicate Mars, $R$ is surface area of Mars, $F_{\text {Mars }}$ is the average surface heat flow $\left(19 \pm 1 \mathrm{~mW} / \mathrm{m}^{2} ;\right.$ Parro et al. 2017). Similarly, the internal heat production in Earth is calculated based on compositions of the BSE and Earth's crust from McDonough (2014) and Rudnick and Gao (2014), respectively, $F_{\text {Earth }}$ from Jaupart et al. (2015), and mass and density of the crust from Wipperfurth et al. (2020).

\section{A.3 Rayleigh number of the Martian mantle}

The Rayleigh number $(R a)$ for the internally-heated present-day Martian mantle is given by

$$
R a=\frac{\alpha \rho^{2} g H d^{5}}{k \mu \kappa}
$$

where $\alpha$ is thermal expansion coefficient, $\rho$ is density of the Martian mantle, $g$ is gravitational acceleration, $H$ is heat production in the present-day Martian mantle, $d$ is thickness of the Martian mantle, $k$ is thermal conductivity, $\mu$ is viscosity and $\kappa$ is thermal diffusivity. We take $\alpha=3 \times 10^{5}$ $\mathrm{K}^{-1}, g=3.7 \mathrm{~m} / \mathrm{s}^{2}, k=4 \mathrm{~W} / \mathrm{m} / \mathrm{K}, \mu=10^{21}-10^{23} \mathrm{~Pa} \mathrm{~s}$, and $\kappa=10^{-6} \mathrm{~m}^{2} / \mathrm{s}$ (Turcotte and Schubert, 2014, Samuel et al. 2019) and obtain $R a=3 \times 10^{5}-3 \times 10^{7}$.

\section{A.4 CAI-free bulk composition of CV chondrite}

Abundances of the MVE are apparently lower in CV chondrites than other carbonaceous chondrites, because of their higher abundance of refractory inclusions. Since relative abundance of refractory lithophile elements in Earth and Mars are distinct from that of CAIs and bulk CV, it is unlikely that the planetary MVE fractionation is inherited from CV CAI-like materials (Stracke et al., 2012; Dauphas and Pourmand, 2015, Barrat et al., 2016). Therefore, to evaluate the contribution of CV chondrules in the bulk CV composition, we calculated a CAI-free chemical composition of bulk CV 
chondrites using mean composition of unaltered Allende CAIs (Mason and Martin, 1977), modal abundance of CAIs in CV (Hezel et al., 2008, Rubin, 2011; Scott and Krot, 2014; Desch et al., 2018), and the bulk CV composition (Alexander, 2019a). The calculated CAI-free bulk CV composition is shown in Figs. 11 and A.4

\section{A.5 Modeling the Earth's accretion}

Here we describe the details of formation model of the Earth (Section 3.3.2). The basic sequence of the Earth's accretion is taken from Wänke et al. (1984) and O'Neill (1991ab), with modifications:

1. the accretion of the proto-Earth (reduced and volatile-depleted) accompanied by continuous core-mantle differentiation ( $\sim 90 \%$ of Earth's mass),

2. followed by a late-stage (e.g., 30-100 Myr after $t_{0}$; Kleine et al., 2009) Moon-forming giant impact event that adds the final $\sim 10 \%$ mass (oxidized and volatile-enriched) to Earth and forms a protolunar accretion disk,

3. subsequently, the mantle loses a Fe-Ni $( \pm \mathrm{O})$ sulfide liquid (sulfide matte; O’Neill, 1991b) to the core ( $\sim 0.5 \%$ BSE mass),

4. and finally, the BSE receives the addition of ( $~ 0.5 \%$ of the BSE mass) a late accretion component that brings the highly siderophile and chalcophile elements in chondritic proportions and highly volatile gases and fluids.

The bulk composition of the proto-Earth (Table A.2) is calculated by subtracting contributions of the Mars-like impactor and late-added materials from the bulk composition of the present-day Earth (McDonough, 2014). In this scenario, the bulk proto-Earth contains $\geq 80 \%$ of the presentday Earth's budgets of most of the MVE (e.g., K/Th $~ 3200 ; \mathrm{Rb} / \mathrm{Sr} \sim 0.026$; Table A.2), since a Mars-like impactor contributes only a limited amount of additional MVE (Fig. 13.

The core-mantle differentiation of proto-Earth is modeled using the calculated bulk proto-Earth composition and metal-silicate distribution coefficients of elements at high P-T conditions $(\sim 30$ GPa and $\sim 3000 \mathrm{~K}$ ) and $\log f_{\mathrm{O}_{2}} \sim \mathrm{IW}-2$ (Table A.1.

The mass fraction of the impactor's core that equilibrated with the Earth's mantle $(k)$ is poorly constrained. While a small impactor might be efficiently emulsified and completely equilibrated with the proto-Earth's magma ocean, the behavior of Mars-sized impactor's core remains controversial (e.g., Rubie et al., 2003, 2015; Dahl and Stevenson, 2010, Samuel, 2012, Deguen et al., 2014). The Hf-W and U-Pb isotopic systematics and abundances of moderately siderophile element in the BSE is consistent with $0.4 \leq k \leq 1$ (Jacobsen, 2005; Nimmo and Agnor, 2006; Rubie et al., 2015, 2016). Recently, Budde et al. (2019) showed that nucleosynthetic Mo isotopic composition of the BSE is well reproduced if $20-100 \%$ of equilibrium was achieved between the impactor's core and 
the proto-Earth's mantle (see also Kleine et al., 2020). We found that $0.5 \leq k \leq 1$ is consistent with the BSE abundances of most siderophile and chalcophile elements (Fig. A.7).

As a consequence of the Moon-forming event, the impactor's mantle and core are emulsified and equilibrated within the Earth's mantle (e.g., O’Neill, 1991b; Rubie et al., 2016), providing not only lithophile, but also siderophile and chalcophile elements to the post-impact silicate Earth (Fig. [13). The Earth's mantle might reach S saturation, given that the addition of the impactor increases the mantle $\mathrm{S}$ abundance, and the $\mathrm{S}$ concentration at sulfide saturation decreases dramatically as the mantle cools (O’Neill, 1991b, Rubie et al., 2016). Thus, an immiscible Fe-Ni $( \pm \mathrm{O})$ sulfide liquid (post-impact sulfide matte) precipitates through a crystallizing mantle into the core due to its high immiscibility, low wetting angle, and high density (Gaetani and Grove, 1999, Rose and Brenan. 2001).

The mass of post-impact sulfide matte is calculated by assuming that all $\mathrm{S}$ in the post-impact BSE was stripped by a sulfide phase, and all $\mathrm{S}$ in the present-day BSE is derived from the lateaccreted materials (Yi et al., 2000; Rose-Weston et al., 2009; Wang and Becker, 2013). Using a metal-silicate partition coefficient of $\mathrm{S}\left(D_{\mathrm{S}}^{\mathrm{met}-\mathrm{sil}}\right)$ of 100 (Rose-Weston et al. 2009, Boujibar et al. 2014), the proto-Earth's mantle is estimated to contain $170 \mathrm{ppm} \mathrm{S.} \mathrm{The} \mathrm{bulk} \mathrm{Mars-like,} \mathrm{Moon-}$ forming impactor has $1.2 \mathrm{wt} \% \mathrm{~S}$ (Yoshizaki and McDonough, 2020), so its addition increases S concentration in the post-impact Earth's mantle to $\sim 0.2 \mathrm{wt} \%$. If all $\mathrm{S}$ in the post-impact BSE is segregated by a sulfide liquid with a composition of sulfides in spinel lherzolite xenoliths (37.7 $\mathrm{wt} \% \mathrm{Fe}, 21.1 \mathrm{wt} \% \mathrm{Ni}, 0.3 \mathrm{wt} \% \mathrm{Co}, 1.6 \mathrm{wt} \% \mathrm{Cu}$, and $38.3 \mathrm{wt} \% \mathrm{~S}$; Lorand and Conquéré, 1983), the amount of the sulfide liquid is $\sim 0.5 \mathrm{wt} \%$ of the present-day Earth's silicate mantle. Fractionation of other siderophile or chalcophile elements due to the sulfide matte precipitation is modeled using the $D^{\text {sul-sil }}$ values listed in Table A.1. Since there are limited numbers of experimental dataset on $D^{\text {sul-sil }}$ values, we do not specify P-T conditions of the sulfide matte formation. The errors accompanied with the wide variation in the expected $D^{\text {sul-sil }}$ values are much larger than those from

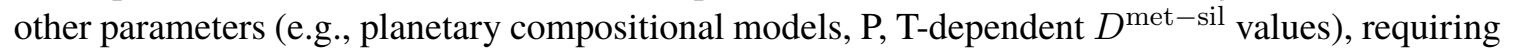
additional experimental efforts in future.

The elevated abundances of highly siderophile and chalcophile elements in the Earth's mantle indicate an addition of $\sim 0.5 \%$ of volatile-rich materials at the final stage of Earth's accretion (e.g., Kimura et al., 1974, Chou, 1978, Walker et al., 2015; Rubie et al., 2016, Wang and Becker, 2013, Righter et al. 2018a). The absence of meteorite class that matches relative abundances and isotopic composition of highly siderophile or chalcophile elements in the BSE keeps the nature of this lateaccreted material controversial, but there is a general consensus that the late-added material had a chondritic elemental composition (Walker et al., 2002; Albarede, 2009; Alexander et al., 2012; Wang and Becker. 2013, Varas-Reus et al., 2019, Fischer-Gödde et al., 2020). In this modeling, we do not specify the type of chondritic materials added during the final stage. Note that all classes of chondrites are similarly enriched in volatiles compared to the rocky planets, and mass fraction of the late-accreted material in the Earth's mantle is only $\sim 0.5 \%$. Therefore, the choice of other type 
of chondrites (e.g., enstatite or ordinary) as the late-accreted material do not affect the main results of this modeling.

The sulfide matte segregation decreases the abundances of the siderophile and chalcophile elements to the present-day BSE levels (Fig. 13). It also removes HSE like Au, Pd, Pt from the Earth's mantle, decreasing their mantle abundance $>10$ times smaller than the present-day values (Rubie et al. 2016, Righter et al. 2018a). As a final step, the late addition of $\sim 0.5 \mathrm{wt} \%$ of chondritic materials to the Earth's mantle after the sulfide matte segregation increases mantle abundances of HSE and chalcogens to the present-day BSE level (Wang and Becker, 2013, Walker et al., 2015) (not shown in Figs. 13, A.6 and A.7). Thus, this accretion scenario successfully reproduces the abundances of the chalcophile and highly siderophile elements in the BSE.

A challenge to our model is the unexplained higher levels of $\mathrm{Cu}$ and $\mathrm{Sn}$ and strong depletion $\mathrm{Sb}$ and Ge in the BSE. These misfits can be due to our limited understanding of chalcophile behavior of these elements at the high $\mathrm{P}$ and $\mathrm{T}$ conditions. The problem with the $\mathrm{Cu}$ abundance is also found even in the CI-like Impactor model (O'Neill, 1991b), and it would be relaxed if the lower BSE abundance of $\mathrm{Cu}$ (20 ppm instead of 30 ppm; O'Neill, 1991b; McDonough, 2014) and/or lower $D_{\mathrm{Cu}}^{\mathrm{sul}-\mathrm{sil}}$ under oxidizing or high-T conditions (e.g., Li and Audétat, 2015) are considered. 
Table A.1: Metal-silicate and sulfide-silicate partition coefficients of elements $(D)$ adopted in the modeling.

\begin{tabular}{|c|c|c|c|c|}
\hline Element & $D^{\text {met-sil }}$ & Reference $\mathrm{e}^{\text {a }}$ & $D^{\text {sul-sil }}$ & Reference $e^{\text {a }}$ \\
\hline $\mathrm{P}$ & 20 & $\mathrm{R} 10$ & $10-300$ & JD86, R97 \\
\hline S & 100 & R09, B14, S17 & $\gg 1000$ & See note ${ }^{b}$ \\
\hline $\mathrm{V}$ & 1.3 & $\mathrm{R} 11$ & $0.1-2$ & GG97 \\
\hline $\mathrm{Cr}$ & 2 & R11 & $2-4$ & KW13 \\
\hline $\mathrm{Mn}$ & 0.8 & $\mathrm{R} 11, \mathrm{~S} 18$ & $1-3$ & KW13 \\
\hline $\mathrm{Fe}$ & 20 & Mass balance $e^{\mathrm{C}}$ & 9 & Mass balance $\mathrm{e}^{\mathrm{d}}$ \\
\hline $\mathrm{Co}$ & 30 & $\mathrm{R} 11$ & $40-100$ & KW13, P13 \\
\hline $\mathrm{Ni}$ & 40 & $\mathrm{R} 11$ & $100-800$ & KW13, P13, WW17 \\
\hline $\mathrm{Cu}$ & 15 & R11 & $100-500$ & KW13, B15 \\
\hline $\mathrm{Zn}$ & 0.5 & Y15 & $2-5$ & KW13, P13 \\
\hline $\mathrm{Ge}$ & 200 & Y15 & $0-5$ & KW15 \\
\hline As & 50 & $\mathrm{R} 17$ & $1-1000$ & KP89, LA15 \\
\hline $\mathrm{Se}$ & 1000 & R09 & 1000-2000 & B 15 \\
\hline Mo & 50 & $\mathrm{R} 11$ & $10-1000$ & KW13, P13, LA15 \\
\hline $\mathrm{Ag}$ & 50 & W14 & $400-1000$ & KW13, P13, B17 \\
\hline $\mathrm{Cd}$ & 2 & $\mathrm{R} 18$ & $40-100$ & KW13 \\
\hline Sn & 50 & R18 & $10-100$ & P13, LA15, B17 \\
\hline $\mathrm{Sb}$ & 100 & $\mathrm{R} 17$ & $10-100$ & KW13, B15 \\
\hline $\mathrm{W}$ & 20 & $\mathrm{R} 11$ & $1-200$ & JD86, KP89, R97 \\
\hline $\mathrm{Pb}$ & 25 & WH10 & $5-200$ & KW13, P13, B15, B17 \\
\hline \multicolumn{5}{|c|}{ 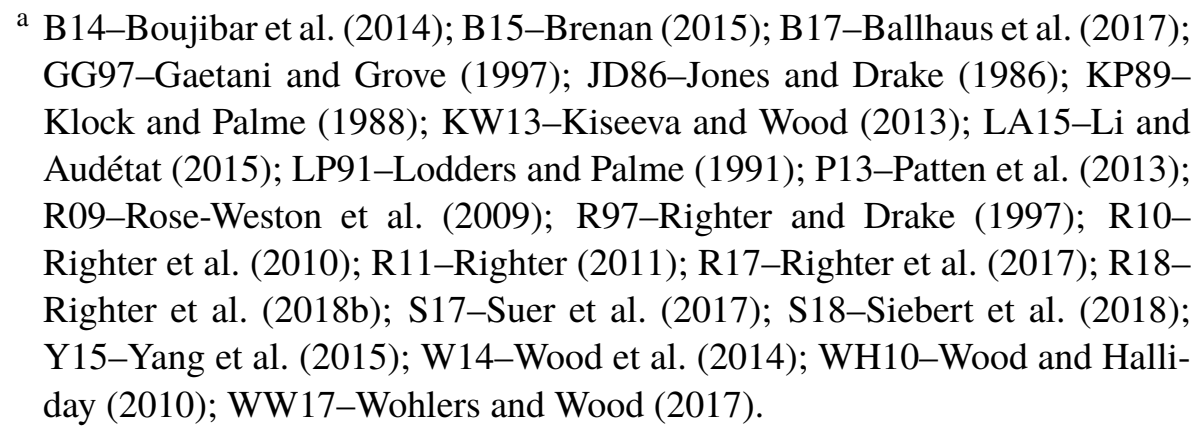 } \\
\hline \multicolumn{5}{|c|}{$\begin{array}{l}\text { b Assumed that all } S \text { in the post-impact Earth's mantle were subtracted by } \\
\text { the sulfide matte with a present-day mantle sulfide composition (Lorand and } \\
\text { Conquéré, 1983). }\end{array}$} \\
\hline \multicolumn{5}{|c|}{$\begin{array}{l}{ }^{c} \text { Based on mass balance between proto-Earth, Mars-like impactor, post- } \\
\text { impact sulfide matte and present-day silicate Earth. }\end{array}$} \\
\hline \multicolumn{5}{|c|}{$\begin{array}{l}\text { d Based on mass balance between post-impact Earth's mantle and sulfide matte } \\
\text { with a present-day mantle sulfide composition (Lorand and Conquéré, 1983). }\end{array}$} \\
\hline
\end{tabular}


Table A.2: Composition of the bulk proto-Earth predicted by the Mars-like Moon-forming impactor model. Concentrations are in ppm $(\mu \mathrm{g} / \mathrm{g})$, otherwise noted.

\begin{tabular}{|c|c|c|c|}
\hline Element & Bulk proto-Earth & Element & Bulk proto-Earth \\
\hline $\mathrm{Li}$ & 1.1 & $\mathrm{Nb}$ & 0.4 \\
\hline $\mathrm{Be}$ & 0.05 & Mo & 2 \\
\hline $\mathrm{B}$ & 0.1 & $\mathrm{Ag}$ & 0.04 \\
\hline $\mathrm{O}(\%)$ & 29.0 & Sn & 0.2 \\
\hline $\mathrm{F}$ & 9 & $\mathrm{Sb}$ & 0.04 \\
\hline $\mathrm{Na}$ & 1600 & Cs & 0.03 \\
\hline $\operatorname{Mg}(\%)$ & 15.4 & $\mathrm{Ba}$ & 4.5 \\
\hline $\mathrm{Al}(\%)$ & 1.59 & $\mathrm{La}$ & 0.44 \\
\hline $\mathrm{Si}(\%)$ & 16.0 & $\mathrm{Ce}$ & 1.1 \\
\hline $\mathrm{P}$ & 660 & $\operatorname{Pr}$ & 0.17 \\
\hline S & 5200 & $\mathrm{Nd}$ & 0.84 \\
\hline $\mathrm{K}$ & 180 & $\mathrm{Sm}$ & 0.27 \\
\hline $\mathrm{Ca}(\%)$ & 1.90 & $\mathrm{Eu}$ & 0.10 \\
\hline $\mathrm{Sc}$ & 11 & $\mathrm{Gd}$ & 0.37 \\
\hline $\mathrm{Ti}$ & 810 & $\mathrm{~Tb}$ & 0.07 \\
\hline $\mathrm{V}$ & 110 & Dy & 0.46 \\
\hline $\mathrm{Cr}$ & 4680 & Ho & 0.10 \\
\hline Mn & 920 & Er & 0.30 \\
\hline $\mathrm{Fe}(\%)$ & 32.9 & $\mathrm{Tm}$ & 0.046 \\
\hline $\mathrm{Co}$ & 900 & $\mathrm{Yb}$ & 0.30 \\
\hline $\mathrm{Ni}(\%)$ & 1.87 & $\mathrm{Lu}$ & 0.046 \\
\hline $\mathrm{Cu}$ & 60 & $\mathrm{Hf}$ & 0.19 \\
\hline $\mathrm{Zn}$ & 30 & $\mathrm{Ta}$ & 0.025 \\
\hline As & 1.7 & W & 0.17 \\
\hline $\mathrm{Rb}$ & 0.3 & $\mathrm{~Pb}$ & 0.17 \\
\hline $\mathrm{Sr}$ & 13 & $\mathrm{Th}$ & 0.055 \\
\hline $\mathrm{Y}$ & 2.9 & $\mathrm{U}$ & 0.015 \\
\hline $\mathrm{Zr}$ & 7.1 & & \\
\hline
\end{tabular}



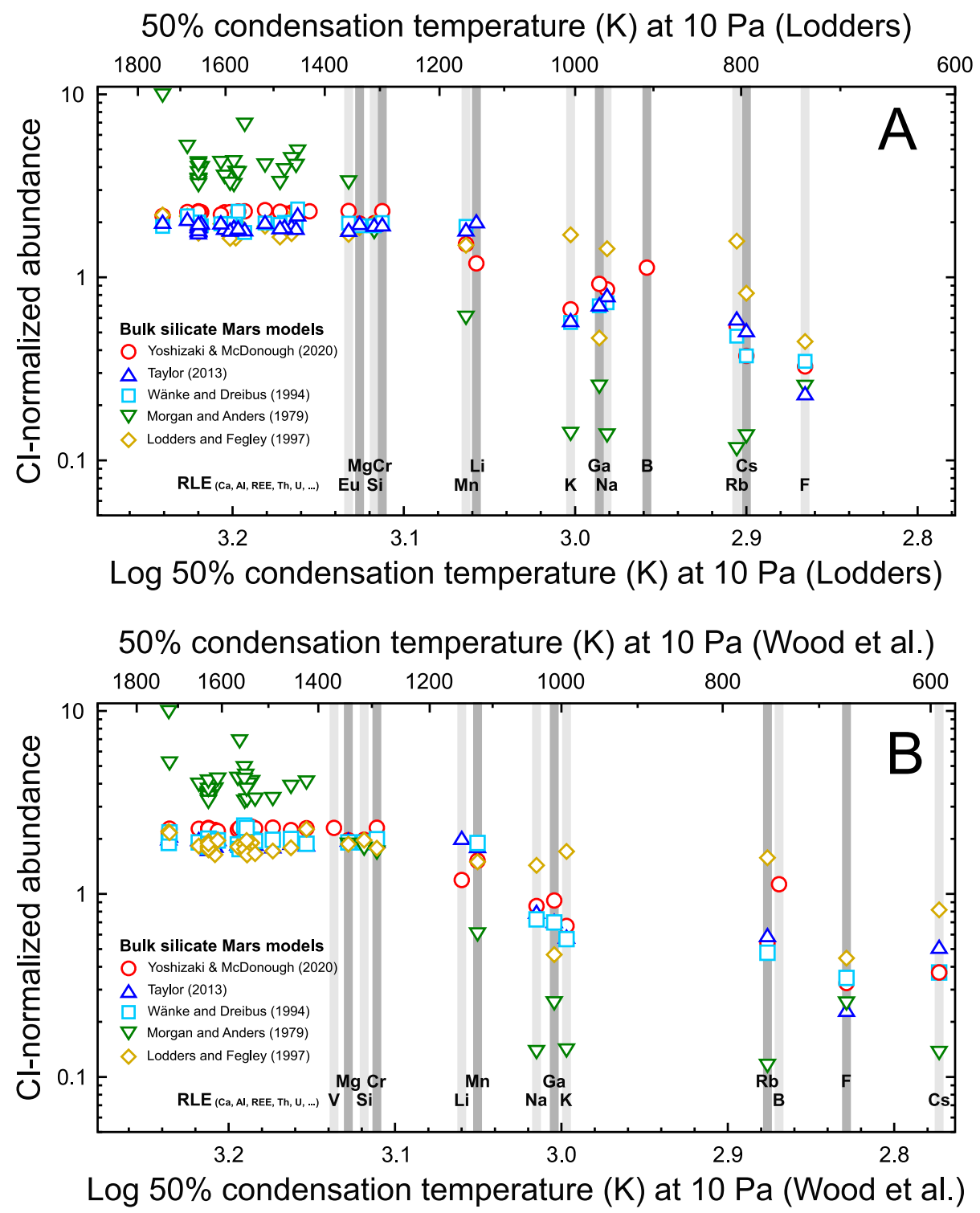

Fig. A.1: Comparison of lithophile element abundances in models of the bulk silicate Mars composition (Yoshizaki and McDonough, 2020; Taylor, 2013, Wänke and Dreibus, 1994; Morgan and Anders, 1979; Lodders and Fegley, 1997). Condensation temperatures of elements are from Lodders (2003) (A) and Wood et al. (2019) (B), and CI composition is from Lodders (2020). RLE-refractory lithophile elements. 


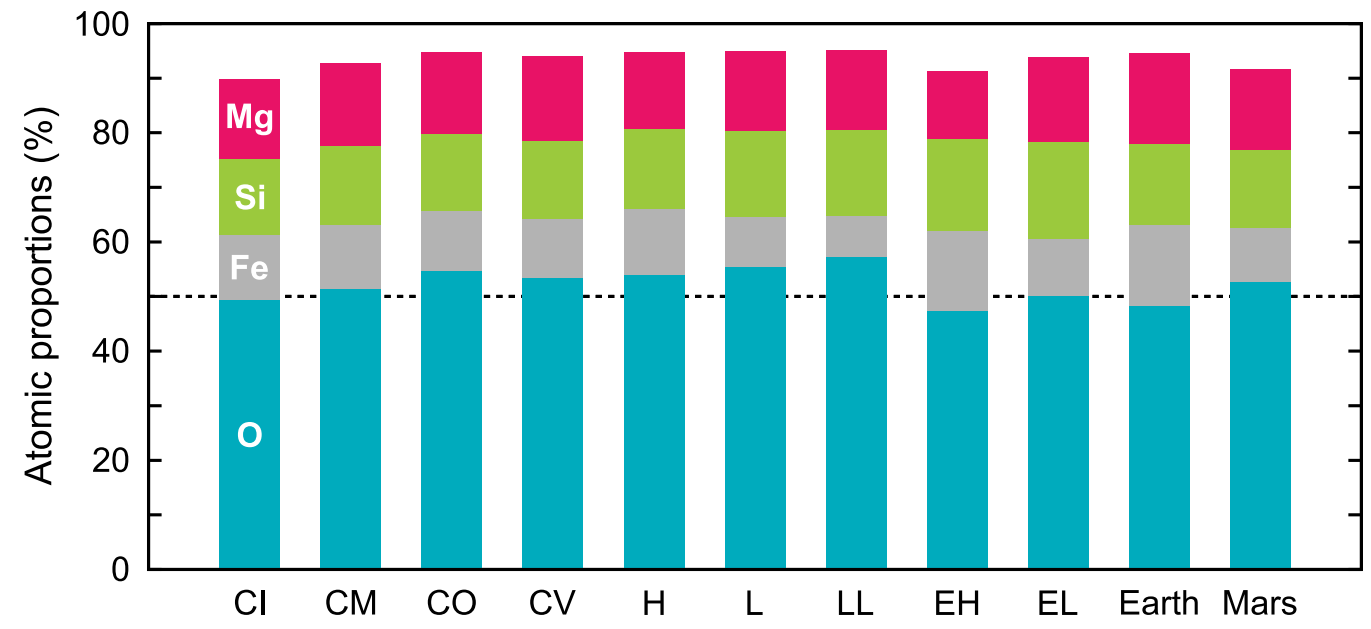

Fig. A.2: Bulk major element compositions by atomic proportions for Earth (McDonough, 2014), Mars (Yoshizaki and McDonough, 2020) and chondritic meteorites (Alexander, 2019ab). 

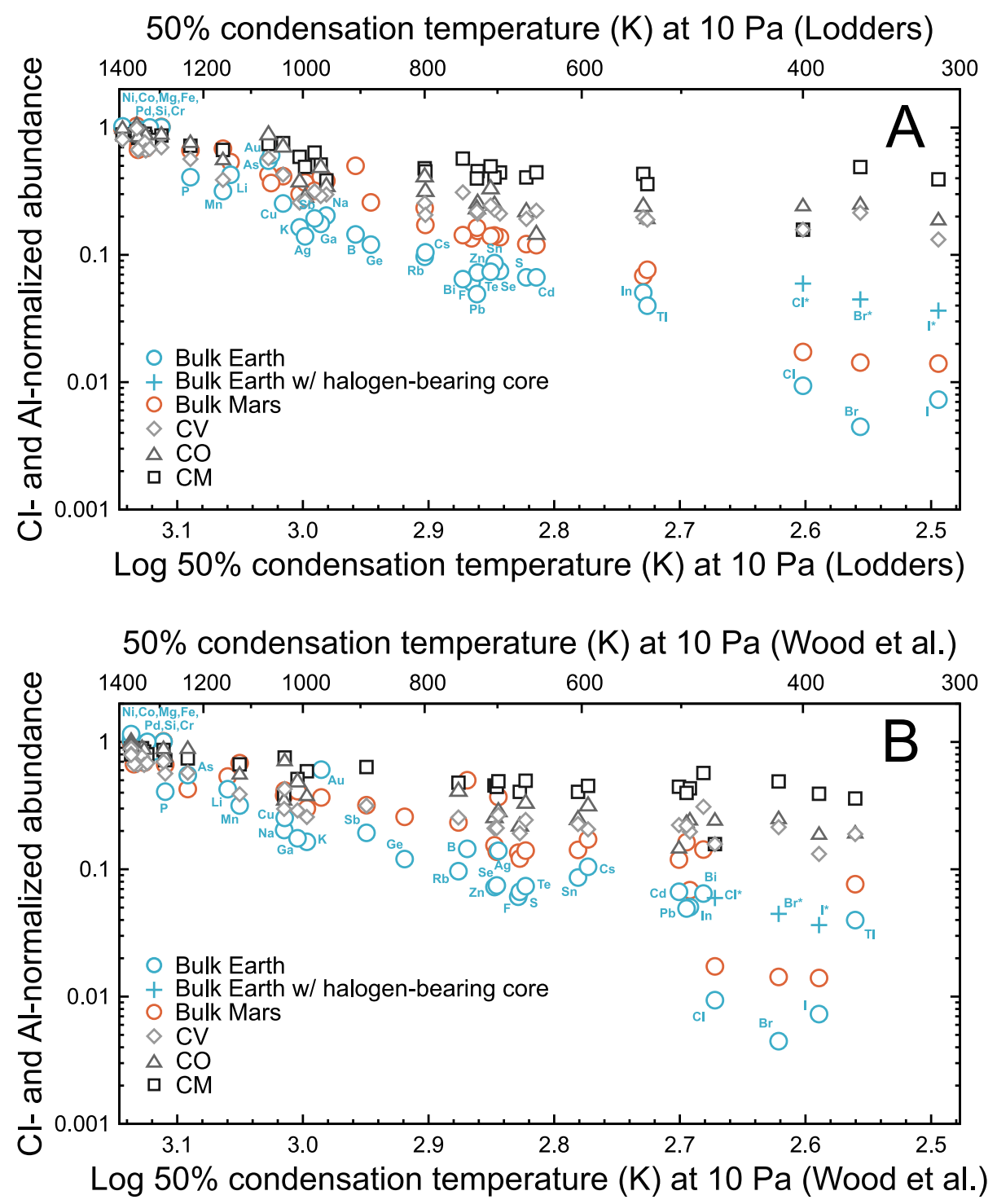

Fig. A.3: Abundances of moderately volatile and volatile elements in Earth (this study; McDonough. 2014), Mars (this study; Yoshizaki and McDonough, 2020) and chondritic meteorites (Alexander. 2019a). The bulk Earth model with a halogen-bearing core (McDonough, 2014) is also shown. The $\mathrm{x}$ axis corresponds to the $50 \%$ condensation temperature of elements at $10 \mathrm{~Pa}$ from Lodders (2003) and Fegley and Lodders (2018) (for halogens) in the top panel, and from Wood et al. (2019) in the bottom. 

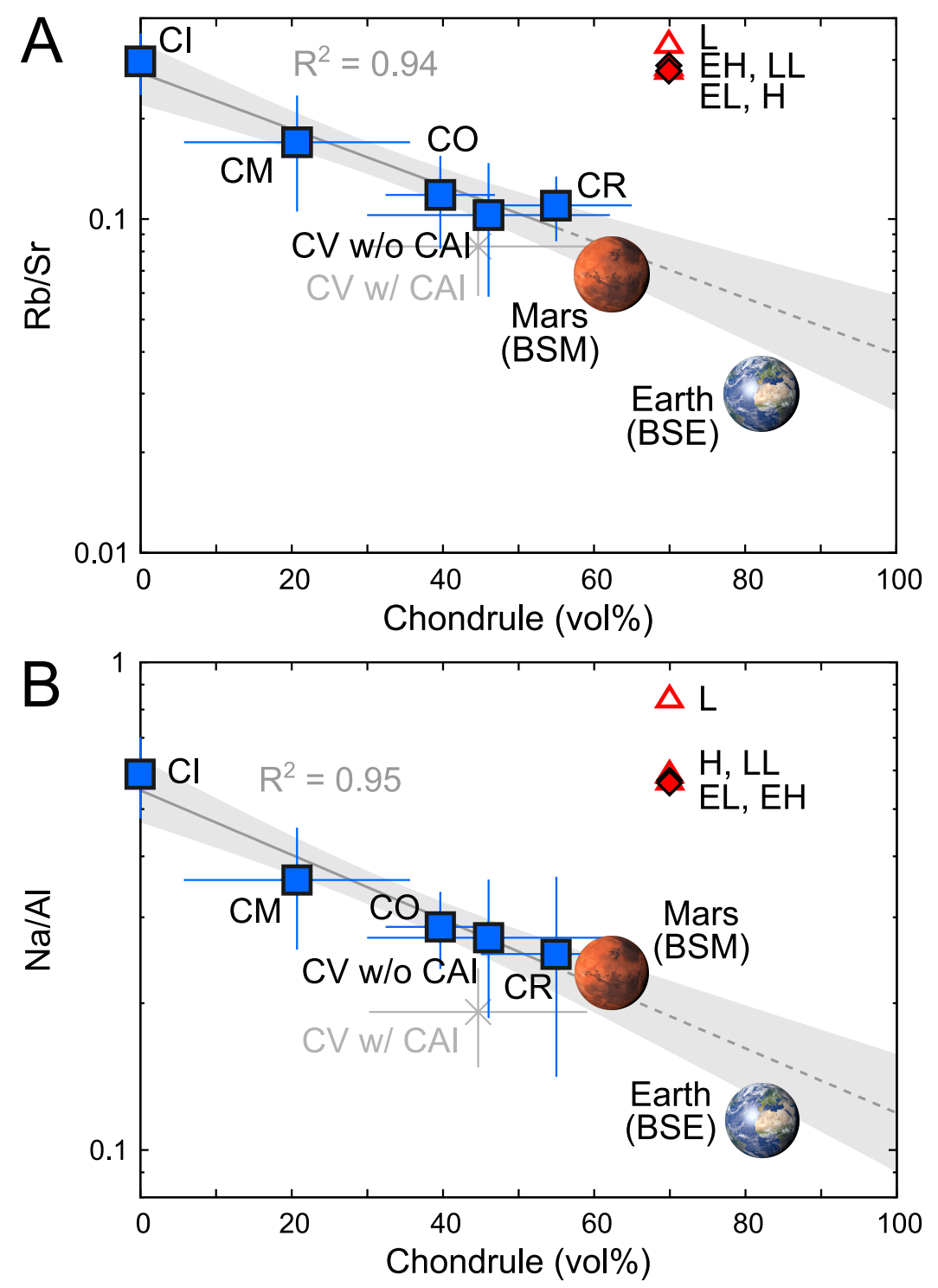

Fig. A.4: Abundance of chondrules (vol\%) vs $\mathrm{Rb} / \mathrm{Sr}$ and $\mathrm{Na} / \mathrm{Al}$ of chondrites and terrestrial planets. Compositions of chondrites, Earth, and Mars are from Alexander (2019a|b), McDonough (2014), and Yoshizaki and McDonough (2020), respectively. The abundances of chondrules in chondrites are taken from Scott and Krot (2014). The amounts of chondrules in Earth and Mars are estimated based on their K/Th values (Fig. 11). 

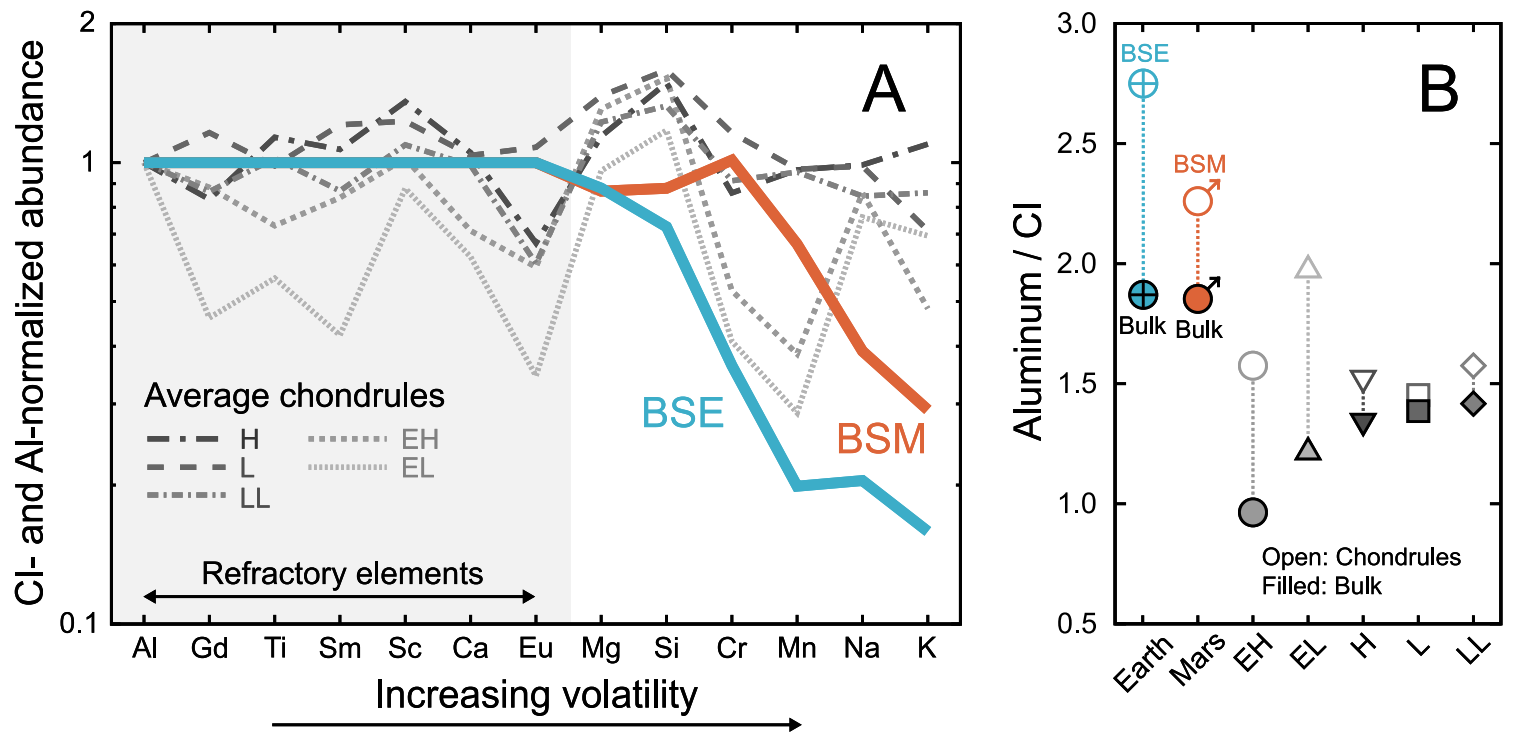

Fig. A.5: Lithophile element composition of Earth, Mars and non-carbonaceous chondrites and their components. (A) Lithophile element abundance in the bulk silicate Mars (BSM), bulk silicate Earth (BSE) and bulk chondrules from non-carbonaceous chondrites. Elemental abundances are normalized to CI chondrite composition and Al. Elements are arranged by their 50\% nebular condensation temperatures. Note that $\mathrm{Cr}$ and $\mathrm{Mn}$ depletion in the BSE and enstatite chondrite chondrules reflects less lithophile behavior of these elements under reduced conditions. (B) CI-normalized Al abundances in the BSE, BSM, bulk planets, bulk chondrules and bulk chondrites. Chemical composition of chondrules is from Hezel et al. (2018), Yoshizaki et al. (2018) and MetBase (1994-2017). Other data sources are as in Fig. 1 . 


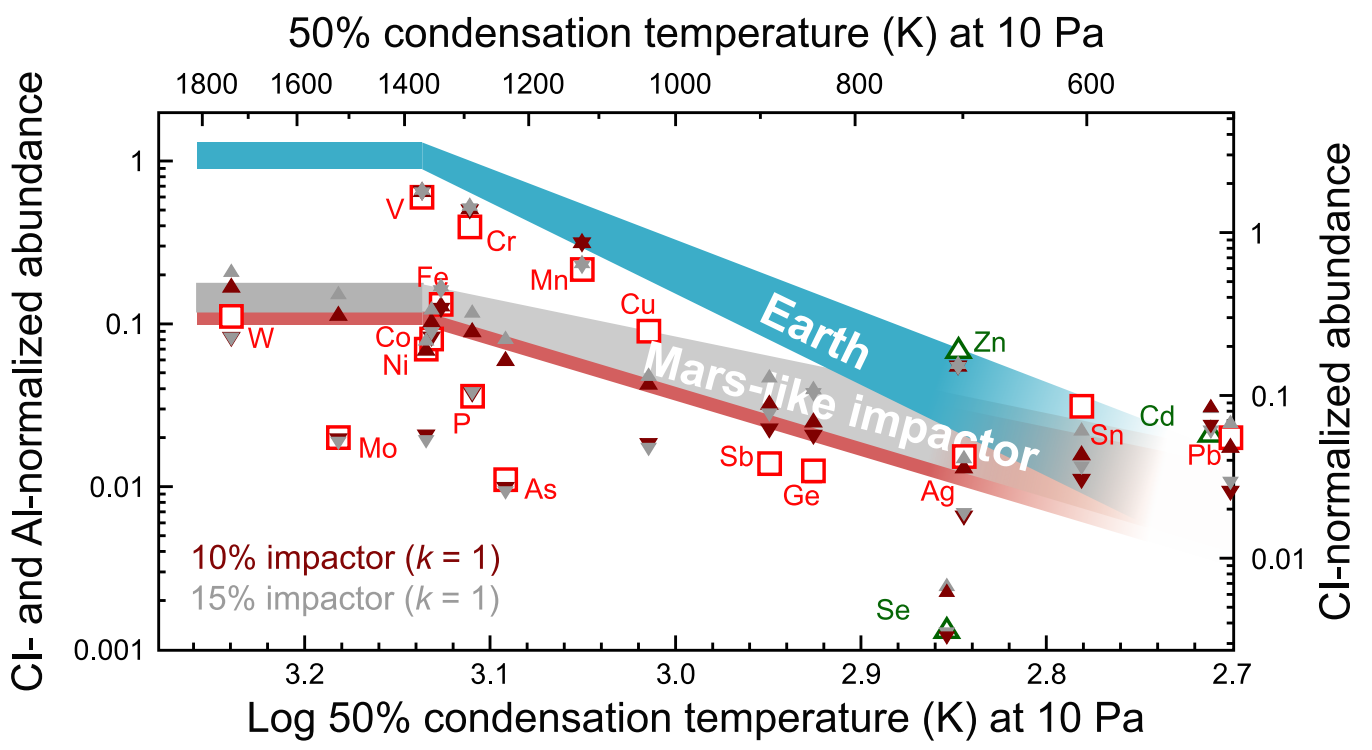

Fig. A.6: Same as Fig. 13, but different mass fractions of the impactor (10\% and 15\%). 


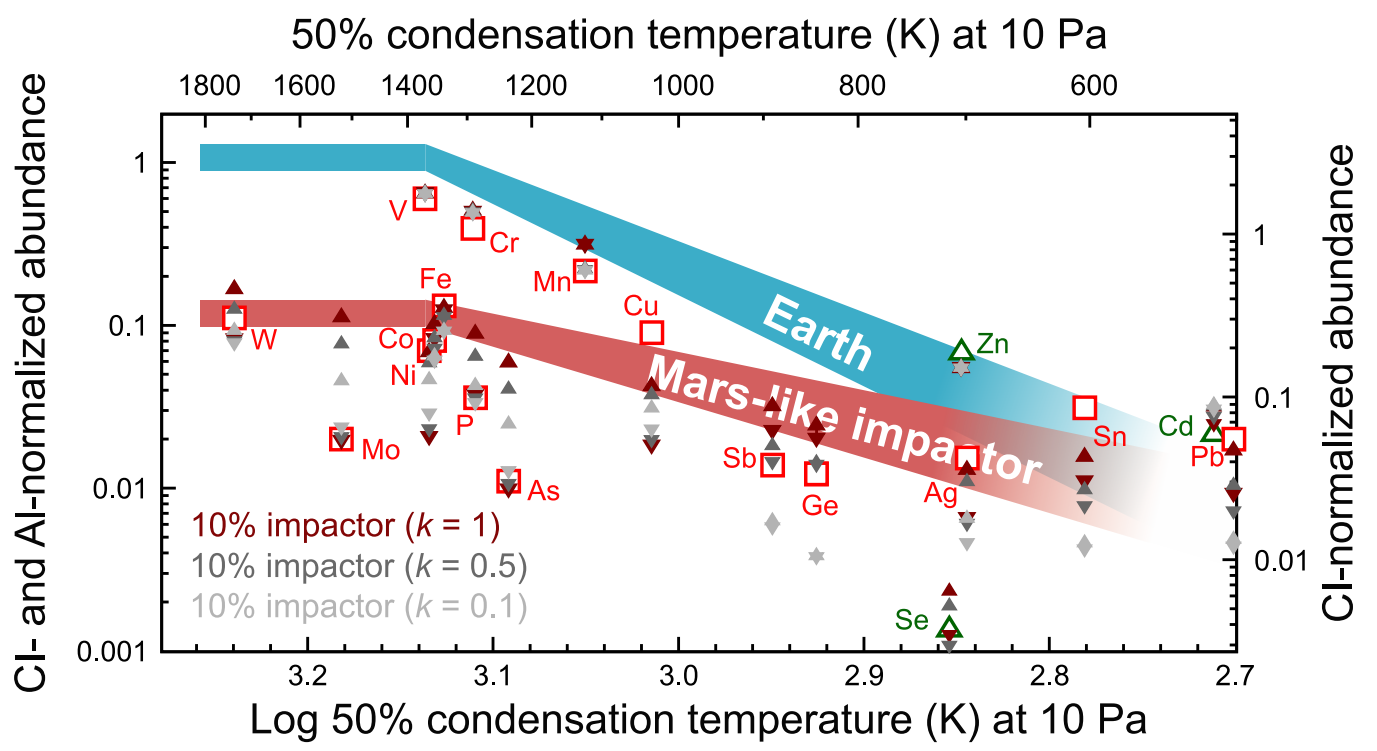

Fig. A.7: Same as Fig. 13, but different equilibrium factors $(k)$ between the impactor core and the proto-Earth's mantle. 


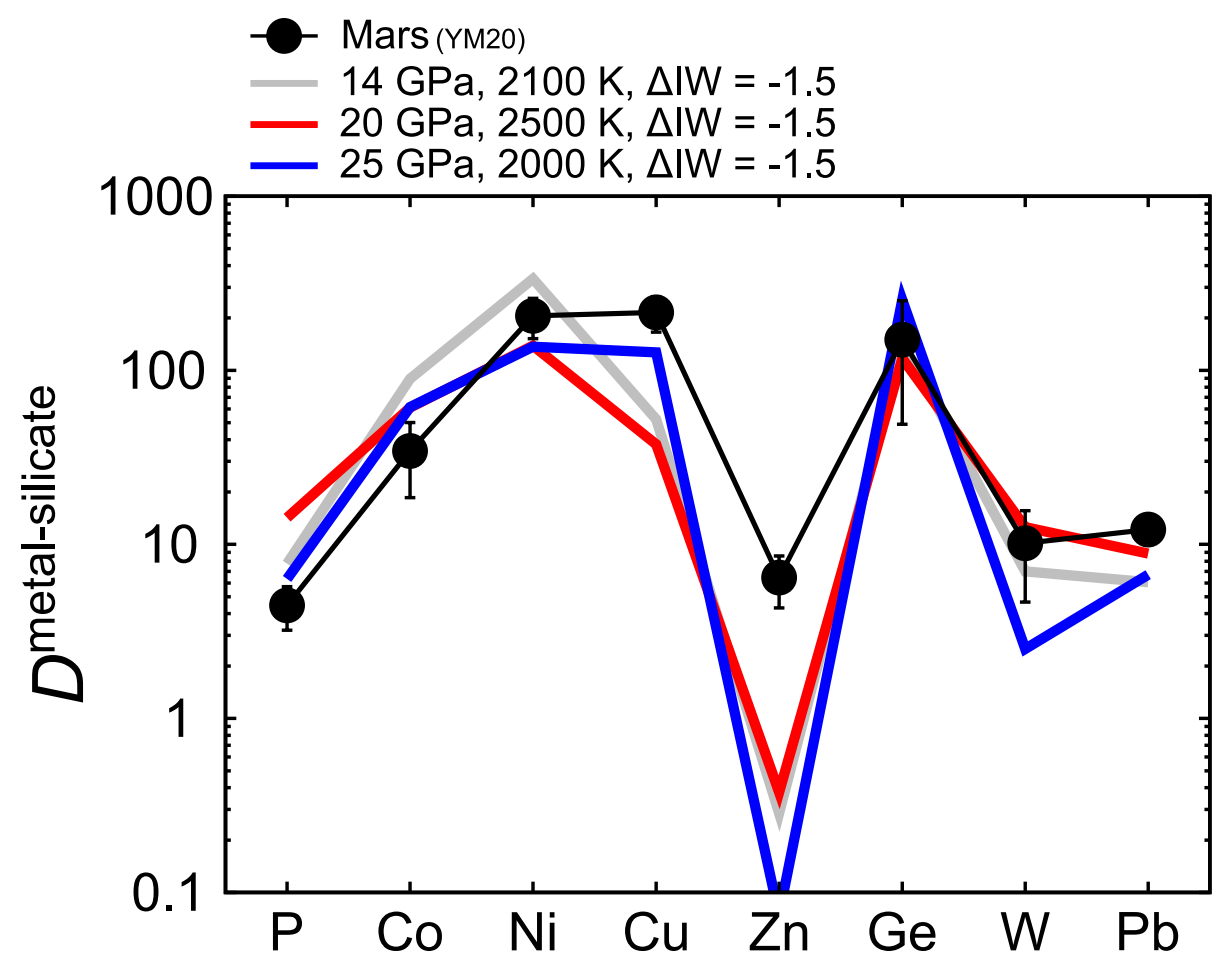

Fig. A.8: Core/mantle enrichment factors of siderophile elements in Mars (Yoshizaki and McDonough, 2020) and metal-silicate distribution coefficients of these elements modeled at $14 \mathrm{GPa}$ and $2100 \mathrm{~K}$ (gray), $20 \mathrm{GPa}$ and $2500 \mathrm{~K}$ (red), and $25 \mathrm{GPa}, 2000 \mathrm{~K}$ (blue) following Righter and Chabot (2011) and Yang et al. (2015). Redox conditions are fixed at $\log f_{\mathrm{O}_{2}}=\mathrm{IW}-1.5$. Error bars on the Mars' values reflect 1 standard deviations in the Martian bulk silicate composition model (Yoshizaki and McDonough, 2020). 


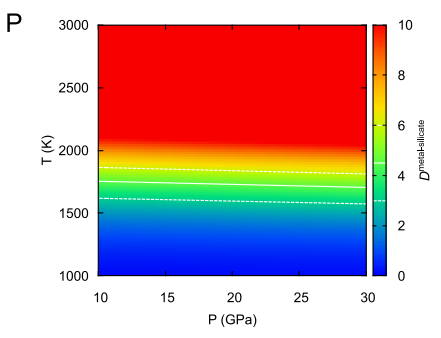

$\mathrm{Ni}$
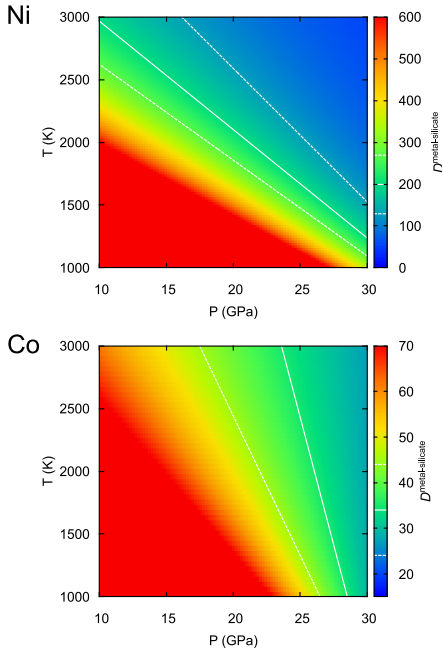

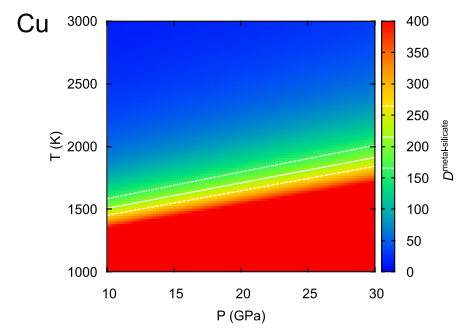

$\mathrm{Zn}$

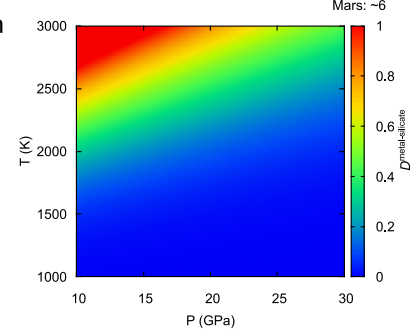

$\mathrm{Ge}$

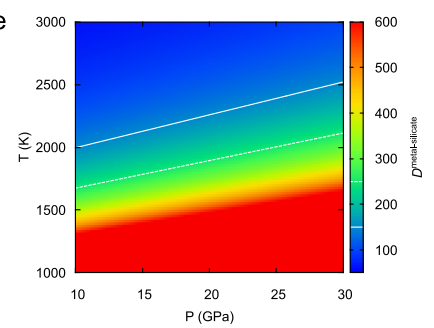

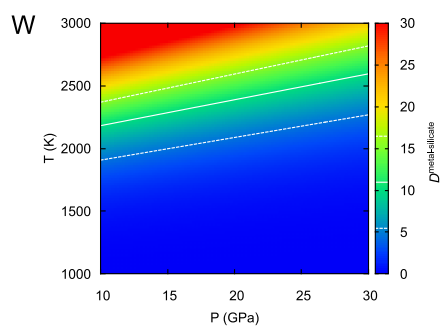

$\mathrm{Pb}$

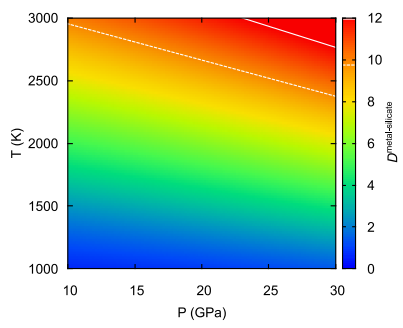

Fig. A.9: Metal-silicate partitioning coefficients of siderophile elements calculated for the Martian core model of Yoshizaki and McDonough (2020). Redox conditions are fixed at $\log f_{\mathrm{O}_{2}}=\mathrm{IW}-$ 1.5. White solid and broken lines show $P-T$ conditions that are consistent with the core-mantle distribution of these elements in Mars within 1 standard deviations (Yoshizaki and McDonough. 2020). 
(A) $\mathrm{P}=15 \mathrm{GPa}, \Delta \mathrm{IW}=-1.5$

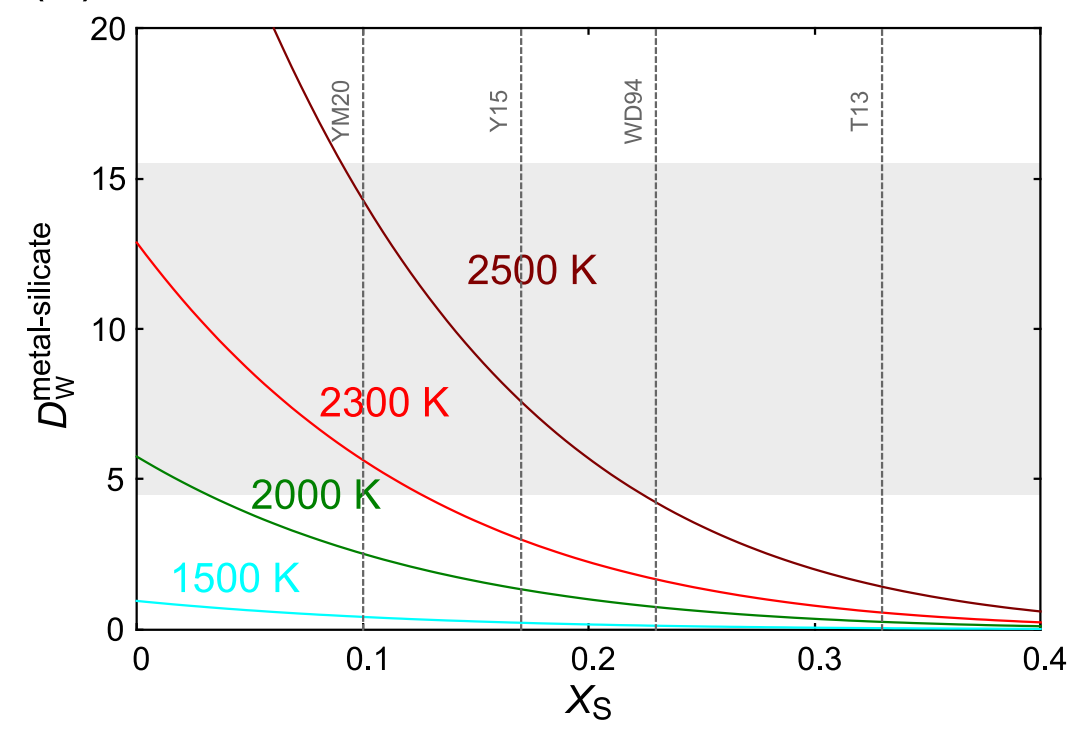

(B) $\mathrm{P}=20 \mathrm{GPa}, \Delta \mathrm{IW}=-1.5$

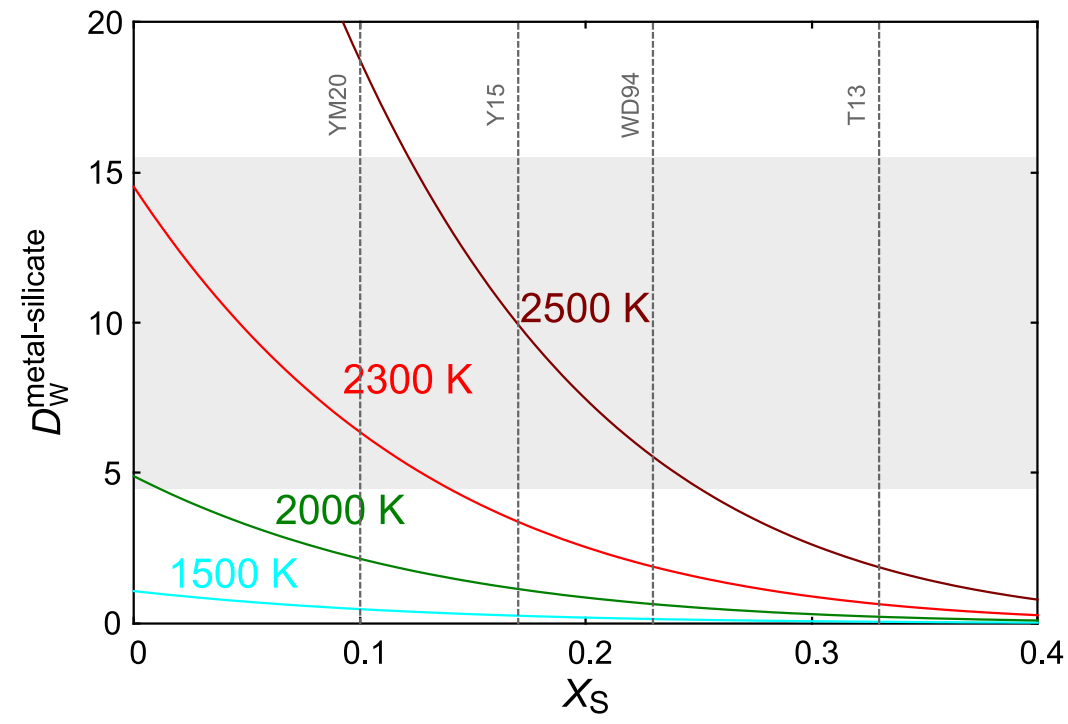

Fig. A.10: Metal-silicate partitioning coefficients of W at (A) $15 \mathrm{GPa}$ and (B) $20 \mathrm{GPa}$ as a function of mole fraction of $S$ in the metal $\left(X_{S}\right)$, calculated using parameters from Righter (2011). The redox condition is fixed at $\Delta \mathrm{IW}=-1.5$. The gray band shows the core-mantle partitioning coefficients ( \pm 1 standard deviation) of $\mathrm{W}$ based on the Mars model of Yoshizaki and McDonough (2020). The vertical dashed gray lines show the core models of Yoshizaki and McDonough (2020) (YM20), Yang et al. (2015) (Y15), Wänke and Dreibus (1994) (WD94), and Taylor (2013) (T13). 
(A) Yoshizaki \& McDonough $\left(X_{S}=0.10, X_{C}=0\right)$

(B) Wänke \& Dreibus $\left(X_{S}=0.23, X_{C}=0\right)$
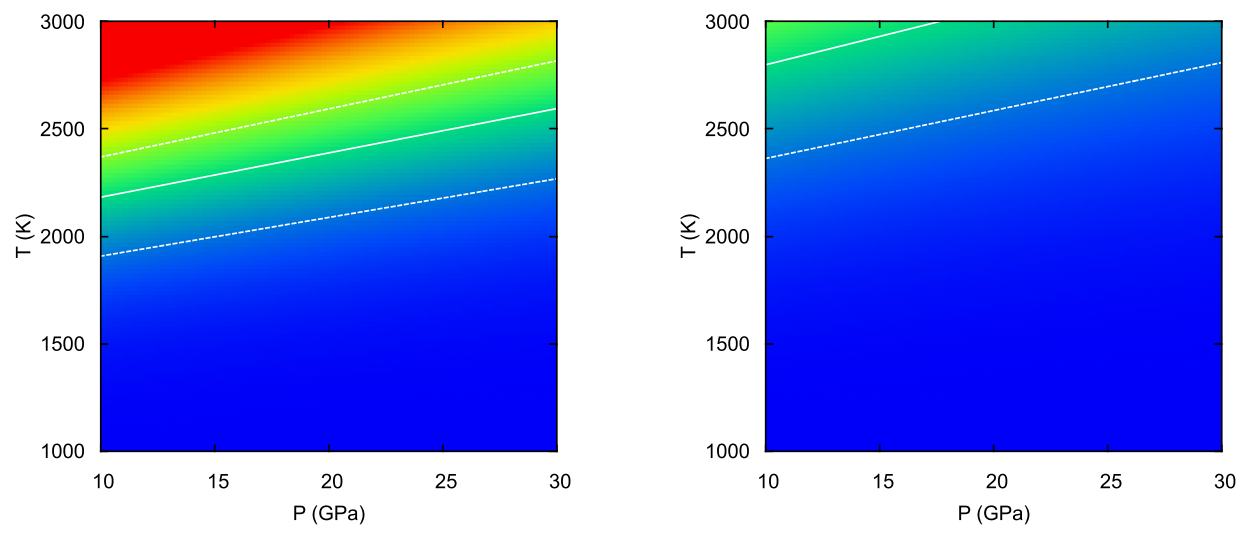

(C) Taylor $\left(X_{S}=0.33, X_{C}=0\right)$

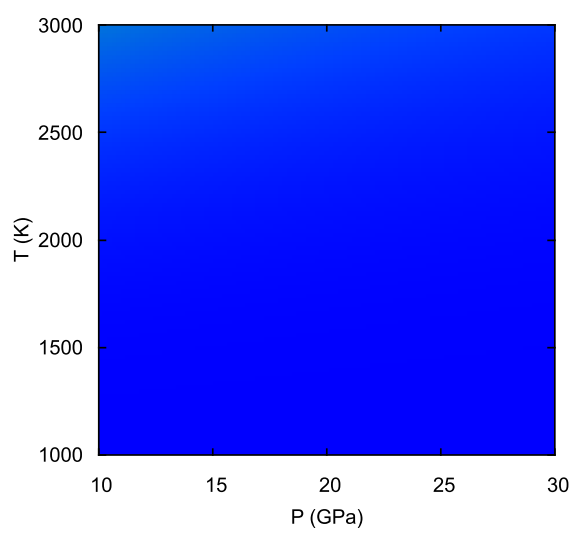

(D) Yang et al. $\left(X_{S}=0.17, X_{C}=0.10\right)$

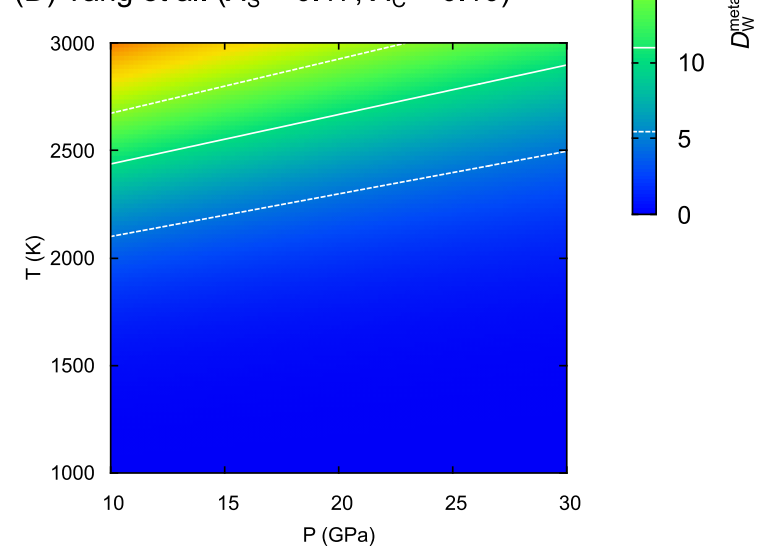

Fig. A.11: Metal-silicate partitioning coefficients of $\mathrm{W}$ calculated for the Martian compositional models of (A) Yoshizaki and McDonough (2020), (B) Wänke and Dreibus (1994), (C) Taylor (2013), and (D) Yang et al. (2015). White solid and broken lines show P-T conditions that are consistent with the core-mantle distribution of $\mathrm{W}$ in Mars within 1 standard deviations (Yoshizaki and McDonough, 2020). 


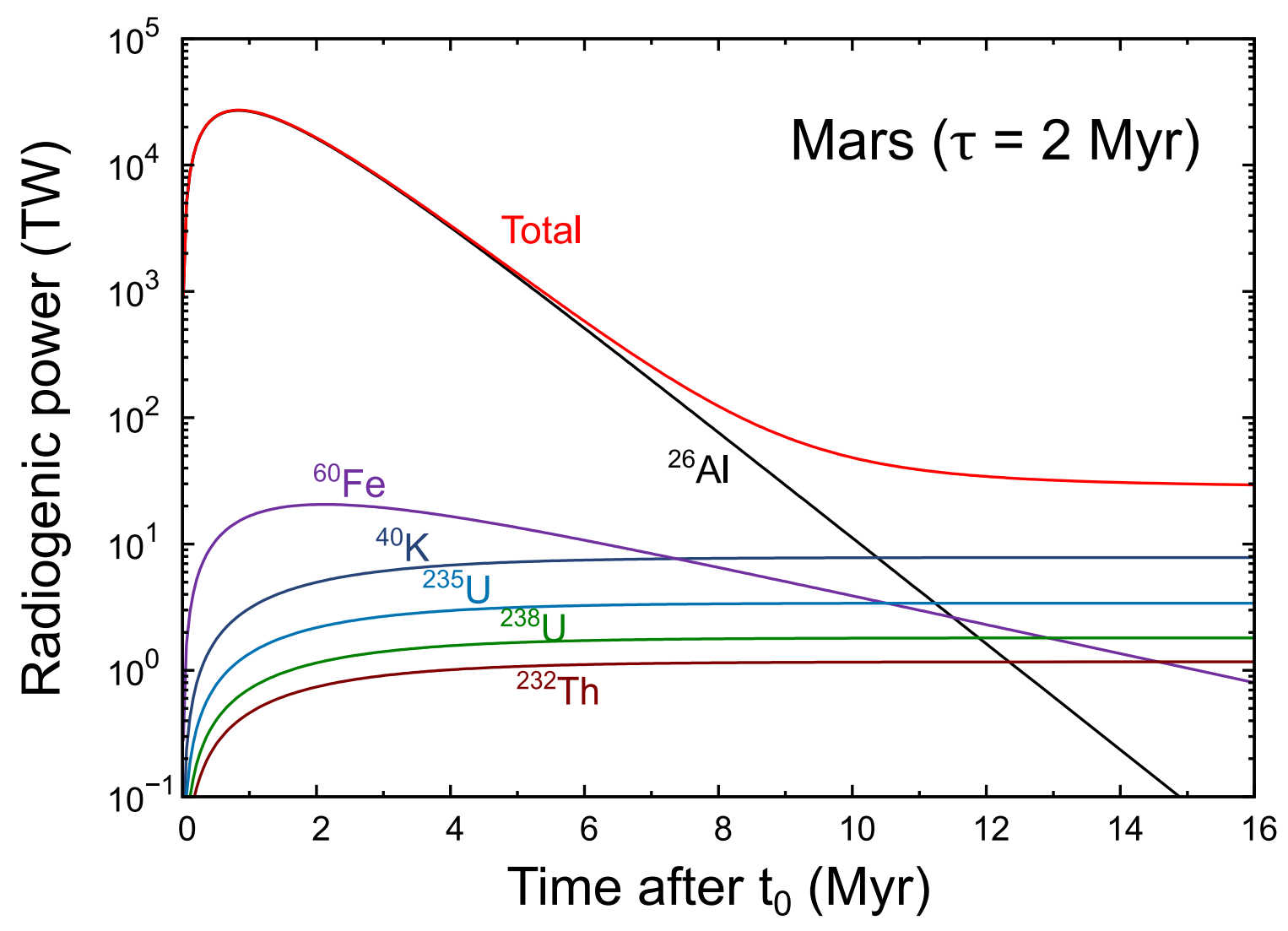

Fig. A.12: Relative contributions of radiogenic heat to Mars during accretion over the first $16 \mathrm{Myr}$ of the solar system history. The compositional model for the bulk Mars is from Yoshizaki and McDonough (2020). The $\tau_{\text {Mars }}^{\text {accretion }}$ age of 2 Myr is adopted in the modeling (Dauphas and Pourmand, 2011). 


\section{Supplementary references}

Albarede, F., 2009. Volatile accretion history of the terrestrial planets and dynamic implications. Nature 461, 1227-1233. doi:10.1038/nature08477.

Alexander, C.M.O'D., 2019a. Quantitative models for the elemental and isotopic fractionations in chondrites: The carbonaceous chondrites. Geochimica et Cosmochimica Acta 254, 277-309. doi: $10.1016 /$ j.gca.2019.02.008

Alexander, C.M.O'D., 2019b. Quantitative models for the elemental and isotopic fractionations in the chondrites: The non-carbonaceous chondrites. Geochimica et Cosmochimica Acta 254, 246-276. doi:10.1016/j.gca.2019.01.026.

Alexander, C.M.O’D., Bowden, R., Fogel, M.L., Howard, K.T., Herd, C.D.K., Nittler, L.R., 2012. The provenances of asteroids, and their contributions to the volatile inventories of the terrestrial planets. Science 337, 721-723. doi:10.1126/science.1223474.

Armytage, R.M., Jephcoat, A.P., Bouhifd, M.A., Porcelli, D., 2013. Metal-silicate partitioning of iodine at high pressures and temperatures: Implications for the Earth's core and ${ }^{129 *}$ Xe budgets. Earth and Planetary Science Letters 373, 140-149. doi 10.1016/j.epsl.2013.04.031

Ballhaus, C., Fonseca, R.O.C., Münker, C., Rohrbach, A., Nagel, T., Speelmanns, I.M., Helmy, H.M., Zirner, A., Vogel, A.K., Heuser, A., 2017. The great sulfur depletion of Earth's mantle is not a signature of mantle-core equilibration. Contributions to Mineralogy and Petrology 172, 68. doi:10.1007/s00410-017-1388-3

Barrat, J.A., Dauphas, N., Gillet, P., Bollinger, C., Etoubleau, J., Bischoff, A., Yamaguchi, A., 2016. Evidence from Tm anomalies for non-CI refractory lithophile element proportions in terrestrial planets and achondrites. Geochimica et Cosmochimica Acta 176, 1-17. doi:10.1016/j.gca. 2015.12.004.

Boujibar, A., Andrault, D., Bouhifd, M.A., Bolfan-Casanova, N., Devidal, J.L., Trcera, N., 2014. Metal-silicate partitioning of sulphur, new experimental and thermodynamic constraints on planetary accretion. Earth and Planetary Science Letters 391, 42-54. doi:10.1016/j .epsl. 2014. 01.021

Braukmüller, N., Wombacher, F., Funk, C., Münker, C., 2019. Earth's volatile element depletion pattern inherited from a carbonaceous chondrite-like source. Nature Geoscience 12, 564-568. doi:10.1038/s41561-019-0375-x

Braukmüller, N., Wombacher, F., Hezel, D.C., Escoube, R., Münker, C., 2018. The chemical composition of carbonaceous chondrites: Implications for volatile element depletion, complementarity and alteration. Geochimica et Cosmochimica Acta 239, 17-48. doi:10.1016/j.gca. 2018. 07.023 
Brenan, J.M., 2015. Se-Te fractionation by sulfide-silicate melt partitioning: implications for the composition of mantle-derived magmas and their melting residues. Earth and Planetary Science Letters 422, 45-57. doi:10.1016/j.epsl.2015.04.011

Budde, G., Burkhardt, C., Kleine, T., 2019. Molybdenum isotopic evidence for the late accretion of outer Solar System material to Earth. Nature Astronomy 3, 736-741. doi $10.1038 /$ s41550-019-0779-y

Cassen, P., 1996. Models for the fractionation of moderately volatile elements in the solar nebula. Meteoritics \& Planetary Science 31, 793-806. doi:10.1111/j.1945-5100.1996.tb02114.x

Cassen, P., 2001. Nebular thermal evolution and the properties of primitive planetary materials. Meteoritics \& Planetary Science 36, 671-700. doi 10.1111/j.1945-5100.2001.tb01908.x

Chase, Jr., M.W., 1998. NIST-JANAF Thermochemical Tables, 4th Edition. doi:10.18434/ T42S31

Chou, C.L., 1978. Fractionation of siderophile elements in the Earth's upper mantle, in: Lunar and Planetary Science Conference Proceedings, pp. 219-230.

Clay, P.L., Burgess, R., Busemann, H., Ruzié-Hamilton, L., Joachim, B., Day, J.M.D., Ballentine, C.J., 2017. Halogens in chondritic meteorites and terrestrial accretion. Nature 551, 614-618. doi:10.1038/nature24625.

Dahl, T.W., Stevenson, D.J., 2010. Turbulent mixing of metal and silicate during planet accretion-And interpretation of the Hf-W chronometer. Earth and Planetary Science Letters 295, 177-186. doi:10.1016/j.epsl.2010.03.038

Dauphas, N., Pourmand, A., 2011. Hf-W-Th evidence for rapid growth of Mars and its status as a planetary embryo. Nature 473, 489-492. doi:10.1038/nature10077.

Dauphas, N., Pourmand, A., 2015. Thulium anomalies and rare earth element patterns in meteorites and Earth: Nebular fractionation and the nugget effect. Geochimica et Cosmochimica Acta 163, 234-261. doi:10.1016/j.gca.2015.03.037

Deguen, R., Landeau, M., Olson, P., 2014. Turbulent metal-silicate mixing, fragmentation, and equilibration in magma oceans. Earth and Planetary Science Letters 391, 274-287. doi:10. $1016 /$ j.epsl.2014.02.007.

Desch, S.J., Kalyaan, A., Alexander, C.M.O’D., 2018. The effect of Jupiter's formation on the distribution of refractory elements and inclusions in meteorites. The Astrophysical Journal Supplement Series 238, 11. doi:10.3847/1538-4365/aad95f

Dreibus, G., Palme, H., 1996. Cosmochemical constraints on the sulfur content in the Earth's core. Geochimica et Cosmochimica Acta 60, 1125-1130. doi:10.1016/0016-7037(96)00028-2. 
Dreibus, G., Spettel, B., Wänke, H., 1979. Halogens in meteorites and their primordial abundances. Physics and Chemistry of the Earth 11,33-38. doi:10.1016/0079-1946 (79)90005-3

Fegley, Jr., B., Lodders, K., 2018. Volatile element chemistry in the solar nebula - revisited 40 years later, in: Nuclei in the Cosmos XV, p. 107.

Fegley, Jr., B., Lodders, K., Jacobsen, N.S., 2020. Volatile element chemistry during accretion of the Earth. Geochemistry 80, 125594. doi:10.1016/j.chemer.2019.125594

Fischer-Gödde, M., Elfers, B.M., Münker, C., Szilas, K., Maier, W.D., Messling, N., Morishita, T., Van Kranendonk, M., Smithies, H., 2020. Ruthenium isotope vestige of Earth's pre-late-veneer mantle preserved in Archaean rocks. Nature 579, 240-244. doi:10.1038/s41586-020-2069-3

Floss, C., El Goresy, A., Zinner, E., Kransel, G., Rammensee, W., Palme, H., 1996. Elemental and isotopic fractionations produced through evaporation of the Allende CV chondrilte: Implications for the origin of HAL-type hibonite inclusions. Geochimica et Cosmochimica Acta 60, 19751997. doi:10.1016/0016-7037(96)00068-3.

Gaetani, G.A., Grove, T.L., 1997. Partitioning of moderately siderophile elements among olivine, silicate melt, and sulfide melt: Constraints on core formation in the Earth and Mars. Geochimica et Cosmochimica Acta 61, 1829-1846. doi 10.1016/S0016-7037(97)00033-1.

Gaetani, G.A., Grove, T.L., 1999. Wetting of mantle olivine by sulfide melt: implications for Re/Os ratios in mantle peridotite and late-stage core formation. Earth and Planetary Science Letters 169, 147-163. doi:10.1016/S0012-821X(99)00062-X.

Gellissen, M., Holzheid, A., Kegler, P., Palme, H., 2019. Heating experiments relevant to the depletion of Na, K and $\mathrm{Mn}$ in the Earth and other planetary bodies. Geochemistry 79, 125540. doi: $10.1016 /$ j.chemer.2019.125540.

Herzog, G.F., Moynier, F., Albarède, F., Berezhnoy, A.A., 2009. Isotopic and elemental abundances of copper and zinc in lunar samples, Zagami, Pele's hairs, and a terrestrial basalt. Geochimica et Cosmochimica Acta 73, 5884-5904. doi:10.1016/j.gca.2009.05.067.

Hezel, D.C., Harak, M., Libourel, G., 2018. What we know about elemental bulk chondrule and matrix compositions: Presenting the ChondriteDB Database. Chemie der Erde-Geochemistry 78, 1-14. doi:10.1016/j.chemer.2017.05.003.

Hezel, D.C., Russell, S.S., Ross, A.J., Kearsley, A.T., 2008. Modal abundances of CAIs: Implications for bulk chondrite element abundances and fractionations. Meteoritics \& Planetary Science 43, 1879-1894. doi:10.1111/j.1945-5100.2008.tb00649.x.

Humayun, M., Clayton, R.N., 1995. Potassium isotope cosmochemistry: Genetic implications of volatile element depletion. Geochimica et Cosmochimica Acta 59, 2131-2148. doi:10.1016/ 0016-7037 (95)00132-8 
Jackson, C.R., Bennett, N.R., Du, Z., Cottrell, E., Fei, Y., 2018. Early episodes of high-pressure core formation preserved in plume mantle. Nature 553, 491-495. doi:10.1038/nature25446.

Jacobsen, S.B., 2005. The Hf-W isotopic system and the origin of the Earth and Moon. Annual Review of Earth and Planetary Sciences 33, 531-570. doi:10.1146/annurev . earth.33.092203. 122614

Jaupart, C., Labrosse, S., Lucazeau, F., Mareschal, J.C., 2015. Temperatures, heat, and energy in the mantle of the earth, in: Schubert, G. (Ed.), Treatise on Geophysics (Second Edition). Elsevier, Oxford. volume 7, pp. 223-270. doi:10.1016/B978-0-444-53802-4.00126-3.

Jones, J.H., Drake, M.J., 1986. Geochemical constraints on core formation in the Earth. Nature 322, 221-228. doi:10.1038/322221a0.

Khan, A., Connolly, J.A.D., 2008. Constraining the composition and thermal state of Mars from inversion of geophysical data. Journal of Geophysical Research: Planets 113, E07003. doi:10. 1029/2007 JE002996.

Khan, A., Liebske, C., Rozel, A., Rivoldini, A., Nimmo, F., Connolly, J.A.D., Plesa, A.C., Giardini, D., 2018. A geophysical perspective on the bulk composition of Mars. Journal of Geophysical Research: Planets 123, 575-611. doi:10.1002/2017JE005371

Kimura, K., Lewis, R.S., Anders, E., 1974. Distribution of gold and rhenium between nickel-iron and silicate melts: implications for the abundance of siderophile elements on the Earth and Moon. Geochimica et Cosmochimica Acta 38, 683-701. doi 10.1016/0016-7037(74)90144-6.

Kiseeva, E.S., Wood, B.J., 2013. A simple model for chalcophile element partitioning between sulphide and silicate liquids with geochemical applications. Earth and Planetary Science Letters 383, 68-81. doi:10.1016/j.epsl.2013.09.034.

Kleine, T., Budde, G., Burkhardt, C., Kruijer, T.S., Worsham, E.A., Morbidelli, A., Nimmo, F., 2020. The Non-carbonaceous-Carbonaceous Meteorite Dichotomy. Space Science Review 216, 55. doi:10.1007/s11214-020-00675-w

Kleine, T., Touboul, M., Bourdon, B., Nimmo, F., Mezger, K., Palme, H., Jacobsen, S.B., Yin, Q.Z., Halliday, A.N., 2009. Hf-W chronology of the accretion and early evolution of asteroids and terrestrial planets. Geochimica et Cosmochimica Acta 73, 5150-5188. doi:10.1016/j. gca.2008.11.047.

Klock, W., Palme, H., 1988. Partitioning of siderophile and chalcophile elements between sulfide, olivine, and glass in a naturally reduced basalt from Disko Island, Greenland, in: Proceedings of Lunar and Planetary Science Conference, pp. 471-483.

Kramers, J.D., 2003. Volatile element abundance patterns and an early liquid water ocean on Earth. Precambrian Research 126, 379-394. doi:10.1016/S0301-9268(03)00106-2. 
Li, Y., Audétat, A., 2015. Effects of temperature, silicate melt composition, and oxygen fugacity on the partitioning of $\mathrm{V}, \mathrm{Mn}, \mathrm{Co}, \mathrm{Ni}, \mathrm{Cu}, \mathrm{Zn}, \mathrm{As}, \mathrm{Mo}, \mathrm{Ag}, \mathrm{Sn}, \mathrm{Sb}, \mathrm{W}, \mathrm{Au}, \mathrm{Pb}$, and Bi between sulfide phases and silicate melt. Geochimica et Cosmochimica Acta 162, 25-45. doi 10.1016/ j.gca.2015.04.036

Lodders, K., 2003. Solar system abundances and condensation temperatures of the elements. The Astrophysical Journal 591, 1220-1247. doi $10.1086 / 375492$

Lodders, K., 2020. Solar Elemental Abundances, in: Read, P. (Ed.), Oxford Research Encyclopedia of Planetary Science. Oxford University Press, Oxford, pp. 1-68. doi:10.1093/acrefore/ 9780190647926.013 .145

Lodders, K., Fegley, Jr., B., 1997. An oxygen isotope model for the composition of Mars. Icarus 126, 373-394. doi:10.1006/icar.1996.5653

Lodders, K., Palme, H., 1991. On the chalcophile character of molybdenum: determination of sulfide/silicate partition coefficients of Mo and W. Earth and Planetary Science Letters 103, 311-324. doi:10.1016/0012-821X(91)90169-I

Lorand, J.P., Conquéré, F., 1983. Contribution à l'étude des sulfures dans les enclaves de lherzolite à spinelle des basaltes alcalins (Massif Central et Languedoc, France). Bulletin de Minéralogie 106, 585-606. doi:10.3406/bulmi.1983.7737.

Mason, B., Martin, P.M., 1977. Geochemical differences among components of the Allende meteorite. Smithsonian Contributions to the Earth Sciences 19, 84-95. doi:10.5479/si.00810274. 22.1

Masuda, A., Tanaka, T., 1979. Experimental studies on behaviors of major and minor lithophile elements in vaporization under evacuated condition. Meteoritics 14, 13-28. doi:10.1111/j . 1945-5100.1979.tb00475.x.

McDonough, W.F., 2014. Compositional model for the Earth's core, in: Holland, H.D., Turekian, K.K. (Eds.), Treatise on Geochemistry (Second Edition). Elsevier, Oxford. volume 3, pp. 559 577. doi:10.1016/B978-0-08-095975-7.00215-1.

McDonough, W.F., Sun, S.s., 1995. The composition of the Earth. Chemical Geology 120, 223 253. doi:10.1016/0009-2541(94)00140-4.

McDonough, W.F., Šrámek, O., Wipperfurth, S.A., 2020. Radiogenic power and geoneutrino luminosity of the Earth and other terrestrial bodies through time. Geochemistry, Geophysics, Geosystems 21, e2019GC008865. doi:10.1029/2019GC008865.

MetBase, 1994-2017. Meteorite Information Database. URL: http://www.metbase.org geoPlatform UG, Germany. Accessed: 2019-11-3. 
Morgan, J.W., Anders, E., 1979. Chemical composition of Mars. Geochimica et Cosmochimica Acta 43, 1601-1610. doi $10.1016 / 0016-7037$ (79)90180-7.

Nimmo, F., Agnor, C.B., 2006. Isotopic outcomes of N-body accretion simulations: constraints on equilibration processes during large impacts from Hf/W observations. Earth and Planetary Science Letters 243, 26-43. doi:10.1016/j.epsl.2005.12.009

Nimmo, F., Faul, U.H., 2013. Dissipation at tidal and seismic frequencies in a melt-free, anhydrous Mars. Journal of Geophysical Research: Planets 118, 2558-2569. doi:10.1002/2013JE004499

Norman, M.D., Yaxley, G.M., Bennett, V.C., Brandon, A.D., 2006. Magnesium isotopic composition of olivine from the Earth, Mars, Moon, and pallasite parent body. Geophysical Research Letters 33, L15202. doi:10.1029/2006GL026446.

Notsu, K., Onuma, N., Nishida, N., Nagasawa, H., 1978. High temperature heating of the Allende meteorite. Geochimica et Cosmochimica Acta 42, 903-907. doi:10.1016/0016-7037(78) 90101-1.

O'Neill, H.S.C., 1991a. The origin of the Moon and the early history of the Earth-A chemical model. Part 1: The Moon. Geochimica et Cosmochimica Acta 55, 1135-1157. doi 10.1016/ 0016-7037(91)90168-5.

O'Neill, H.S.C., 1991b. The origin of the Moon and the early history of the Earth-A chemical model. Part 2: The Earth. Geochimica et Cosmochimica Acta 55, 1159-1172. doi 10.1016/ 0016-7037(91)90169-6

O'Neill, H.S.C., Palme, H., 2008. Collisional erosion and the non-chondritic composition of the terrestrial planets. Philosophical Transactions of the Royal Society of London A: Mathematical, Physical and Engineering Sciences 366, 4205-4238. doi:10.1098/rsta.2008.0111.

Palme, H., O'Neill, H.S.C., 2014. Cosmochemical estimates of mantle composition, in: Holland, H.D., Turekian, K.K. (Eds.), Treatise on Geochemistry (Second Edition). Elsevier, Oxford. volume 3, pp. 1-39. doi:10.1016/B978-0-08-095975-7.00201-1.

Paniello, R.C., Day, J.M.D., Moynier, F., 2012. Zinc isotopic evidence for the origin of the Moon. Nature 490, 376-379. doi:10.1038/nature11507.

Parro, L.M., Jiménez-Díaz, A., Mansilla, F., Ruiz, J., 2017. Present-day heat flow model of Mars. Scientific Reports 7, 45629. doi:10.1038/srep45629

Patten, C., Barnes, S.J., Mathez, E.A., Jenner, F.E., 2013. Partition coefficients of chalcophile elements between sulfide and silicate melts and the early crystallization history of sulfide liquid: LA-ICP-MS analysis of MORB sulfide droplets. Chemical Geology 358, 170-188. doi:10. $1016 / j$.chemgeo.2013.08.040 
Poitrasson, F., Halliday, A.N., Lee, D.C., Levasseur, S., Teutsch, N., 2004. Iron isotope differences between Earth, Moon, Mars and Vesta as possible records of contrasted accretion mechanisms. Earth and Planetary Science Letters 223, 253-266. doi:10.1016/j .epsl.2004.04.032

Righter, K., 2011. Prediction of metal-silicate partition coefficients for siderophile elements: an update and assessment of PT conditions for metal-silicate equilibrium during accretion of the Earth. Earth and Planetary Science Letters 304, 158-167. doi:10.1016/j .epsl.2011.01.028

Righter, K., Chabot, N.L., 2011. Moderately and slightly siderophile element constraints on the depth and extent of melting in early Mars. Meteoritics \& Planetary Science 46, 157-176. doi: 10 . $1111 / j .1945-5100.2010 .01140 . x$

Righter, K., Drake, M.J., 1997. Metal-silicate equilibrium in a homogeneously accreting earth: new results for Re. Earth and Planetary Science Letters 146, 541-553. doi 10.1016/ S0012-821X(96) 00243-9

Righter, K., Nickodem, K., Pando, K., Danielson, L., Boujibar, A., Righter, M., Lapen, T.J., 2017. Distribution of $\mathrm{Sb}, \mathrm{As}, \mathrm{Ge}$, and In between metal and silicate during accretion and core formation in the Earth. Geochimica et Cosmochimica Acta 198, 1-16. doi:10.1016/j .gca.2016.10.045

Righter, K., Pando, K., Humayun, M., Waeselmann, N., Yang, S., Boujibar, A., Danielson, L.R., 2018a. Effect of silicon on activity coefficients of siderophile elements (Au, Pd, Pt, P, Ga, Cu, $\mathrm{Zn}$, and $\mathrm{Pb}$ ) in liquid $\mathrm{Fe}$ : Roles of core formation, late sulfide matte, and late veneer in shaping terrestrial mantle geochemistry. Geochimica et Cosmochimica Acta 232, 101-123. doi:10. $1016 / \mathrm{j} \cdot \mathrm{gca} .2018 .04 .011$.

Righter, K., Pando, K., Marin, N., Ross, D.K., Righter, M., Danielson, L., Lapen, T.J., Lee, C., 2018b. Volatile element signatures in the mantles of Earth, Moon, and Mars: Core formation fingerprints from Bi, Cd, In, and Sn. Meteoritics \& Planetary Science 53, 284-305. doi: 10 . $1016 /$ j.gca.2017.05.024.

Righter, K., Pando, K.M., Danielson, L., Lee, C.T., 2010. Partitioning of Mo, P and other siderophile elements $(\mathrm{Cu}, \mathrm{Ga}, \mathrm{Sn}, \mathrm{Ni}, \mathrm{Co}, \mathrm{Cr}, \mathrm{Mn}, \mathrm{V}$, and $\mathrm{W})$ between metal and silicate melt as a function of temperature and silicate melt composition. Earth and Planetary Science Letters 291, 1-9. doi:10.1016/j.epsl.2009.12.018

Rivoldini, A., Van Hoolst, T., Verhoeven, O., Mocquet, A., Dehant, V., 2011. Geodesy constraints on the interior structure and composition of Mars. Icarus 213, 451-472. doi: $10.1016 / \mathrm{j}$. icarus.2011.03.024

Rose, L.A., Brenan, J.M., 2001. Wetting properties of Fe-Ni-Co-Cu-Os melts against olivine: Implications for sulfide melt mobility. Economic Geology 96, 145-157. doi:10.2113/gsecongeo. 96.1 .145 . 
Rose-Weston, L., Brenan, J.M., Fei, Y., Secco, R.A., Frost, D.J., 2009. Effect of pressure, temperature, and oxygen fugacity on the metal-silicate partitioning of Te, Se, and S: Implications for earth differentiation. Geochimica et Cosmochimica Acta 73, 4598-4615. doi:10.1016/j.gca. 2009.04 .028

Rubie, D.C., Jacobson, S.A., Morbidelli, A., O'Brien, D.P., Young, E.D., de Vries, J., Nimmo, F., Palme, H., Frost, D.J., 2015. Accretion and differentiation of the terrestrial planets with implications for the compositions of early-formed Solar System bodies and accretion of water. Icarus 248, 89-108. doi $10.1016 / j$. icarus . 2014.10.015

Rubie, D.C., Laurenz, V., Jacobson, S.A., Morbidelli, A., Palme, H., Vogel, A.K., Frost, D.J., 2016. Highly siderophile elements were stripped from Earth's mantle by iron sulfide segregation. Science $353,1141-1144$. doi $10.1126 /$ science .aaf6919

Rubie, D.C., Melosh, H.J., Reid, J.E., Liebske, C., Righter, K., 2003. Mechanisms of metal-silicate equilibration in the terrestrial magma ocean. Earth and Planetary Science Letters 205, 239-255. doi: $10.1016 /$ S0012-821X (02)01044-0.

Rubin, A.E., 2011. Origin of the differences in refractory-lithophile-element abundances among chondrite groups. Icarus $213,547-558$. doi: $10.1016 / j$. icarus .2011.04.003

Rudnick, R.L., Gao, S., 2014. Composition of the continental crust, in: Holland, H.D., Turekian, K.K. (Eds.), Treatise on Geochemistry (Second Edition). Elsevier, Oxford, pp. 1-51. doi:10. 1016/B978-0-08-095975-7.00301-6

Samuel, H., 2012. A re-evaluation of metal diapir breakup and equilibration in terrestrial magma oceans. Earth and Planetary Science Letters 313, 105-114. doi:10.1016/j.epsl.2011.11. 001 .

Samuel, H., Lognonné, P., Panning, M., Lainey, V., 2019. The rheology and thermal history of Mars revealed by the orbital evolution of Phobos. Nature 569, 523-527. doi $10.1038 /$ s41586-019-1202-7

Scott, E.R.D., Krot, A.N., 2014. Chondrites and their Components, in: Holland, H.D., Turekian, K.K. (Eds.), Treatise on Geochemistry (Second Edition). Elsevier, Oxford. volume 1, pp. 65-137. doi:10.1016/B978-0-08-095975-7.00104-2.

Sharp, Z.D., Draper, D.S., 2013. The chlorine abundance of Earth: implications for a habitable planet. Earth and Planetary Science Letters 369, 71-77. doi:10.1016/j.eps1.2013.03.005.

Siebert, J., Corgne, A., Ryerson, F.J., 2011. Systematics of metal-silicate partitioning for many siderophile elements applied to Earth's core formation. Geochimica et Cosmochimica Acta 75, 1451-1489. doi:10.1016/j.gca.2010.12.013. 
Siebert, J., Sossi, P.A., Blanchard, I., Mahan, B., Badro, J., Moynier, F., 2018. Chondritic Mn/Na ratio and limited post-nebular volatile loss of the Earth. Earth and Planetary Science Letters 485, 130-139. doi:10.1016/j.epsl.2017.12.042

Sossi, P.A., Fegley, Jr., B., 2018. Thermodynamics of element volatility and its application to planetary processes. Reviews in Mineralogy and Geochemistry 84, 393-459. doi 10.2138/ rmg. 2018.84.11

Sossi, P.A., Klemme, S., O’Neill, H.S.C., Berndt, J., Moynier, F., 2019. Evaporation of moderately volatile elements from silicate melts: Experiments and theory. Geochimica et Cosmochimica Acta 260, 204-231. doi $10.1016 /$ j.gca.2019.06.021

Sossi, P.A., Nebel, O., Anand, M., Poitrasson, F., 2016. On the iron isotope composition of Mars and volatile depletion in the terrestrial planets. Earth and Planetary Science Letters 449, 360-371. doi:10.1016/j.epsl.2016.05.030.

Sossi, P.A., Nebel, O., O’Neill, H.S.C., Moynier, F., 2018. Zinc isotope composition of the Earth and its behaviour during planetary accretion. Chemical Geology 477, 73-84. doi:10.1016/j . chemgeo.2017.12.006

Steenstra, E.S., van Haaster, F., van Mulligen, R., Flemetakis, S., Berndt, J., Klemme, S., van Westrenen, W., 2020. An experimental assessment of the chalcophile behavior of $\mathrm{F}, \mathrm{Cl}, \mathrm{Br}$ and I: implications for the fate of halogens during planetary accretion and the formation of magmatic ore deposits. Geochimica et Cosmochimica Acta 273, 275-290. doi:10.1016/j.gca. 2020. 01.006

Stracke, A., Palme, H., Gellissen, M., Münker, C., Kleine, T., Birbaum, K., Günther, D., Bourdon, B., Zipfel, J., 2012. Refractory element fractionation in the Allende meteorite: Implications for solar nebula condensation and the chondritic composition of planetary bodies. Geochimica et Cosmochimica Acta 85, 114-141. doi:10.1016/j.gca.2012.02.006.

Suer, T.A., Siebert, J., Remusat, L., Menguy, N., Fiquet, G., 2017. A sulfur-poor terrestrial core inferred from metal-silicate partitioning experiments. Earth and Planetary Science Letters 469, 84-97. doi:10.1016/j.epsl.2017.04.016.

Taylor, G.J., 2013. The bulk composition of Mars. Chemie der Erde-Geochemistry 73, 401-420. doi:10.1016/j.chemer.2013.09.006

Taylor, S.R., McLennan, S., 2009. Planetary Crusts: Their Composition, Origin and Evolution. volume 10. Cambridge University Press, Cambridge. doi:10.1017/CB09780511575358

Turcotte, D., Schubert, G., 2014. Geodynamics (3rd Edition). Cambridge University Press, Cambridge. doi:10.1017/cbo9780511843877. 
Varas-Reus, M.I., König, S., Yierpan, A., Lorand, J.P., Schoenberg, R., 2019. Selenium isotopes as tracers of a late volatile contribution to Earth from the outer Solar System. Nature Geoscience 12, 779-782. doi:10.1038/s41561-019-0414-7.

Wade, J., Wood, B.J., Tuff, J., 2012. Metal-silicate partitioning of Mo and W at high pressures and temperatures: evidence for late accretion of sulphur to the Earth. Geochimica et Cosmochimica Acta 85, 58-74. doi: $10.1016 / \mathrm{j} \cdot \mathrm{gca} .2012 .01 .010$.

Walker, R.J., Bermingham, K., Liu, J., Puchtel, I.S., Touboul, M., Worsham, E.A., 2015. In search of late-stage planetary building blocks. Chemical Geology 411, 125-142. doi:10.1016/j. chemgeo.2015.06.028

Walker, R.J., Horan, M.F., Morgan, J.W., Becker, H., Grossman, J.N., Rubin, A.E., 2002. Comparative ${ }^{187} \mathrm{Re}-{ }^{187}$ Os systematics of chondrites: Implications regarding early solar system processes. Geochimica et Cosmochimica Acta 66, 4187-4201. doi:10.1016/S0016-7037(02)01003-7.

Wang, Z., Becker, H., 2013. Ratios of S, Se and Te in the silicate Earth require a volatile-rich late veneer. Nature 499, 328-331. doi:10.1038/nature12285.

Wänke, H., Dreibus, G., 1994. Chemistry and accretion history of Mars. Philosophical Transactions of the Royal Society of London. Series A, Mathematical and Physical Sciences 349, 285-293. doi:10.1098/rsta.1994.0132.

Wänke, H., Dreibus, G., Jagoutz, E., 1984. Mantle chemistry and accretion history of the Earth, in: Kröner, A., Hanson, G.N., Goodwin, A.M. (Eds.), Archaean Geochemistry. Springer, pp. 1-24. doi: $10.1007 / 978-3-642-70001-9 \_1$

Wasson, J.T., 1985. Meteorites: Their Record of Early Solar-System History. W.H. Freeman and Company, New York.

Wasson, J.T., Kallemeyn, G.W., 1988. Compositions of chondrites. Philosophical Transactions of the Royal Society of London A: Mathematical, Physical and Engineering Sciences 325, 535-544. doi:10.1098/rsta.1988.0066

Wipperfurth, S.A., Šrámek, O., McDonough, W.F., 2020. Reference models for lithospheric geoneutrino signal. Journal of Geophysical Research: Solid Earth 125, e2019JB018433. doi:10.1029/2019JB018433.

Wohlers, A., Wood, B.J., 2017. Uranium, thorium and REE partitioning into sulfide liquids: Implications for reduced S-rich bodies. Geochimica et Cosmochimica Acta 205, 226-244. doi:10.1016/j.gca.2017.01.050

Wombacher, F., Rehkämper, M., Mezger, K., Bischoff, A., Münker, C., 2008. Cadmium stable isotope cosmochemistry. Geochimica et Cosmochimica Acta 72, 646-667. doi:10.1016/j . gca.2007.10.024. 
Wood, B.J., Halliday, A.N., 2010. The lead isotopic age of the Earth can be explained by core formation alone. Nature 465, 767-770. doi $10.1038 /$ nature09072.

Wood, B.J., Kiseeva, E.S., Mirolo, F.J., 2014. Accretion and core formation: The effects of sulfur on metal-silicate partition coefficients. Geochimica et Cosmochimica Acta 145, 248-267. doi:10. $1016 / j . g c a .2014 .09 .002$.

Wood, B.J., Smythe, D.J., Harrison, T., 2019. The condensation temperatures of the elements: A reappraisal. American Mineralogist 104, 844-856. doi:10.2138/am-2019-6852CCBY

Yang, S., Humayun, M., Righter, K., Jefferson, G., Fields, D., Irving, A.J., 2015. Siderophile and chalcophile element abundances in shergottites: Implications for Martian core formation. Meteoritics \& Planetary Science 50, 691-714. doi:10.1111/maps.12384.

Yi, W., Halliday, A.N., Alt, J.C., Lee, D.C., Rehkämper, M., Garcia, M.O., Langmuir, C.H., Su, Y., 2000. Cadmium, indium, tin, tellurium, and sulfur in oceanic basalts: Implications for chalcophile element fractionation in the Earth. Journal of Geophysical Research: Solid Earth 105, 18927-18948. doi:10.1029/2000JB900152.

Yoshizaki, T., Ash, R.D., Yokoyama, T., Lipella, M.D., McDonough, W.F., 2018. Chemically defining the building blocks of the Earth. arXiv preprint arXiv:1812.11717 .

Yoshizaki, T., McDonough, W.F., 2020. The composition of Mars. Geochimica et Cosmochimica Acta $273,137-162$. doi $10.1016 /$ j.gca.2020.01.011

Zambardi, T., Poitrasson, F., Corgne, A., Méheut, M., Quitté, G., Anand, M., 2013. Silicon isotope variations in the inner solar system: Implications for planetary formation, differentiation and composition. Geochimica et Cosmochimica Acta 121, 67-83. doi $10.1016 /$ j.gca.2013.06. 040 .

Zolotov, M.Y., Mironenko, M.V., 2007. Hydrogen chloride as a source of acid fluids in parent bodies of chondrites, in: Lunar and Planetary Science Conference, p. 2340. 